\title{
The role of the mammalian GET pathway in the mouse liver
}

\author{
Dissertation \\ for the award of the degree \\ "Doctor rerum naturalium" \\ of the Georg-August-Universität Göttingen \\ within the doctoral program Molecular Biology \\ of the Georg-August University School of Science (GAUSS)
}

\author{
submitted by \\ Lena Musiol \\ from Nümbrecht, Germany
}

Göttingen, 2016 


\section{Thesis Committee}

Prof. Dr. Blanche Schwappach

Department of Molecular Biology, Göttingen University Medical School

Prof. Dr. Reinhard Jahn

Department of Neurobiology, Max Planck Institute for Biophysical Chemistry

Prof. Dr. Andreas Janshoff

Institute for Physical Chemistry, Georg August University Göttingen

\section{Members of the Examination Board}

Referee: Prof. Dr. Blanche Schwappach

Department of Molecular Biology, Göttingen University Medical School

$2^{\text {nd }}$ Referee: Prof. Dr. Reinhard Jahn

Department of Neurobiology, Max Planck Institute for Biophysical Chemistry

\section{Further members of the Examination Board}

Prof. Dr. Andreas Janshoff

Institute for Physical Chemistry, Georg August University Göttingen

Prof. Dr. Michael Meinecke

Department of Cellular Biochemistry, Göttingen University Medical School

Nuno Raimundo, PhD

Department of Cellular Biochemistry, Göttingen University Medical School

Dr. Hans-Dieter Schmitt

Department of Neurobiology, Max Planck Institute for Biophysical Chemistry

Date of oral examination: 15th November 2016 


\section{Affidavit}

Herewith I declare that I prepared the PhD Thesis "The role of the mammalian GET pathway in the mouse liver" on my own and with no other sources and aids than quoted.

Göttingen, $28^{\text {th }}$ September 2016 
Für meine Omi

Helga Wilhelmine Musiol

$1921-2015$ 
"There have been times, lately, when I dearly wished that I could change the past. Well, I can't, but I can change the present, so that when it becomes the past it will turn out to be a past worth having."

Sir Terry Pratchett, "I Shall Wear Midnight" 


\section{Contents}

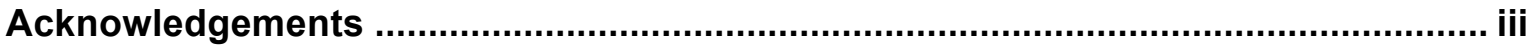

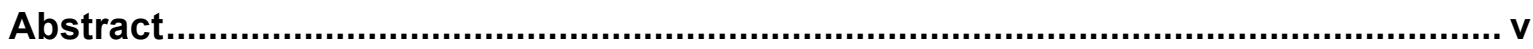

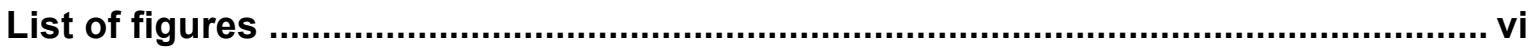

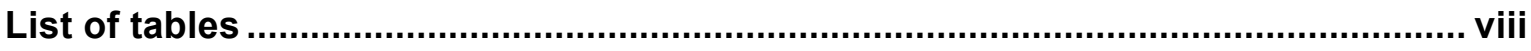

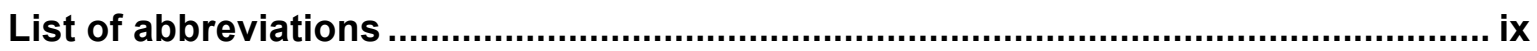

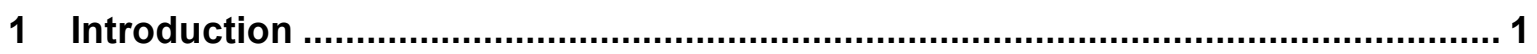

1.1 Cellular compartments and the secretory pathway ….................................. 1

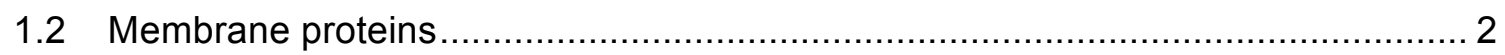

1.2.1 Different topologies of transmembrane proteins ....................................... 2

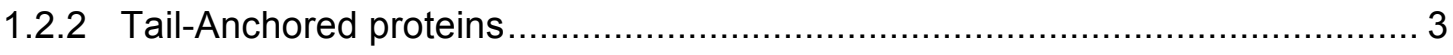

1.3 Targeting and membrane insertion of transmembrane proteins in the eukaryotic

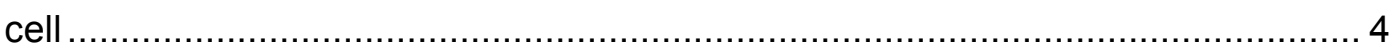

1.3.1 Co-translational protein insertion into the ER membrane ............................. 4

1.3.2 Post-translational insertion of Tail-Anchored proteins into the ER membrane . 5

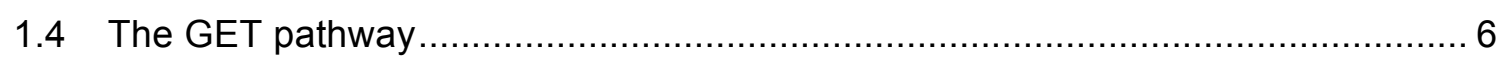

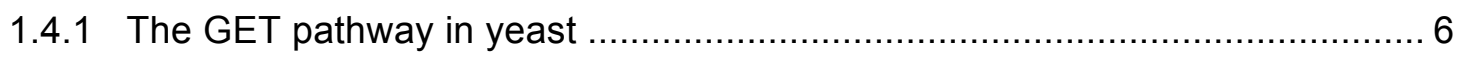

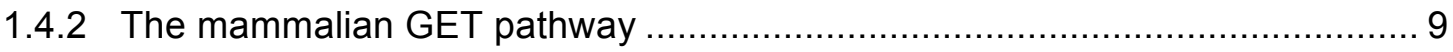

1.4.3 The GET pathway in development and cellular physiology ........................ 11

1.5 The mouse liver as a model system for studying the mammalian GET pathway . 12

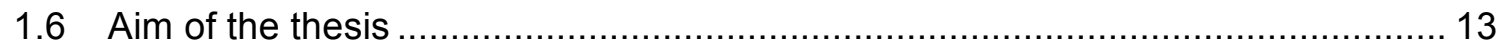

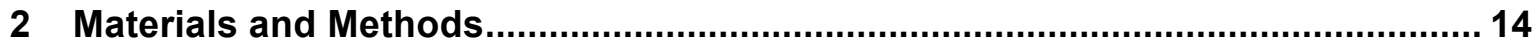

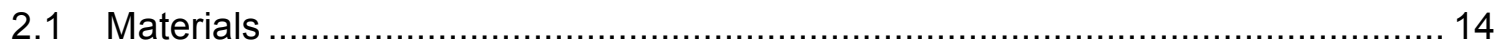

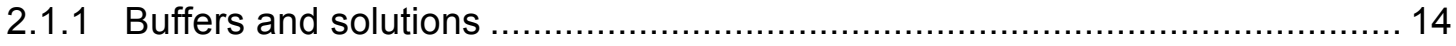

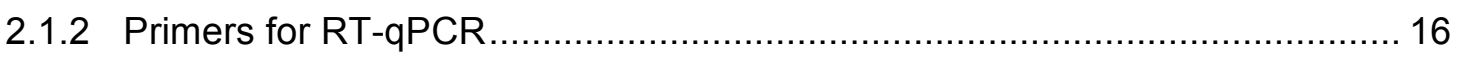

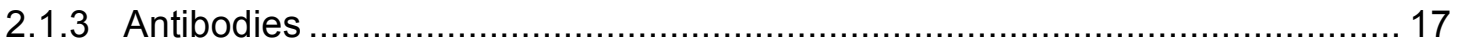

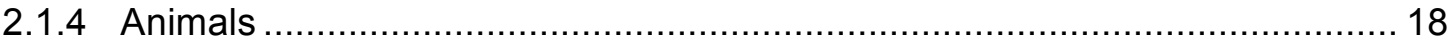

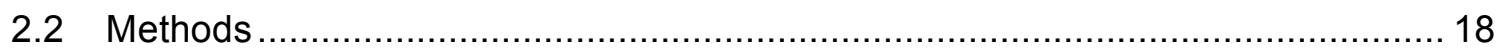

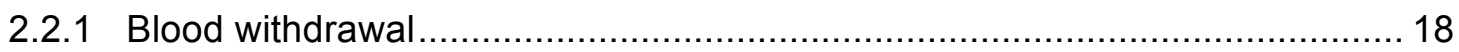

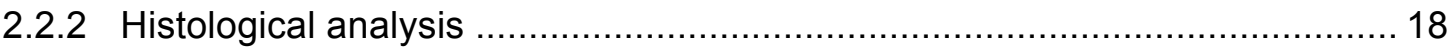

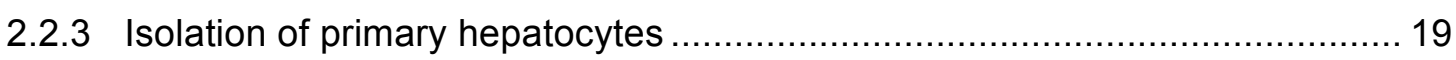

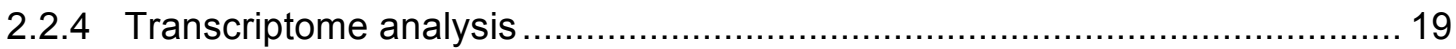




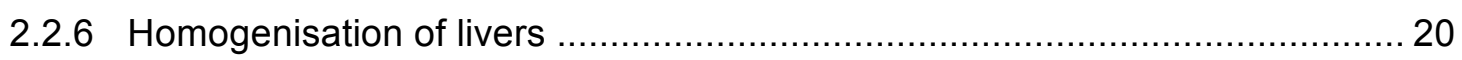

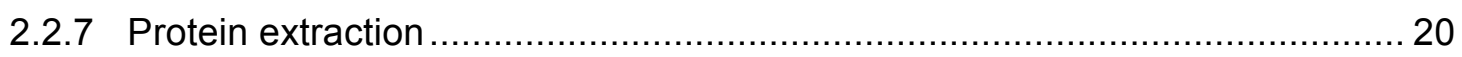

2.2.8 SDS Polyacrylamide gel electrophoresis and Western Blot ....................... 21

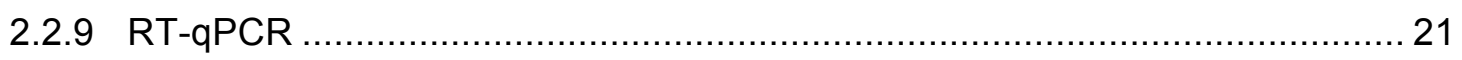

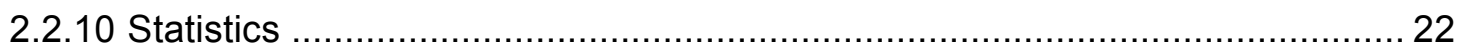

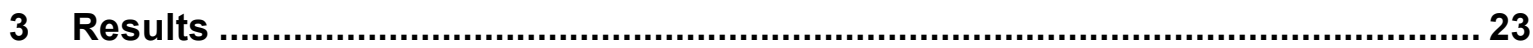

3.1 Mice with a hepatocyte-specific WRB knockout are viable .............................. 23

3.2 Hepatocyte-specific WRB knockout leads to strong liver damage in situ ............. 23

3.3 The extent of liver damage is reflected in blood parameters ............................... 24

3.4 WRB knockout in hepatocytes causes alterations in liver tissue .......................... 25

3.5 Hepatocyte-specific knockout of WRB leads to differential gene expression in AlbCre+ animals

3.6 The components of the mammalian GET pathway are influenced by the knockout of WRB in hepatocytes

3.6.1 In 6 week old animals, liver tissue and isolated hepatocytes react differently to the knockout

3.6.2 In older animals, the hepatocyte-specific WRB knockout affects liver tissue and isolated hepatocytes in different ways

3.7 A hepatocyte-specific WRB knockout has varying effects on selected substrates of the mammalian GET pathway

3.7.1 In 6 week old animals, selected substrates behave differently in liver tissue and isolated hepatocytes of Alb-Cre+ animals

3.7.2 In older animals, the effect of a WRB knockout on TA proteins depends on the sample type 54

3.8 WRB knockout in hepatocytes influences Stx5 subcellular localisation ..... 58

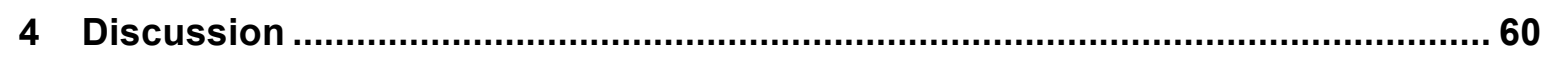

4.1 Knockout of WRB in hepatocytes leads to substantial liver damage ....................60

4.2 Penetrance of WRB knockout varies strongly in its extent .................................. 64

4.3 Substrates show different susceptibility to a disturbed GET pathway ..................66

4.4 Expressed TA proteins in the liver and liver damage ........................................ 70

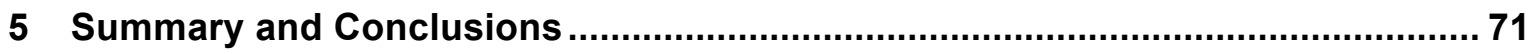

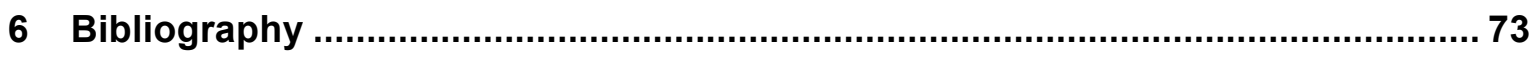

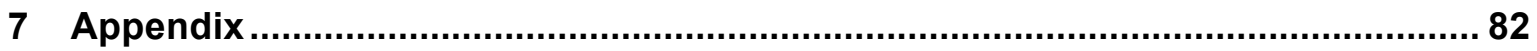




\section{Acknowledgements}

The last four years would not have been possible without a lot of support and help from many people, for which I am very grateful.

I would like to thank Prof. Dr. Blanche Schwappach for offering me to work on this project after my lab rotation, and her support both on scientific and personal matters during this time.

I am very thankful for the support und valuable input from Prof. Dr. Reinhard Jahn and Prof. Dr. Andreas Janshoff during my thesis committee meetings.

Moreover I would like to thank my supervisor, Dr. Fabio Vilardi, for all he taught me in the last years and the helpful discussions.

I would like to thank Prof. Dr. Philipp Ströbel from the Pathology at the Göttingen University Medical School for his help with performing the histology and his expertise in this field. I am thankful for the help I got from Dr. Thomas Lingner from the Transcriptome Analysis Laboratory, who answered all my questions regarding the data their facility provided.

I am more than grateful for all the help and support of Kirsten Unthan-Fechner regarding the mouse work. Without Kirsten I could not have finished this thesis and I learned a lot from her, and really enjoyed working together with her during many hours in the primary cell culture lab. Another person from the Department I want to thank is Gabriela Brodkorb, who was a great help with all the bureaucracy that had to be managed during the last four years.

The four years in the lab would have been a lot less enjoyable without my colleagues, both in the Schwappach lab and in the whole Department. The atmosphere in the Department was always good, and I enjoyed that. I especially want to thank Anne Clancy for being an amazing colleague, good friend and office neighbor. She endured my many many questions, taught me so much and always had time for me, no matter whether it was for scientific or personal matters. My PhD would not have been the same if not for the many nice coffee breaks with her! I am very thankful for all the support I got from Dr. Eric Arakel, who gave a lot of helpful input over the last four years. Moreover I would like to thank Ákos Farkas, who was always open for helpful discussions in the office. Furthermore I want to thank the other current and recent members of the Schwappach lab.

I am more than thankful to the International Max Planck Research School for Molecular Biology, especially Dr. Steffen Burkhardt and Kerstin Grüniger. No matter what problems 
arose, they were always supportive and a great help. My time in the IMPRS created many happy memories and I will always remember it.

A PhD cannot be managed without the help and support of friends. I am glad I have great friends who were always there for me during the last four years. I want to thank Isi, Rike and Thomas for the relaxing weekends we spent together, and their many surprise care packages. Moreover I would like to thank Muna for being an amazing friend and for the Skype sessions, making it seem as if Vienna and Göttingen are not really that far apart. I am thankful to Jens and Katja for the many hours we spend on the vertical playground that is the Roxx Climbing Center, getting our minds off science for some time, and for being good friends and colleagues. I would like to thank Anna, who has been a part of my scientific career from BSc to PhD, and was always a great support. Another person I would like to thank is Arne, who l've known for almost all my life and who has always been a great friend.

In the end, I want to thank my (extended) family for all their love and support. My parents, Petra and Heiner, were always there for me and had nothing but support for me, both from Germany and from across the Atlantic Ocean during some times. My sister, Runa, will always be one of the most important persons in my life, and I am thankful for all her help and support during the last four years. And last but not least I want to thank Ole, who has, independent of the circumstances, always been there for me. 


\section{Abstract}

The correct insertion of membrane proteins is essential for the normal functioning of a eukaryotic cell, and different classes of membrane proteins employ different mechanisms of insertion into their target membrane. One of these pathways is the GET pathway, which promotes the insertion of tail-anchored proteins into the ER membrane. Tail-anchored protein substrates of this pathway are then involved in trafficking, metabolism, or protein translocation in the cell. The key players of the pathway in mammals are the cytosolic ATPase TRC40 and the heterodimeric receptor at the ER membrane consisting of CAML and WRB. Recent studies showed a second function for the yeast homologue of TRC40, Get3, to not only work in tail-anchored protein targeting, but also as an ATP-independent chaperone under oxidative stress conditions. While the pathway is not essential in yeast, loss of some of its main components results in early embryonic lethality in mice, but the reason for this is so far not fully understood. In this study, a mouse model was established to further elucidate the role of the mammalian GET pathway in vivo. The model allows a deletion of the middle exons of WRB in a hepatocyte-specific manner by using the CreLox system, leading to an impairment of the pathway in the liver, a tissue that is high in secretion, protein biosynthesis and trafficking. The results obtained show that this deletion leads to severe liver damage in mice, which was evident in situ, as well is in liver enzyme levels in the blood and increasing fibrosis in the organs, shown by histological analysis. The liver damage changed from an acute state to a more chronic damage with increasing age of the animals. Furthermore, the massive damage and loss of hepatocytes led to subsequent liver regeneration. At the stage of acute liver damage, some of the substrates of the mammalian GET pathway were shown to be affected by the disturbance of the pathway. The protein levels of Syntaxin5 and Syntaxin6, two SNAREs, were decreased in hepatocytes, and Stx5 displayed a clear loss of targeting to the Golgi membrane in hepatocytes. In conclusion, the study shows that a targeted disruption of WRB in hepatocytes severely impairs liver function and integrity, and some substrates of the mammalian GET pathway show a higher susceptibility to this impairment than others. 


\section{List of figures}

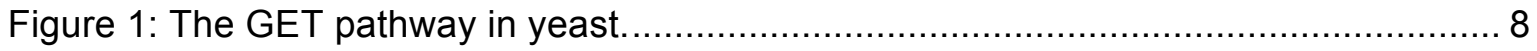

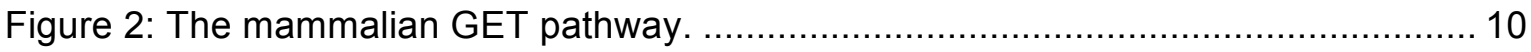

Figure 3: Livers of Alb-Cre+ animals show a strong phenotype in situ. .......................... 24

Figure 4: Blood parameters of Alb-Cre+ animals at two different age points confirm a strong liver damage.

Figure 5: Liver sections of $6 \mathrm{w}$ old Alb-Cre+ animals show drastic changes in the tissue structure and cellular organization. 26

Figure 6: Livers of older Alb-Cre+ animals show a clear histological phenotype. 27

Figure 8: In isolated hepatocytes of $6 \mathrm{w}$ old Alb-Cre+ animals mRNA levels of WRB and TRC40 were significantly changed.

Figure 9: In total liver homogenate of $6 \mathrm{w}$ old Alb-Cre+ animals the mRNA level of WRB was significantly changed.

Figure 10: In total liver homogenates of $6 \mathrm{w}$ old Alb-Cre+ animals only CAML was significantly affected at protein level

Figure 11: In isolated hepatocytes of $6 \mathrm{w}$ old Alb-Cre+ animals, no significant change of the protein levels of the pathway components was observed

Figure 12: Variability in the knockout strength of WRB at mRNA level correlated with changes at protein level of the pathway components in Alb-Cre+ animals

Figure 13: In older Alb-Cre+ animals, WRB and TRC40 remained unchanged at mRNA level, while CAML increased in total liver homogenate.

Figure 14: Isolated hepatocytes of older Alb-Cre+ animals showed a significant reduction of WRB at mRNA level.

Figure 15: In total liver homogenate from older animals, only TRC40 showed a significant change in Alb-Cre+ animals.

Figure 16: In isolated hepatocytes of older Alb-Cre+ animals, WRB and CAML were significantly reduced at protein level.

Figure 17: In total liver homogenate of 6 w old Alb-Cre+ animals Stx5 and EMD showed a significant change.

Figure 18: In isolated hepatocytes of $6 \mathrm{w}$ old Alb-Cre+ animals only steady-state protein levels of Stx6 displayed a significant change.

Figure 19: In isolated hepatocytes of $6 \mathrm{w}$ old Alb-Cre+ animals Stx6 was significantly reduced at mRNA level.

Figure 20: In isolated hepatocytes of $6 \mathrm{w}$ old Alb-Cre+ animals, penetrance of the WRB knockout at mRNA level highly correlated with the change at protein level for Stx5. 53 
Figure 21: In total liver homogenate of older Alb-Cre+ animals, Stx5, Stx6 and EMD were significantly increased at protein level. 55

Figure 22: In isolated hepatocytes of older Alb-Cre+ animals, steady-state levels of no TA protein were significantly affected by the WRB knockout. 56

Figure 23: The cellular appearance of Stx5 was strongly affected in isolated hepatocytes of $6 \mathrm{w}$ old Alb-Cre+ animals.

Figure 24: A heatmap for additional genes involved in liver fibrosis and regeneration..... 63

Figure 25: Alignment of Stx5, Stx6 and Stx8. 69 


\section{List of tables}

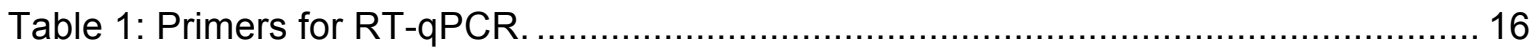

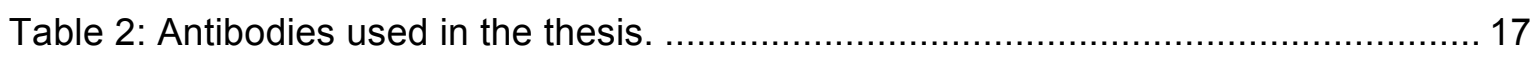

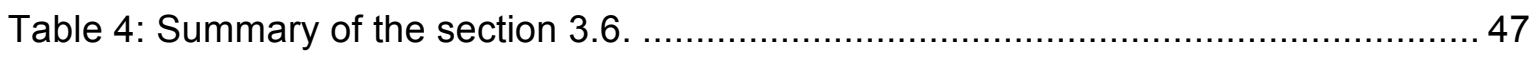

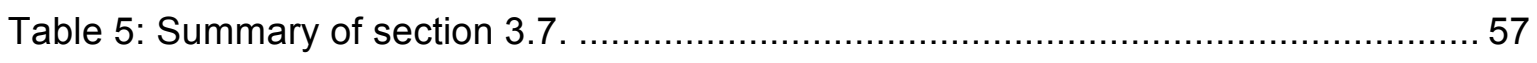

Table 6: List of all the animals appearing in this thesis................................................. 82

Table 7: The top 50 of the differentially expressed genes in isolated hepatocytes of $6 \mathrm{w}$

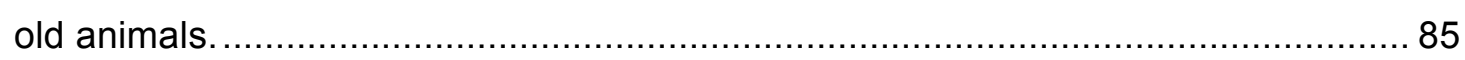

Table 8: A subset of TA proteins expressed in hepaotcytes from $6 \mathrm{w}$ old animals. .......... 88 


\section{List of abbreviations}

\begin{tabular}{ll}
$\begin{array}{l}\text { appr. } \\
\text { cf. }\end{array}$ & approximately \\
EDTA & compare \\
ER & Ethylenediaminetetraacetic acid \\
FCS & endoplasmic reticulum \\
g & fetal calf serum \\
g & gram(s) \\
h & gravitational force \\
HE & hour(s) \\
min & Hematoxylin/Eosin \\
o/n & minute(s) \\
PAGE & over night \\
PBS & polyacrylamide gel electrophoresis \\
PFA & phosphate buffered saline \\
RT & paraformaldehyde \\
SDS & room temperature \\
TCA & Sodium Dodecyl Sulfate \\
w & trichloroacetic acid \\
w/v & weeks \\
\hline & weight per volume
\end{tabular}




\section{Introduction}

\subsection{Cellular compartments and the secretory pathway}

Every eukaryotic cell is composed of several distinct compartments, all of which differ in their functions and along with this in their biochemical properties. All of these compartments together master the various processes that take place in the cell, from the different biosynthesis pathways to metabolic tasks, signalling or secreting. Depending on the cell-type, some of these functions are more prominent than others. To allow every compartment to perform its functions with the biochemical and biophysical conditions needed, and to allow separation of processes, the different compartments are enclosed by biomembranes. However, by one way or another, these membranes stay on close contact to each other, giving rise to the endomembrane system. In the eukaryotic cell, organelles forming endomembrane system are the membranes of the nucleus, the Endoplasmic Reticulum (ER), the Golgi apparatus, lysosomes, endosomes and vesicles. The plasma membrane is surrounding this whole system, as the outmost border of the cell (Alberts, 2008).

The membranes of this system carry individual biochemical signatures that mark the specific compartment the membrane encloses. This unique signature consists amongst others of both lipid as well as protein composition (as reviewed in e.g. Mellman and Warren, 2000; van Meer et al., 2008) and allows a directed and specific interchange between the different compartments of the eukaryotic cell. In general, traffic in cells can occur in two distinct directions: In the endocytic pathway, cargo is transported from the plasma membrane into the cell, whereas in the secretory pathway, cargo is transported towards the plasma membrane and finally secreted from the cell. This traffic between different compartments, such as the Golgi apparatus, the Endoplasmic Reticulum (ER) or the endosomes, is enabled by vesicles carrying the cargo. To ensure that this transport in the cell is targeted is role of the above-mentioned markers, which are also found on the vesicles. Cargo receptors are located in the membrane of the individual compartments and bind to specific cargo. The adaptor proteins bind to the receptors as well as to the coating proteins, and this whole process allows the formation of small vesicles, in whose membrane the cargo, bound to the receptor, is enriched. With the help of the coating protein, the vesicles can reach their typical vesicular shape, and finally be released from their originating compartment and perform their function in trafficking. Upon reaching the target membrane, the coat is then disassembled, the vesicle fuses with the target membrane and the cargo is released (Mellman and Warren, 2000).

Depending on the direction of trafficking and the originating compartment, different coated vesicles are responsible for the transport. The main characterised ones are Clathrin 
coated vesicles, which predominantly form on the plasma membrane, endosomes and the trans-Golgi network, COPI vesicles, which can carry ER resident proteins back to the ER from the Golgi, and COPII vesicles, which form on the ER and carry their cargo to the Golgi (reviewed in Barlowe and Miller, 2013; Mellman and Warren, 2000).

After the correct formation of vesicles on the donor compartment, the next task of the cell is to ensure for the vesicle to reach its destined target compartment. The process of targeting and then fusion is mediated by a set of proteins on both the vesicle and the target membrane. One group of proteins playing a major role in both tethering and fusion are the so called soluble $\mathrm{N}$-ethylmaleimide-sensitive factor attachment protein receptors (SNAREs) (Jahn and Scheller, 2006). They allow the last steps in vesicle trafficking, which are the fusion of the vesicle with the target membrane and thus allowing the release of the cargo. SNAREs are transmembrane proteins and can be found on both the vesicle and target compartment, and by being distributed in specific subsets, they add to the specificity in targeting (Jahn and Scheller, 2006).

\subsection{Membrane proteins}

In both the compartmentalisation and trafficking within the cell, membrane proteins are indispensable for the cell. They allow transport and exchange between the different compartments and the cytosol and fulfil a remarkable variety of roles, for example in enzymatic processes, signalling, trafficking or energy supply. Membrane proteins come in a lot of different flavours regarding their topology and structure.

In general one can separate membrane proteins into two groups, depending on how they are associated with the membrane. The group of peripheral membrane proteins does not actually penetrate the membrane, but is peripherally linked to the membrane, e.g. by means of a lipid anchor, non-covalent interactions with other membrane proteins, lipids or an oligosaccharide connected to the protein. The group of integral membrane proteins on the other hand is incorporated into the membrane with a hydrophobic part of the protein, the transmembrane domain (TMD). Again two subgroups can be described. It is possible that the protein does not actually span the full bilayer, but is only integrated in one part of the bilayer. These proteins belong to the group of integral monotopic proteins. Transmembrane proteins, the second subgroup of integral membrane proteins, span the full bilayer with either one or more hydrophobic transmembrane domains (Alberts, 2008).

\subsubsection{Different topologies of transmembrane proteins}

When a protein spans the membrane with one or more transmembrane domains, its orientation with regard to the cytosol may vary. Depending on how the transmembrane 
protein is integrated and where the N-Terminus of the protein resides, different types of proteins are described. Since the nomenclature or classification has been continually changing during the last years it should be mentioned that the one described here is the one that is used on uniprot.org and in (Chou and Shen, 2007). Here, only the first four types of transmembrane proteins are briefly introduced. Type I transmembrane proteins face the organelle lumen with their $\mathrm{N}$-terminus while their $\mathrm{C}$-terminus faces the cytosol. They possess both a cleavable signal sequence and stop-transfer sequence that remains in the membrane as a single transmembrane domain. Type II and Type III transmembrane proteins do not have a cleavable signal sequence, but only a signal anchor sequence that functions both in targeting and as the single transmembrane domain. Type II transmembrane proteins have an $\mathrm{N}$-terminus facing the cytosol, whereas Type III transmembrane proteins show the opposite orientation. The orientation of the protein in the membrane depends on the charge of the amino acids flanking the signal anchor sequence and follows the "positive inside rule", meaning that positively charged amino acids in the flanking regions are mainly found on the cytosolic side (Hartmann et al., 1989; Heijne and Gavel, 1988). Like Type I-III, Type IV transmembrane proteins only have a single transmembrane domain that acts as signal sequence and membrane anchor. This domain is located at the very C-terminus, leading to the term Tail-Anchored proteins (TA proteins) (Borgese et al., 2003; Kutay et al., 1993). Their N-terminus faces the cytosol, while their $\mathrm{C}$-terminus is luminal. This last class of proteins are the main focus of this study and their features and biogenesis will be described in more detail in the next subchapter.

\subsubsection{Tail-Anchored proteins}

Tail-Anchored proteins differ from all other membrane proteins by their very unique topology. Their single transmembrane domain is located at the very C-terminus of the protein, meaning that the transmembrane domain lies within the last 50 residues of the primary sequence and usually not more than $\sim 30$ residues follow in the protein sequence after the transmembrane domain (Borgese et al., 2003; Kutay et al., 1993). They cover a wide range of functions and can be found at various membranes in the eukaryotic cell. Some examples are Cytochrome b5 or UBC6 at the ER, both performing enzymatic functions, or SNARE proteins, which act in vesicular fusion. Other TA proteins act in protein translocation or regulation of Apoptosis (Borgese et al., 2003). In a bioinformatic study, it was suggested that more than 400 TA proteins are encoded in the human genome (Kalbfleisch et al., 2007). 


\subsection{Targeting and membrane insertion of transmembrane proteins in the eukaryotic cell}

Since transmembrane proteins fulfil many essential functions in the cell, it is important to ensure correct targeting and insertion of the protein into the membrane of its destined compartment. The cell must recognise the protein as a transmembrane protein during synthesis, and the protein has to be targeted correctly to the right localisation in the cell. After reaching its target membrane, correct insertion has to be ensured as well.

In the eukaryotic cell, two basic mechanisms can be distinguished. Proteins can either be inserted into the membrane in a co-translational manner, with translation and translocation taking place at the same time at the target membrane, or proteins are targeted to and inserted into their target membrane in a post-translational manner after protein synthesis has been finished. The structure and topology of the protein mainly determines the way of insertion, but also its target. Direct import into mitochondria, peroxisomes, the nucleus and chloroplasts happens in a post-translational manner, whereas transport into the ER membrane can take place in both forms.

According to current hypotheses, the co-translational pathway has evolved later and presents a more complex and advanced mechanism for protein insertion (Cross et al., 2009).

\subsubsection{Co-translational protein insertion into the ER membrane}

Many membrane proteins are first inserted into the ER membrane, and either stay there as ER resident proteins or reach their final destination via vesicle transport. The signal that guides proteins to the ER membrane is given by either the cleavable signal sequence in type I or multispanning proteins, or the signal anchor sequence in type II and type III proteins. The factor responsible for recognising either the signal sequence or the signal anchor sequence is the Signal Recognition Particle (SRP), and binding of the SRP to the hydrophobic signal or signal anchor sequence takes place during active translation. Due to this interaction between the SRP and the ribosome, further elongation is slowed down and translation is stalled (Halic et al., 2004). This allows the complex of the ribosome nascent chain and the SRP to be targeted to the ER membrane, where the SRP binds to the SRP receptor (SR), an ER membrane protein consisting of the two subunits $\mathrm{SR} \alpha$ and SR $\beta$ (Gilmore et al., 1982a; 1982b; Montoya et al., 1997; Tajima et al., 1986). The SRP as well as the two SR subunits are active GTPases (Connolly and Gilmore, 1989; Miller et al., 1995; 1993), and GTP binding and hydrolysis acts as the driving force for the steps in targeting and transferring the RNC to the translocon. After GTP hydrolysis, SRP is released from $\mathrm{SR}$ and can engage in another targeting process. 
The following translocation of the protein across the ER membrane takes place via the Sec61 translocon. This complex consists of three subunits: $\alpha, \beta$ and $\gamma$. The $\alpha$-subunit is the actual pore-forming unit while $\beta$ and $\gamma$ act as accessory factors(Mothes et al., 1994). The Sec61 complex works as the main receptor for the ribosome at the ER membrane (Kalies et al., 1994; Prinz et al., 2000b), and upon binding, the ribosome exit tunnel and the pore formed by the Sec61 translocon fully align, thus allowing translocation of the emerging protein (Becker et al., 2009; Beckmann et al., 1997; Prinz et al., 2000a).

\subsubsection{Post-translational insertion of Tail-Anchored proteins into the ER membrane}

TA proteins strongly differ from other transmembrane proteins in their topology, as their single transmembrane domain is located only within the last 50 residues of the protein and not more than $\sim 30$ residues following the TMD (Borgese et al., 2003; Kutay et al., 1993). During translation of TA proteins, the TMD stays in the ribosome machinery until the very end of translation, making it impossible for the SRP machinery to bind to the TMD before the end of translation. This prohibits a co-translational translocation, implicating that TA proteins can insert only post-translationally (Borgese and Fasana, 2011; Kutay et al., 1995).

TA proteins have different target membranes and are inserted into the ER, peroxisomes, mitochondria and chloroplasts, always via post-translational pathways (Borgese and Fasana, 2011). The following part will mainly discuss the insertion into to $E R$, since many TA proteins first insert into the ER and are only later exported to their final target organelle. Insertion into the ER can, at least in vitro, happen via two general ways. Proteins can either insert unassisted into the ER membrane, or in a Chaperone-mediated manner.

For unassisted insertion, cytochrome b5 (b5) is the best-characterised substrate TA protein. It has been subject of many studies and was shown to insert in vitro into a lipid bilayer without any cytosolic or membrane protein assisting, but already small amounts of cholesterol in the target membrane prevent insertion (Brambillasca et al., 2005; Colombo et al., 2009). Further studies revealed that the capacity of b5 to insert unassisted is promoted by the moderate hydrophobicity of its TMD. If the TMD of Synaptobrevin 2 (Syb2), another TA protein not displaying this feature, was substituted for the TMD of b5, this was sufficient to promote unassisted insertion of Syb2. This effect can also be observed in the inverse way, making b5 incapable of spontaneous insertion if its TMD is replaced by the one of Syb2 (Brambillasca et al., 2006).

In vivo, the most crucial step is for each TA protein to reach its destined organelle by way of correct targeting. Since hydrophobic patches of proteins are very aggregation-prone in 
the cytosolic environment, chaperones are needed to keep the TA proteins in an insertioncompetent state until they reach the correct target membrane. The involvement of chaperones is also likely since research has already early shown the ATP dependency of insertion of some TA proteins such as Syb2 (Kutay et al., 1995).

Several chaperones have been associated with TA protein targeting and insertion. The SRP has been found to be capable of binding and targeting certain TA proteins to the ER membrane in a post-translational manner. Sec61 $\beta$ and Syb2 can both be cross-linked to SRP54, and SRP and GTP both increase insertion of Syb2 and Sec61 $\beta$ into microsomes (Abell et al., 2004). Other studies show that the cytosolic chaperones Hsc70/Hsp40 can interact with Sec61ß, and together Hsc70 and Hsp40 enable membrane insertion of Sec61 $\beta$ and other TA proteins in a reconstituted system in the same manner as complete cytosol (Abell et al., 2007; Rabu et al., 2008). On the other hand these studies show that only very few TA proteins depend on Hsc70/Hsp40 in their targeting, but are mainly dependent on a different ATP-dependent factor (Rabu et al., 2008). This factor was identified to be the cytosolic ATPase TRC40 (Transmembrane Recognition Complex subunit of $40 \mathrm{kDa}$ ), previously known as Asna1 (arsenical pump-driving ATPase protein) (Stefanovic and Hegde, 2007). TRC40 is part of a by now fairly well characterised pathway that mediates posttranslational TA protein insertion into the ER membrane.

\subsection{The GET pathway}

The main components of the GET pathway are both identified in yeast and mammalian cells. Several factors, both cytosolic and membrane-bound, interact to enable a correct targeting of TA proteins into the ER membrane.

After TRC40 had been identified as the chaperone binding the TMD of TA proteins in the mammalian system (Stefanovic and Hegde, 2007), the pathway was extensively studied in yeast, and many structural studies provided insight into the suggested molecular mechanisms of the pathway.

\subsubsection{The GET pathway in yeast}

The yeast homologue of TRC40, Get3, was shown to be involved in targeting and insertion of TA proteins in yeast, together with the two membrane proteins Get1 and Get2 (Schuldiner et al., 2008). These three proteins had previously been observed to interact in a genetic interaction screen and were thought to play a role in the Golgi-to-ER traffic, resulting in the GET nomenclature (Schuldiner et al., 2005). After it became clear that their main role was in TA protein targeting and insertion, GET was redefined to Guided Entry of Tail-Anchored proteins. In this newly discovered pathway, Get3 interacts with the 
TMD of TA proteins and targets them to the ER membrane, where Get1/Get2 form a heterodimeric receptor for the Get3-TA-protein-complex (Schuldiner et al., 2008). Deletion of the receptor leads to cytosolic accumulation and aggregation of TA proteins in complex with Get3, and simultaneous overexpression of some substrates leads to mislocalisation of these TA proteins to mitochondria (Schuldiner et al., 2008). In subsequent studies, three additional factors were identified to participate in the GET pathway in yeast: Get4, Get5 and Sgt2 (small glutamine-rich tetratricopeptide repeat-containing protein 2), which together form the so-called pretargeting complex (Copic et al., 2009; Jonikas et al., 2009; Liou et al., 2007). Get4 and Get5 were first identified in studies regarding protein folding at the ER and retrieval of escaped ER resident proteins, and both proteins could be shown to interact with Get3. Moreover, their deletion also leads to defects in TA protein targeting (Jonikas et al., 2009). Sgt2 on the other hand was shown to interact with Get4 and Get5 in a tight complex (Chang et al., 2010).

For all the main components of the GET pathway, structural and functional analyses allowed a deeper insight into the molecular mechanisms behind targeting and insertion of TA proteins into the ER membrane (reviewed in Denic et al., 2013), as shown simplified in Figure 1.

Accordingly, initial capturing of the TA protein after translation is realised by Sgt2 via its carboxy-terminal domain. This domain is able to discriminate between TA proteins with the ER as their destined target and TA proteins with the mitochondria as their destined target (Wang et al., 2010). Sgt2 presents the first step in a cascade that ends with the handing over of the TA protein substrate to Get3. The N-terminal domain of Sgt2 enables it to form a homodimer and interact with the ubiquitin-like domain of Get5 (Chang et al., 2010; Chartron et al., 2011; Liou and Wang, 2005; Simon et al., 2013). Get5 itself can also dimerise via its carboxy-terminal (Chartron et al., 2012b), and Get4 and Get5 form a heterotetramer consisting of two copies of each protein. This interaction is promoted by the binding of Get4 to the N-terminus of Get5 (Chartron et al., 2010). Get4 also facilitates contact of the pretargeting complex with Get3, which binds to a conserved surface in Get4 (Chartron et al., 2010). Binding of Get3 to Get4 locally increases the concentration of Get3 close to the pretargeting complex and allows the transfer of the TA protein to Get3 (Wang et al., 2010).

Get3 forms a homodimer, with a zinc ion being coordinated between the two monomers by Cysteine residues. Besides a nucleotide binding domain, each monomer owns another $\alpha$-helical subdomain. These subdomains provide the binding groove for the TA proteins, as suggested by several studies. They are rich in methionine and hydrophobic residues, resembling the properties of the M-domain of SRP54, which is the part of SRP binding to signal or signal anchor sequences (Keenan et al., 1998; Rosendal et al., 2003). 
V. Denic et al.

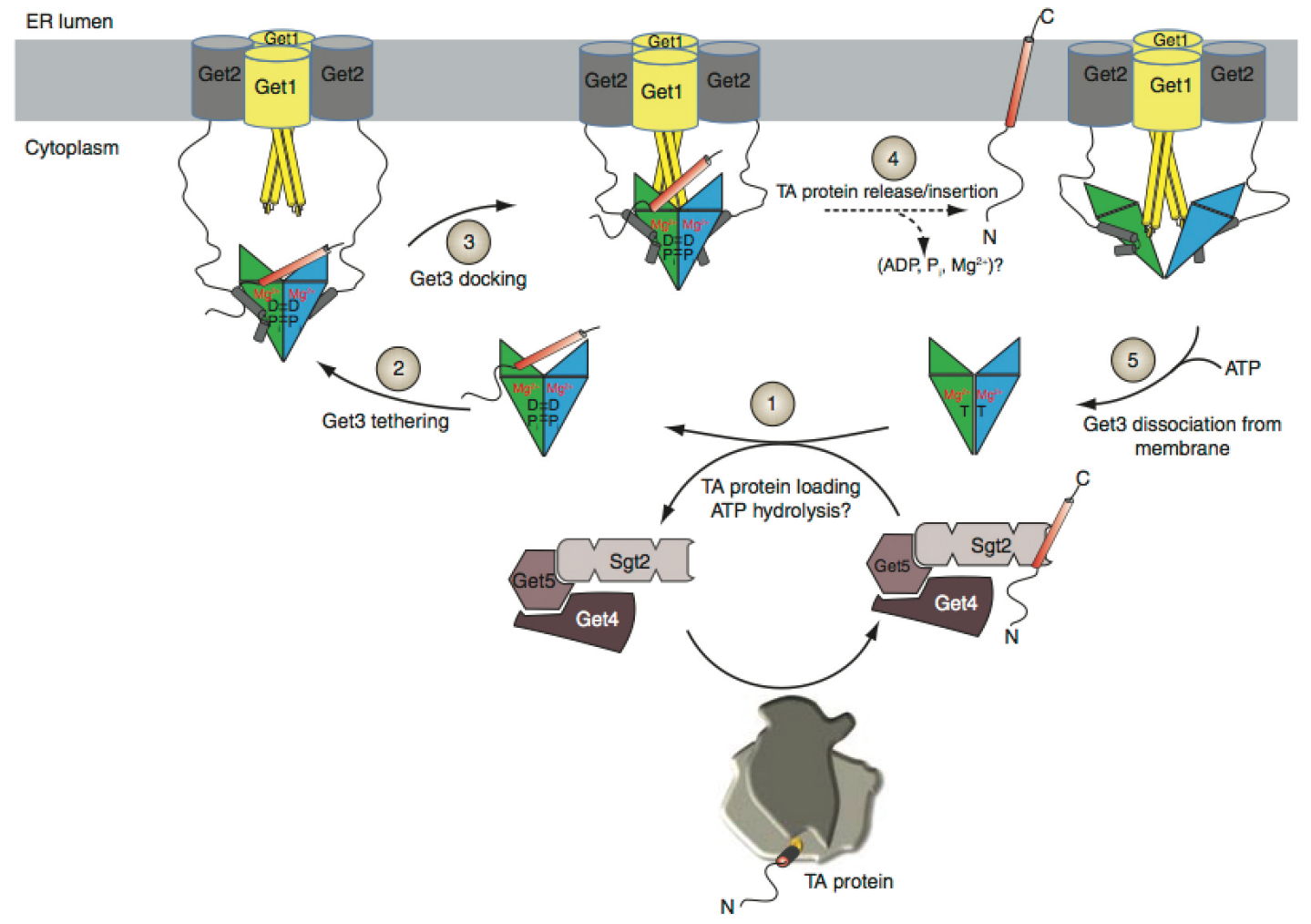

Figure 1: The GET pathway in yeast.

After release from the ribosome, a TA protein substrate is bound by the pretargeting complex consisting of Get4, Get5 and Sgt2, which hands it over to Get3 (1). After the complex of Get3 and the TA protein is tethered to the ER membrane by Get2 (2), it docks to the membrane (3). TA protein and release follows (4) before Get3 dissociates from the ER membrane and can be loaded with another substrate (5).

Adopted from Denic et al., 2013

Furthermore, Deuterium exchange experiments suggested a protection of this area in a TA protein bound state (Bozkurt et al., 2009).

Get3 cycles between different conformations as well as between the ER and the cytosol, and this correlates with different nucleotide states. Upon ATP binding, the dimer is suggested to go into a closed state, which is then transferred to a fully closed state upon ATP hydrolysis, allowing the final formation of the binding groove (Bozkurt et al., 2009; Mateja et al., 2009; Suloway et al., 2009). In this conformation, Get3 is in a TA protein binding competent state, and can then cycle to the ER membrane in a Get3-TA-proteincomplex. At the ER membrane, this complex first interacts with Get 2, which is able to bind Get3 in its closed conformation (Mariappan et al., 2011; Stefer et al., 2011). This binding occurs via the cytoplasmic N-terminus of Get2 and a negatively charged surface patch of Get3 (Stefer et al., 2011). Current hypotheses suggest that after the Get3-TAprotein-complex has been tethered to the ER membrane by Get2, Get1 binding to Get3 is 
responsible for the TA protein release from Get3. Get1 can interact with Get3 also in its open conformation, and interaction sites include parts of the TA protein binding region as well as the same region that is previously bound by Get2 (Mariappan et al., 2011; Stefer et al., 2011). One suggested role for Get1 in this process is that it functions similar to a nucleotide exchange factor and can induce or maintain the open conformation of Get3 by interfering with nucleotide binding (Stefer et al., 2011). The open conformation of Get3 is associated with nucleotide release as well as TA protein release. After returning to the open conformation, Get3 can bind ATP again, regain its closed conformation and bind to another new TA protein substrate.

In the final step, the TA protein is inserted into the ER membrane. For a long time it was unclear how the TMD of TA proteins is integrated into the membrane. Since in vitro some TA proteins were shown to insert unassisted into lipid bilayers, one discussed possibility was that proximity to the ER membrane is sufficient to allow unassisted insertion (Brambillasca et al., 2005). However, recent studies have shown that the Get1/Get2 complex acts as an insertase for TA proteins (Wang et al., 2014). In this process, the cytosolic domains of Get1/Get2 cooperate with the transmembrane segments of Get1/2 to allow a successful release of the TA protein TMD from Get3. The TMD is then handed over to the transmembrane segments of Get1/Get2. This mechanism might suggest a general possibility of how TA proteins are inserted if they are not able to cross the membrane in an unassisted manner.

\subsubsection{The mammalian GET pathway}

In recent years, the main components of the pathway were identified in the mammalian system as well. An overview of the components is shown in Figure 2. After TRC40 had been identified early (Stefanovic and Hegde, 2007), the receptor was characterised only later. Similar to the situation in yeast, the receptor in the mammalian pathway is a heterodimer comprised of WRB and CAML (Vilardi et al., 2011; Yamamoto and Sakisaka, 2012). WRB (tryptophan-rich basic protein) was suggested as a potential mammalian receptor for TRC40 based on sequence similarity to Get1. It could subsequently be shown to be an ER resident protein that can bind to TRC40 via its cytosolic coiled-coil domain, and this domain alone can act as a suppressor for TA protein insertion in vitro, showing that WRB acts as the receptor for TRC40 at the ER membrane (Vilardi et al., 2011). CAML (calcium-modulating cyclophilin ligand) has been identified in pull-down assays via its interaction with TRC40, and has been shown to interact with WRB as well. Similarly to the cytosolic domain of WRB, recombinantly expressed CAML could also suppress the insertion of TA proteins in vitro (Yamamoto and Sakisaka, 2012). Interestingly, also the expression levels of WRB and CAML influence insertion. 


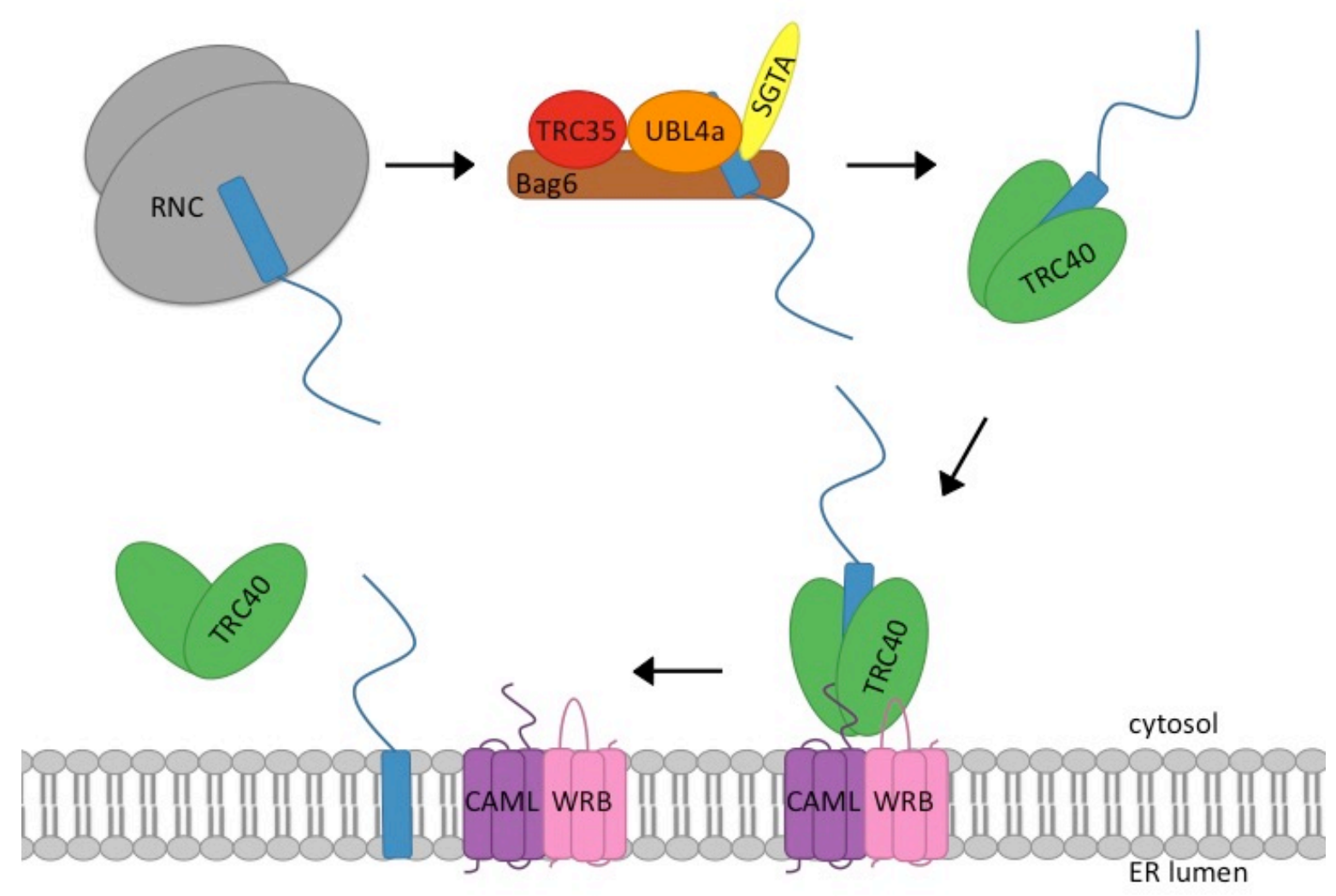

Figure 2: The mammalian GET pathway.

After the TA protein substrate (blue) emerges from the ribosome (grey), it is captures by the pretargeting complex consisting of TRC35, Ubl4a, SGTA and Bag6. It is then transferred to TRC40, which targets it to the ER membrane. There, the complex of TRC40 and the TA protein binds to the dimeric receptor comprised of WRB and CAML. The TA protein is inserted into the ER membrane and TRC40 is released.

Overexpression of one or the other inhibits insertion of TA proteins in cells (Yamamoto and Sakisaka, 2012). Complementary studies in yeast with recombinantly expressed WRB and CAML showed that both together are necessary and sufficient to mediate TA protein targeting to the ER membrane (Vilardi et al., 2014).

As in yeast, the TA protein in the mammalian system is captured by a pretargeting complex after its release from the ribosome, which is composed of Bag6 (also termed Bat3), TRC35 and Ubl4a (Leznicki et al., 2010; Mariappan et al., 2010). TRC35 and Ubl4a are the homologues of Get4 and Get5, respectively (Hu et al., 2006; Simpson et al., 2010), but for Bag6, no equivalent yeast component is known. However, the mammalian homologue of yeast Sgt2, SGTA, is also associated with the mammalian pretargeting complex (Chartron et al., 2012a; Simon et al., 2013; Xu et al., 2012) and is suggested to play a role in TA protein targeting as well (Leznicki et al., 2010).

Bag6 is also involved in several protein quality control mechanisms in the cell, being required in the process of ubiquitin dependent degradation of irregular proteins after 
release from the ribosome, in ER associated degradation (ERAD) of certain membrane proteins, and the ubiquitination and degradation of mislocalized membrane and secretory proteins (Ernst et al., 2011; Hessa et al., 2011; Minami et al., 2010; Wang et al., 2011). Interestingly, SGTA was found to promote substrate loading to Bag6 during ERAD to prevent aggregation of ERAD substrate (Xu et al., 2012). On the other hand, SGTA counteracts the role of Bag6 in ubiquitination of mislocalised membrane proteins by enhancing deubiquitination of these substrates (Leznicki and High, 2012). All of these findings support a role of the full mammalian pre-targeting complex in protein quality control as well. One current hypothesis is that Bag6 can recruit different effectors via its $\mathrm{N}$ terminal Ubl-domain, with SGTA being one of these effectors and helping to prevent degradation of mislocalised proteins and support their correct targeting. SGTA is also thought to bind to either Bag6 or Ubl4a, and can also bind to TA proteins (Leznicki et al., $2010 ; 2013$; 2011), supporting a possible role of SGTA in targeting of TA proteins and keeping them in a targeting competent state. However, the full mechanism of how Bag6, TRC35, Ubl4a and SGTA work together is not yet fully understood.

\subsubsection{The GET pathway in development and cellular physiology}

While in both yeast and in the mammalian system the main components are known, there are still quite a few unanswered questions regarding the pathway. In yeast, the GET pathway is known to be non-essential under normal growth conditions, but deletion of its components makes yeast more susceptible to certain stress conditions such as oxidative or temperature stress (Metz et al., 2006; Schuldiner et al., 2008; Shen et al., 2003). In higher eukaryotes on the other hand knockout of the individual components has severe consequences. Knockout of TRC40 or CAML both results in embryonic lethality in mice (Mukhopadhyay et al., 2006; Tran et al., 2003). WRB is also known as CHD5 (congenital heart disease 5) since it was mapped to the region on Chromosome 21 that is connected to congenital heart diseases in trisomy 21 patients (21q22.3) (Egeo et al., 1998), and its disruption in Medaka fish leads to severe cardiac disorders during development (Murata et al., 2009). Results from our lab also suggest a role for WRB in cardiac development in mice and also suggest a general WRB knockout in mice to be embryonic lethal (unpublished). A knockout of WRB in the inner ear leads to reduced levels of the TA protein Otoferlin and causes impairment of the synaptic structure and function in the inner ear (Vogl et al., 2016).

CAML was previously mainly known for its role in signalling and in the development and regulation of the immune system (Bram and Crabtree, 1994; Edgar et al., 2010; Tran et al., 2003). For Get3 recently a second function as an ATP-independent holdase chaperone under oxidative stress conditions has been found (Powis et al., 2013; Voth et 
al., 2014). The different functions of the pathway components show that the mammalian GET pathway might be system far more complex than just a targeting pathway for TA proteins. Also so far the versatile phenotypes in yeast and higher eukaryotes upon deletion of parts of the pathway are mechanistically not fully understood. In yeast, the different phenotypes can partially be accounted for by reduced insertion of TA proteins, but the observed copper sensitivity in strains lacking Get3 is a result of the loss of its chaperone function (Schuldiner et al., 2008; Voth et al., 2014). In the mammalian system, the full client spectrum of the pathway is not known and an ATP-independent chaperone function for TRC40 has not yet been observed. It is unclear whether certain substrates fully depend on the pathway or whether a certain redundancy in the insertion of TA proteins is always given due to the participation of other chaperones in the targeting and insertion (Abell et al., 2004; 2007; Rabu et al., 2008). The indispensability of TRC40, CAML and most likely WRB however shows that some functions of the mammalian GET pathway or its components are absolutely necessary for the development and viability in higher eukaryotes. Whether this is a result of mis- or non-targeted TA proteins or is due to a more complex role of the pathway in general protein quality control is yet to be analysed.

\subsection{The mouse liver as a model system for studying the mammalian GET pathway}

So far the mammalian GET pathway has not been studied in vivo. In this study we chose the mouse liver as a model organ to investigate the role of this pathway in an animal model.

The tissue organisation of the liver shows a relatively homogenous cell population. $80 \%$ of the liver mass are made up by hepatocytes (Duncan, 2000; Kmieć, 2001), providing the liver parenchyma in the adult organism. The main functions of the liver are versatile and change during development. In the foetus, the liver is the main hematopoietic organ and shows a high population of hematopoietic stem cells (Mikkola and Orkin, 2006; Paul et al., 1969). The conversion to the typical composition of the adult liver along with the typical function occurs perinatally (Zaret, 2000). The functions of the adult liver cover a wide range of processes. It has a detoxifying function and shows high levels of protein synthesis, for example of serum proteins. The most abundant protein in the serum, albumin, is produced in the liver. Additionally, hormones such as angiotensinogen are synthesised. Other important functions of the liver include roles in the cholesterol and lipid metabolism and in glycogen storage. All these processes are dependent on a functioning ER and/or a high degree of vesicle formation and trafficking. 
Being of such a great importance also makes the liver prone to diseases. Different causes can lead to malfunction and damage of the liver. Prominent examples are inflammatory diseases like Hepatitis C (Wang et al., 2016), alcoholic liver disease (O'Shea et al., 2010) or hemochromatosis (Powell et al., 2016). Often diseases of the liver lead to the formation of fibrotic tissue in the damaged organ, ultimately leading to liver cirrhosis (Friedman, 2000). In some diseases, ER stress in hepatocytes has been described with an impairment of normal function of the cells (Baiceanu et al., 2016).

\subsection{Aim of the thesis}

The components of the mammalian GET pathway are essential in higher eukaryotes, yet the specific reason why remains unknown. The involvement of some of the components such as Bag6 in other protein quality control systems of the cell, and the role of Get3, the yeast homologue of TRC40, as an ATP-independent chaperone raise the question whether the mammalian GET pathway is essential due to roles in larger context of protein quality control, or whether its indispensability in higher eukaryotes is solely based on its role in TA protein targeting. Additionally, the in vivo client (TA protein or chaperone clients) spectrum of the pathway is not yet fully known.

To address these questions, the following aims were defined for this study:

Firstly, using the Cre-Lox system to generate a mouse line with a hepatocyte-specific deletion of WRB, one subunit of the heterodimeric GET receptor, and to characterise the morphological, histological and physiological phenotype after WRB knockout in hepatocytes. The liver was chosen because of its high ER content and important role in protein biosynthesis and secretion.

Secondly, to analyse how the WRB knockout in hepatocytes affects the main pathway components in their expression.

Thirdly, to investigate the consequences of the WRB knockout for substrates expressed in hepatocytes, and potentially identify clients that strictly depend on the pathway thereby explaining its essentiality. 


\section{Materials and Methods}

\section{$2.1 \quad$ Materials}

\subsubsection{Buffers and solutions}

Homogenisation buffer

Krebs-Ringer/EGTA

Krebs-Ringer/HEPES/CaCl ${ }_{2}$

plus Collagenase
$50 \mathrm{mM} \mathrm{NaCl}$

$0.32 \mathrm{M}$ sucrose

20 mM HEPES pH $7.4(\mathrm{NaOH})$

2 mM EDTA

protease inhibitors (Roche)

$120 \mathrm{mM} \mathrm{NaCl}$

$4.8 \mathrm{mM} \mathrm{KCl}$

$1.2 \mathrm{mM} \mathrm{MgSO}_{4}$

$1.2 \mathrm{mM} \mathrm{KH}_{2} \mathrm{PO}_{4}$

$24 \mathrm{mM} \mathrm{NaHCO}_{3}$

0.25 mM EGTA

$120 \mathrm{mM} \mathrm{NaCl}$

$4.8 \mathrm{mM} \mathrm{KCl}$

$1.2 \mathrm{mM} \mathrm{MgSO}_{4}$

$1.2 \mathrm{mM} \mathrm{KH}_{2} \mathrm{PO}_{4}$

$24 \mathrm{mM} \mathrm{NaHCO}_{3}$

15 mM HEPES

$0.4 \%(w / v)$ Collagenase

aerate with Carbogen for $30 \mathrm{~min}$, bring $\mathrm{pH}$ to 7.4 , then add $\mathrm{CaCl}_{2}$ from $1 \mathrm{mM}$ stock to $4 \mathrm{mM}$ final

filtrate to sterilize

$137 \mathrm{mM} \mathrm{NaCl}$

$2,7 \mathrm{mM} \mathrm{KCl}$

$8 \mathrm{mM} \mathrm{Na}_{2} \mathrm{HPO}_{4}$

$1,5 \mathrm{mM} \mathrm{KH}_{2} \mathrm{PO}_{4}$ 
4\% PFA in PBS

Percoll buffer

Ponceau

SDS loading buffer

SDS running buffer

Solubilisation buffer

Transfer buffer
$4 \%(w / v)$ PFA powder, dissolve in water plus $\mathrm{NaOH}$ with heating

add $1 / 10$ volume $10 x$ PBS, adjust $\mathrm{pH}$ to 7.4 with $\mathrm{HCl}$

fill up to final volume with water

$1.4 \mathrm{M} \mathrm{NaCl}$

$50 \mathrm{mM} \mathrm{KCl}$

$8 \mathrm{mM} \mathrm{MgCl}_{2}$

$16 \mathrm{mM} \mathrm{Na}_{2} \mathrm{HPO}_{4}$

$4 \mathrm{mM} \mathrm{KH}_{2} \mathrm{PO}_{4}$

$0.2 \%(w / v)$ Ponceau S

$3 \%(w / v)$ TCA

$3 \%(w / v)$ Sulfosalicylic acid

$50 \mathrm{mM}$ Tris $(\mathrm{pH} \mathrm{6.8)}$

$1 \% \operatorname{SDS}$

$0.1 \%(\mathrm{w} / \mathrm{v})$ Bromophenol blue

$5 \%$ Glycerol

100 mM DTT (added freshly)

$25 \mathrm{mM}$ Tris

250 mM Glycine pH 8.3

$0.1 \%$ SDS

$1.5 \%$ Triton-X 100

0.75\% Sodium Deoxycholate (added freshly)

$0.1 \%$ SDS (added freshly)

50 mM TRIS-HCl (pH 7.4)

$2.5 \mathrm{mM}$ EGTA

5 mM EDTA

protease inhibitors

$250 \mathrm{mM}$ Tris

1.92 M Glycine 
Williams E medium

Williams E medium

(cell attachment)

Williams E medium

(maintaining cells)
$1 \times$ medium from powder (Applichem, custom made with $5 \mathrm{mM}$ instead of $10 \mathrm{mM}$ Glucose)

$26.2 \mathrm{mM} \mathrm{NaHCO} 3$

15 mM HEPES

$0.2 \%$ BSA

Williams E Medium

$5-10 \%$ FCS

1\% Gentamycin (Applichem)

$10^{-7} \mathrm{M}$ Dexamethasone (Sigma-Aldrich)

$10^{-8} \mathrm{M}$ Insulin (Sigma-Aldrich)

Williams E Medium

$1 \%$ Gentamycin

$10^{-7} \mathrm{M}$ Dexamethasone

$10^{-8} \mathrm{M}$ Insulin

\subsubsection{Primers for RT-qPCR}

The following table contains all sequences of the primers used for RT-qPCR. Sequences are always in 5'-3' direction. For all primers used, a primer efficiency test was performed, using a dilution series of $1: 5$ to $1: 625$ of $c D N A$ for each primer.

All primers were ordered from Sigma-Aldrich.

Table 1: Primers for RT-qPCR.

Names and sequences of all primers are listed. Sequences are always in 5'-3' direction. For, Forward. Rev, reverse.

\begin{tabular}{|c|c|c|}
\hline Target & Name & Sequence \\
\hline \multirow{2}{*}{ WRB } & mWRB-Ex3-4-For & CTACATACTACAAGCAGCGCTGATG \\
\cline { 2 - 3 } & mWRB-Ex5-Rev & ATCCAACAGGTGATTCCAATTCCAC \\
\hline \multirow{2}{*}{ CAML } & mCAML-for & CTCACCACGGCCTAGAACAG \\
\cline { 2 - 3 } & mCAML-rev & AACTCTTCCGCGGTACTTCC \\
\hline \multirow{2}{*}{ TRC40 } & mTRC40-for & GTCCTTGTACGAGACGGAGC \\
\cline { 2 - 3 } & mTRC40-rev & TTGCAGGGTTTCTCAGGGTC \\
\hline \multirow{2}{*}{ Cre recombinase } & Cre_recombinase_For4_qPCR & GCAAACGGACAGAAGCATTTTC \\
\cline { 2 - 3 } & Cre_recombinase_Rev4_qPCR & GCAACGAGTGATGAGGTTCG \\
\hline \multirow{2}{*}{ Stx5 } & mStx5_qPCR_primer1_for & GAGTGCTGTCACTGCTGCTA \\
\cline { 2 - 3 } & mStx5_qPCR_primer1_rev & TCTCACGAGTTGGAGAGCAC \\
\hline \multirow{2}{*}{ Stx6 } & mStx6_qPCR_primer2_for & AGAGGATGGCTATGGCACAC \\
\cline { 2 - 3 } & mStx6_qPCR_primer2_rev & \\
\hline
\end{tabular}




\begin{tabular}{|c|c|c|}
\hline \multirow{2}{*}{ Stx8 } & mStx8_qPCR_primer2_for & GGAGGGGGATCGAAGACAGA \\
\cline { 2 - 3 } & mStx8_qPCR_primer2_rev & GCTTCTTCGCTCATCAGGCT \\
\hline \multirow{2}{*}{ Sec61b } & mSec61b_qPCR_primer2_for & ATGTGGCGATTCTACACGGAA \\
\cline { 2 - 3 } & mSec61b_qPCR_primer2_rev & GCAGCATAAATACAGCAGCGA \\
\hline \multirow{2}{*}{ EMD } & mEMD_qPCR_primer1_for & GACCACCAAGACATACGGGG \\
\cline { 2 - 3 } & mEMD_qPCR_primer1_rev & AGTGTGCGATGCTCTGGTAG \\
\hline \multirow{2}{*}{ Stt3b } & mStt3b_qPCR_primer1_for & CTCCAGTCCAAGTGTGGTCC \\
\cline { 2 - 3 } & mStt3b_qPCR_primer1_rev & TGATAGCCGTAGTCCCACCA \\
\hline \multirow{2}{*}{ GAPDH } & mGPADH_For & CCAATGTGTCCGTCGTGGATCT \\
\cline { 2 - 3 } & mGAPDH_Rev & GTTGAAGTCGCAGGAGACAACC \\
\hline
\end{tabular}

\subsubsection{Antibodies}

The following tables list antibodies used for different applications. Antibodies were used for Western Blot and immunofluorescence as indicated in the table.

Table 2: Antibodies used in the thesis.

All antibodies used are listed with their application and the working dilution. For commercial antibodies, product numbers are listed.

\begin{tabular}{|c|c|c|c|c|}
\hline Raised against & Species & Company & Application & Dilution \\
\hline CAML & Guinea pig & $\begin{array}{c}\text { Synaptic Systems } \\
(359004)\end{array}$ & WB & $1: 500$ \\
\hline Emerin & rabbit & $\begin{array}{l}\text { Santa Cruz } \\
(\mathrm{sc}-15378)\end{array}$ & WB & $1: 1000$ \\
\hline GM 130 & mouse & $\begin{array}{c}\text { BD Transduction } \\
\text { Laboratories } \\
(610823)\end{array}$ & IF & $1: 200$ \\
\hline HMGCS & rabbit & Abcam (ab137043) & WB & $1: 000$ \\
\hline $\begin{array}{l}\text { LICOR IRDye } \\
\text { secondary } \\
\text { antibodies }\end{array}$ & different & LICOR & $\begin{array}{c}\text { WB secondary } \\
\text { antibodies }\end{array}$ & $1: 5000$ \\
\hline Sec61b & rabbit & $\begin{array}{c}\text { Gift from } \\
\text { Dobberstein lab }\end{array}$ & WB & $1: 1000$ \\
\hline Syntaxin 5 & rabbit & $\begin{array}{c}\text { Synaptic Systems } \\
(110053)\end{array}$ & WB, IF & $\begin{array}{c}1: 1000 \text { (WB) } \\
1: 100 \text { (IF) }\end{array}$ \\
\hline Syntaxin 6 & rabbit & $\begin{array}{c}\text { Synaptic Systems } \\
(110062)\end{array}$ & WB, IF & 1:1000 (WB) \\
\hline
\end{tabular}




\begin{tabular}{|c|c|c|c|c|}
\hline Syntaxin 8 & rabbit & $\begin{array}{c}\text { Synaptic Systems } \\
(110083)\end{array}$ & WB, IF & $\begin{array}{c}1: 1000 \text { (WB) } \\
1: 300 \text { IF }\end{array}$ \\
\hline TRC40 & rabbit & $\begin{array}{c}\text { Proteintech ( } \\
15450-1-A P)\end{array}$ & WB & $1: 1000$ \\
\hline WRB & rabbit & Synaptic Systems & WB & $1: 500$ \\
\hline
\end{tabular}

WB, western blot; IF, immunofluorescence

\subsubsection{Animals}

All animal procedures were reviewed and approved by the Institutional Animal Care and Use Committees of the University Medical Center Göttingen.

The Pwi ${ }^{f / f l}$ mouse line carrying a floxed allele of WRB was a kind gift from Professor David Corey and was published previously (Vogl et al., 2016).

Albumin-Cre mice (B6.Cg-Tg(Alb-cre)21Mgn/J) were purchased from the Jackson Laboratory. In the following, mice either lacking the Cre-recombinase or being positive for the transgene.Alb-Cre- and Alb-Cre+ will be referred to as Alb-Cre- or Alb-Cre+. Given that all animals used for this work were $\mathrm{Pwi}^{\mathrm{fl} / \mathrm{fl}}$ (or WRB ${ }^{\mathrm{f} / \mathrm{fl}}$ ), animals are only named AlbCre- and Alb-Cre+ in the text for simplicity.

For this study, mice of two different age groups were used. Mice were either $6 \mathrm{w}$ old or at least $10 \mathrm{w}$ old. A full list of all animals used for experiments including age, sex and genotype can be found in the Appendix (Table 6).

\subsection{Methods}

\subsubsection{Blood withdrawal}

For analysis of different parameters, blood was taken from animals aged $6 \mathrm{w}$ and at least $12 \mathrm{w}$. For this purpose, animals were anesthetized with Isoflurane followed by injection of appr. $400 \mu \mathrm{L}$ Nembutal $(10 \mathrm{mg} / \mathrm{mL})$. The body cavity was opened and blood was taken from the Vena cava caudalis with a small syringe. For obtaining serum for the analysis, the syringe was rinsed with Lithium Heparine $(5 \mathrm{U} / \mathrm{mL}$ in water, Sigma-Aldrich) before drawing blood. Samples were then centrifuged at $500 \mathrm{xg}$ for $30 \mathrm{~min}$ to collect the serum.

\subsubsection{Histological analysis}

For histological analysis, single lobes or the whole liver of animals at age $6 \mathrm{w}$ or at least $10 \mathrm{w}$ were dissected. Animals were anesthetized with Isoflurane followed by injection of appr. $400 \mu \mathrm{L}$ Nembutal $(10 \mathrm{mg} / \mathrm{mL})$. The whole liver or individual lobes were excised and rinsed in PBS, followed by fixation in 4\% PFA in PBS o/n. The tissue was then brought to the Pathology Department of the University Medical Center Göttingen, where subsequent 
fixation and dehydration steps were carried out. Afterwards, the tissue samples were embedded in Paraffin for sectioning and staining. Staining on $3 \mu \mathrm{m}$ thick sections was carried out by the Pathology Department under Professor Ströbel.

\subsubsection{Isolation of primary hepatocytes}

Buffers for perfusion were prewarmed to $37^{\circ} \mathrm{C}$ and aerated with Carbogen $\left(95 \% \mathrm{O}_{2}, 5 \%\right.$ $\mathrm{CO}_{2}$ ).

Animals were anesthetized with Isoflurane, followed by intraperitoneal injection of $400 \mu \mathrm{L}$ Nembutal $(10 \mathrm{mg} / \mathrm{mL})$. After opening the body cavity, a ligature was placed around the Vena cava caudalis. The liver was perfused via the Vena cava caudalis, using the Vena portae as outflow. The liver was first perfused with appr. $125 \mathrm{~mL}$ Krebs-Ringer/EGTA, followed by perfusion with Krebs-Ringer substituted with Collagenase/HEPES/CaCl 2 . Due to the fragility of the hepatocytes in $6 \mathrm{w}$ old Alb-Cre+ animals, perfusion in $6 \mathrm{w}$ old animals in general was restricted to $4 \mathrm{~min}$. After perfusion, the liver was excised, rinsed in Williams E medium (referred to below as medium) and manually pulled apart with forceps to wash out the cells, followed by a filtering step $(70 \mu \mathrm{m}$ pore size). The cells were centrifuged through a Percoll gradient (GE Healthcare) to separate parenchymal cells (hepatocytes) from non-parenchymal cells. For this purpose, the filtered cells were resuspended in $8 \mathrm{~mL}$ medium and mixed with $2.1 \mathrm{~mL}$ Percoll buffer and $13.9 \mathrm{~mL}$ Percoll. The gradient was followed by a washing step and the hepatocytes were resuspended in medium $(1 \mathrm{~g}$ of cells in $50 \mathrm{~mL}$ ). The amount of cells was quantified using a counting chamber. Cells were then either plated or pelleted, washed with PBS and snap frozen in liquid $\mathrm{N}_{2}$, followed by storage at $-80^{\circ} \mathrm{C}$. In case of plating, cells were allowed to attach in medium with serum for 3-4 $\mathrm{h}$, then medium was changed to medium without serum.

\subsubsection{Transcriptome analysis}

Total RNA isolated from isolated hepatocytes of $6 \mathrm{w}$ old Alb-Cre- and Alb-Cre+ animals was subjected to Transcriptome Analysis. The analysis was performed by the Transcriptome and Genome Analysis Laboratory (TAL) of the University Medical School Göttingen (http://biochemie.uni-goettingen.de/index.php?id=709). The final list of differentially expressed genes was further analysed by gene ontology (GO) term enrichment and functional annotation clustering using the DAVID Bioinformatics Resources 6.7 web-based application (https://david.ncifcrf.gov/). For this analysis, only GO terms for biological processes were considered (using GOterm_BP_ALL).

Also, a heatmap was created with the 50 genes showing the highest change in expression level according to the FDR-corrected $p$-values (provided by the TAL). 


\subsubsection{Immunofluorescence}

Primary hepatocytes were plated on glass coverslips coated with collagen. Cells were allowed to attach, using a medium with serum, and after 3-4 $\mathrm{h}$, the medium was changed once to remove serum. Cells were cultured o/n.

Cells were washed with PBS. Fixation was performed with PFA or methanol (depending on the antibody). For PFA fixation, cells were first incubated for 20 min with $2 \%$ PFA and $0.125 \mathrm{M}$ sucrose in PBS. After washing twice with PBS, cells were incubated for another 10 min in $1 \%$ PFA in PBS.

For methanol fixation, cells were washed twice with PBS, and fixed with ice-cold methanol for $5 \mathrm{~min}$, preferably at $4^{\circ} \mathrm{C}$ with the cells on ice. Methanol was then taken off and the cells were washed twice with PBS.

After fixation, cells were permeabilised for 10 min with $0.1 \%$ Triton $X-100$ and $0.05 \%$ SDS in PBS and afterwards washed twice with PBS. Blocking was performed with $10 \%$ FCS in PBS. Primary antibodies were incubated in PBS supplemented with $5 \%$ FCS. Incubation was carried out either at RT for $1 \mathrm{~h}$ or at $4^{\circ} \mathrm{C}$ o/n. Cells were washed three times with PBS before incubation with appropriate secondary antibodies in 5\% FCS in PBS at RT for 30 min was performed.

\subsubsection{Homogenisation of livers}

Livers (fresh or frozen) were homogenised using a glass Dounce homogeniser. Each liver was homogenised using 1 to $1.5 \mathrm{~mL}$ of homogenisation buffer, depending on the size. In a first round, a large clearance pestle was used, on average for 10 to 15 strokes. In a second round, a small clearance pestle was used to improve homogenisation further.

The protein content of the homogenate was quantified with Bradford quantification, using the same standard curve for all samples.

\subsubsection{Protein extraction}

Proteins were extracted from tissue homogenate or cells by solubilisation of the sample, followed by TCA precipitation.

Equal amounts of tissue homogenate (quantified by Bradford) or equal numbers of cells were solubilized for $30 \mathrm{~min}$ on ice in solubilisation buffer. Unsolubilised material was pelleted by ultracentrifugation at $50.000 \mathrm{x}$ for $25 \mathrm{~min}$ (TLA-55 rotor, Beckmann). Proteins in the supernatant were precipitated on ice for $10 \mathrm{~min}$ using TCA precipitation $(12.5 \%$ final concentration from a $50 \%(\mathrm{w} / \mathrm{v})$ stock solution). After pelleting at full speed (appr. $16,873 \times \mathrm{g}$ ) for $15 \mathrm{~min}$ at $4^{\circ} \mathrm{C}$, the precipitated proteins were washed twice with acetone (possible to perform the second step o/n). Residual acetone was dried off at $37^{\circ} \mathrm{C}$ and the 
proteins were resuspended in 1 -fold SDS loading buffer and put to shaking at $37^{\circ} \mathrm{C}$ for at least $30 \mathrm{~min}$.

\subsubsection{SDS Polyacrylamide gel electrophoresis and Western Blot}

Proteins in SDS loading buffer were separated by discontinuous SDS PAGE and transferred onto Nitrocellulose membrane (Amersham Protran Premium). Blotting was performed in a tank blot system (Hoefer) at $60 \mathrm{~V}, 0.5 \mathrm{~A}$ or $1 \mathrm{~A}$ (depending in the tank size) for $80 \mathrm{~min}$. Blots were stained with Ponceau and blocking was carried out for at least 30 min at RT with $5 \%$ milk in PBS $/ 0.1 \%$ Tween.

Incubation with primary antibodies was performed in blocking solution at $4^{\circ} \mathrm{C}$ o/n or for at least $2 \mathrm{~h}$ at RT. Incubation with secondary antibodies was performed in blocking solution for at least $1.5 \mathrm{~h}$ at RT. Blots were imaged using an Odyssey®SA imaging system with the corresponding secondary antibodies (IRDye LICOR).

\subsubsection{RT-qPCR}

To assess mRNA levels of different targets, real time quantitative PCR (RT-qPCR) was performed. RNA was extracted from total liver homogenate or isolated hepatocytes using two different methods. Either a commercial RNA extraction kit (Roche High Pure RNA isolation kit) was used, following manufacturer's instructions, or an isolation method with TRIzol ${ }^{\circledR}$ (Ambion ${ }^{\mathrm{TM}} /$ ThermoFisher Scientific) was used. For isolated hepatocytes, both methods were applied, for total liver homogenate, only the latter was used. For this purpose, hepatocytes or small pieces of liver tissue were homogenised in $500 \mu \mathrm{L}$ TRIzol, followed by addition of another $500 \mu \mathrm{L}$ of the reagent. $200 \mu \mathrm{L}$ Chloroform were added, and the tube was inverted 10-15 times. After incubation at RT for $3 \mathrm{~min}$, the sample was centrifuged at $12,000 \times \mathrm{g}, 4^{\circ} \mathrm{C}$ for $15 \mathrm{~min}$. The aqueous upper layer was transferred to a fresh tube. RNA was precipitated by adding $500 \mu \mathrm{L}$ Isopropanol and mixing well. Precipitation was carried out at $-20{ }^{\circ} \mathrm{C}$ for at least $30 \mathrm{~min}$, preferably o/n. The RNA pellet was then washed two times with $1 \mathrm{~mL}$ ice-cold $75 \%$ ethanol, followed by centrifugation at $12,000 \times \mathrm{g}$ at $4{ }^{\circ} \mathrm{C}$ for $5 \mathrm{~min}$. The residual ethanol was allowed to dry off, and the pellet was dissolved in 20-30 $\mu \mathrm{L}$ of DEPC-treated water.

The concentration of the isolated RNA was in all cases measured with a Nanodrop spectrophotometer. Equal amounts (500 ng to $2 \mu \mathrm{g}$, depending on the concentration of the RNA) were subjected to cDNA synthesis, using the SuperScript ${ }^{\circledR}$ III First-Strand Synthesis System (Invitrogen). Random hexamer primers were used, and manufacturer's protocol was followed for all procedures. For subsequent RT-qPCR, cDNA was diluted 1:25. For all RT-qPCRs performed, GAPDH was used as reference gene. 


\subsubsection{Statistics}

In experiments where an average of values was calculated, both the standard deviation and the standard error of the mean (SEM) were calculated. In graphs, the error bars represent the SEM.

Statistical significance was calculated with the Excel function for the regular two-tailed Student's t-Test, with a two-sample equal variance (non-paired). Significance levels were set as follows: ${ }^{*}=\mathrm{P} \leq 0.05,{ }^{* *}=\mathrm{P} \leq 0.01,{ }^{* * *}=\mathrm{P} \leq 0.001$. 


\section{Results}

\subsection{Mice with a hepatocyte-specific WRB knockout are viable}

The Cre-LoxP deletion system was employed to allow a cell-specific knockout of WRB in hepatocytes. For this purpose, a mouse line carrying a WRB allele in which the exons 2, 3 and 4 are flanked by loxP sites was crossed with a mouse line expressing the Cre recombinase under the Albumin promoter, ensuring a hepatocyte-specific activity of the Cre-recombinase (Postic et al., 1999). Two generations after the first crossing, animals were obtained which had two alleles of the floxed WRB and were either Alb-Cre- or AlbCre+. Up to an age of 35 weeks and older, these animals were viable and displayed no obvious signs of sickness or any impairment.

The expression of the Cre recombinase under the Albumin promoter reaches completion at around $6 \mathrm{w}$ after birth (Postic and Magnuson, 2000). Until that time point, tissue development is not yet complete and the liver undergoes a functional transition from its role in haematopoiesis during the foetal stages to the roles it has in the adult animal, which influences the number of hepatocytes in the organ and thereby the level of Albumin expression (Paul et al., 1969; Weisend et al., 2009). Animals at the age of $6 \mathrm{w}$ should show a clear phenotype, if the knockout results in such. Most of the experiments were carried out with animals both at $6 \mathrm{w}$ and at least 10 to $12 \mathrm{w}$ old to obtain a comprehensive characterisation. The latter group will be referred to as older animals throughout the thesis, and detailed information for all the animals is listed in Table 6 in the appendix.

\subsection{Hepatocyte-specific WRB knockout leads to strong liver damage in situ}

While no effect of the knockout appeared outwardly, upon opening of the body cavity a strong macroscopic phenotype of the liver in situ was observed. This phenotype was clearly visible at the age of $6 \mathrm{w}$, and increased with age. At $6 \mathrm{w}$, livers of Alb-Cre- animals displayed a normal liver phenotype with a smooth glossy surface of the organ and a homogeneous dark red colour (Figure 3A). In comparison, livers of Alb-Cre+ animals appeared pale and showed an irregular surface (Figure 3B). With increasing age, the livers of Alb-Cre+ animals differed more strongly from the ones of control animals (Figure 3C), with nodular structures becoming visible all over the organ (Figure 3D). The severity of this phenotype showed variability throughout the animals that were used in this work. These differences in the livers influenced how well the tissue could be processed. Homogenisation of livers from Alb-Cre+ animals required more mechanical force to be applied due to the change in tissue organization and structure (cf. section 3.4). 
To further characterise the observed in situ phenotype, I carried out experiments to assess the extent of liver damage.
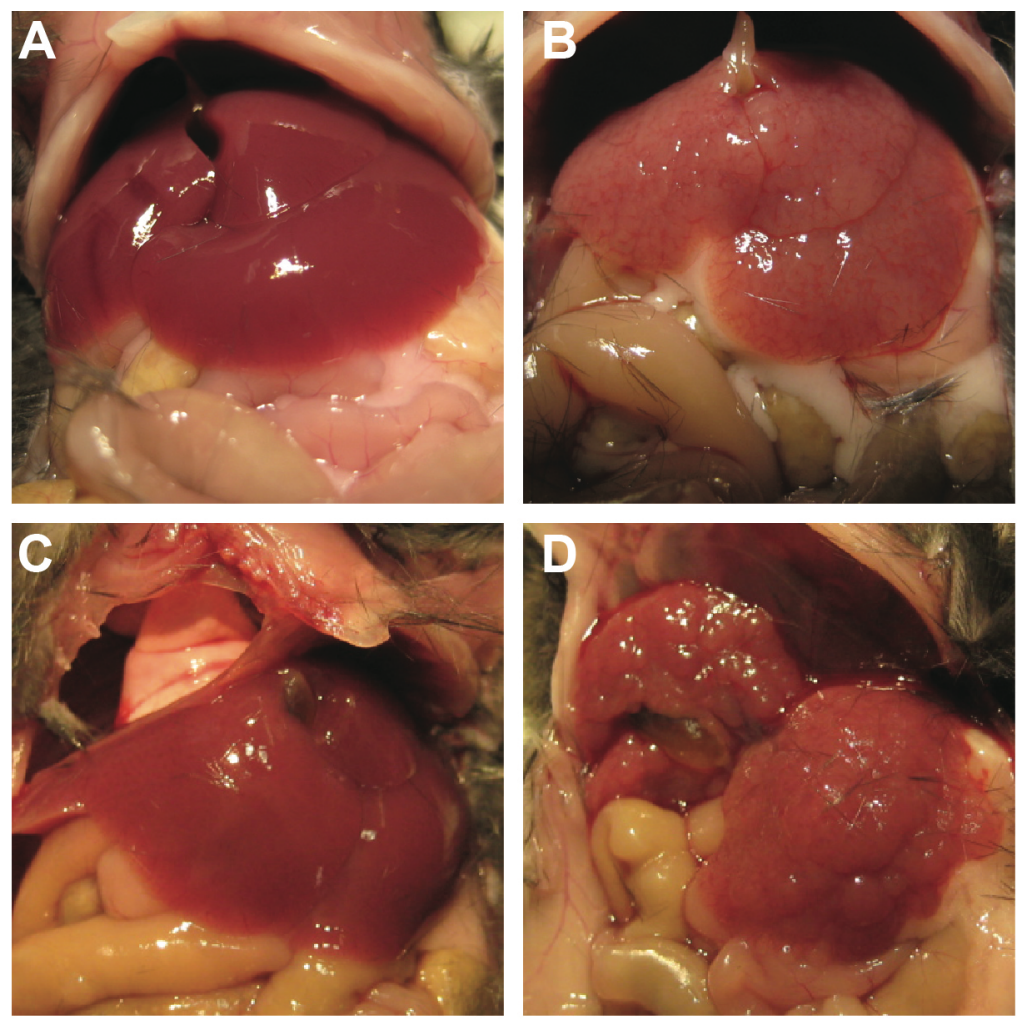

Figure 3: Livers of Alb-Cre+ animals show a strong phenotype in situ.

Pictures of $6 \mathrm{w}$ old $(\mathbf{A}, \mathbf{B})$ or older animals (C, D) animals were taken in situ. A and $\mathbf{C}$ show the liver of one Alb-Cre- animal each, while $\mathbf{B}$ and $\mathbf{D}$ show the liver of one Alb-Cre+ animal each

\subsection{The extent of liver damage is reflected in blood parameters}

Since the mouse livers showed different levels of damage on a macroscopic level, analysis of blood parameters related to liver damage was performed. Serum from Alb-Creand Alb-Cre+ animals at two different age points was tested for the levels of two liver enzymes, Alanine transaminase (ALT) and Aspartate transaminase (AST). Both enzymes are common markers to assess the degree of cellular damage in the liver (McClatchey, 2002).

In older animals, a significant increase in both ALT and AST in the serum of Alb-Cre+ animals compared to Alb-Cre- animals was observed (Figure 4A), indicating liver damage in the Alb-Cre+ animals. This increase was more drastic in the $6 \mathrm{w}$ old animals, where the levels of both enzymes were increased by several orders of magnitude (Figure 4B), leading to the conclusion that the liver damage was more extensive in the younger animals. 
A

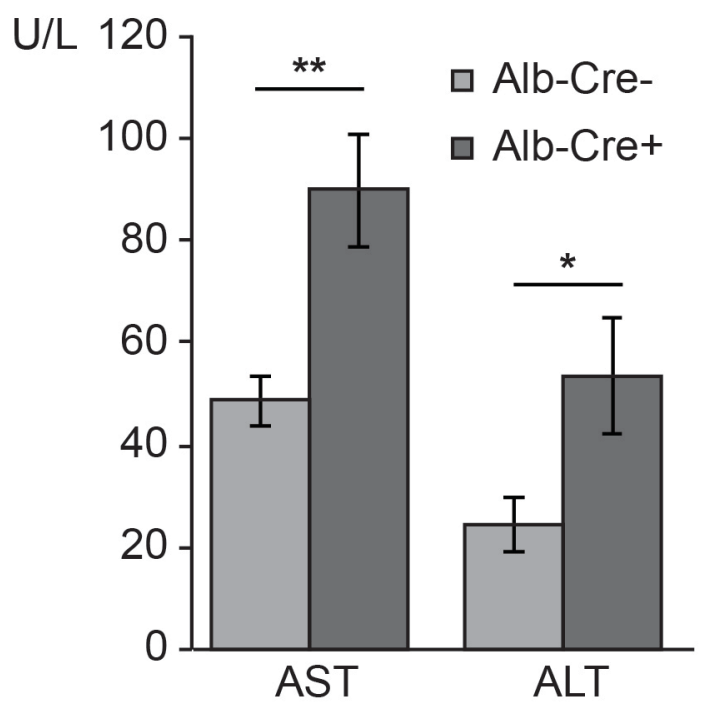

$>11 \mathrm{w}$ old animals
B

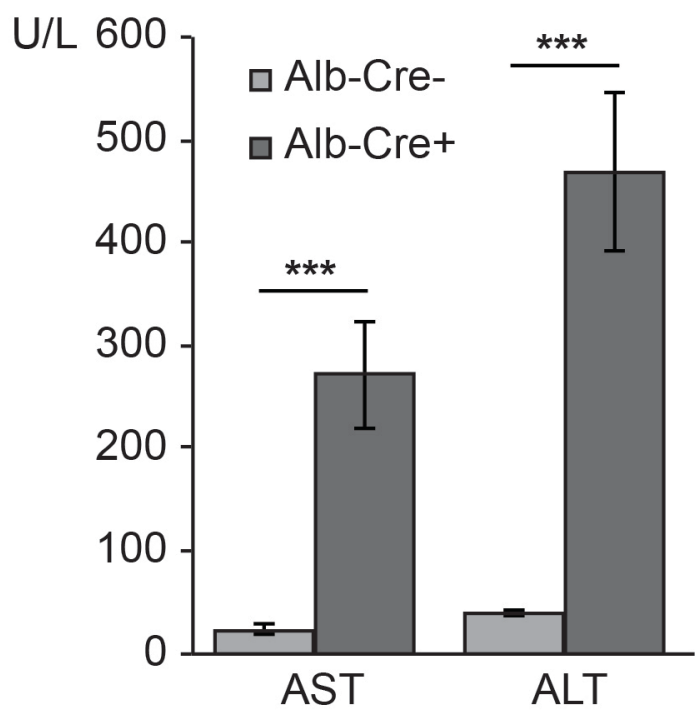

$6 \mathrm{w}$ old animals

Figure 4: Blood parameters of Alb-Cre+ animals at two different age points confirm a strong liver damage.

Serum levels of the Aspartate Transaminase (AST) and Alanine Transaminase (ALT) were analysed in either older animals (A) or $6 \mathrm{w}$ (B) old. For the older animals, $n=7$ and $n=7$ for Alb-Cre- and Alb-Cre+ animals, respectively. For the $6 \mathrm{w}$ old animals, $\mathrm{n}=9$ and $\mathrm{n}=7$ for the Alb-Cre- and Alb-Cre+ animals, respectively. Bars show averages $-/+$ SEM

\subsection{WRB knockout in hepatocytes causes alterations in liver tissue}

Since the overall appearance of livers from Alb-Cre+ animals suggested changes in the tissue structure itself, livers from both Alb-Cre- and Alb-Cre+ animals were subjected to histological analysis. Individual lobes were embedded in paraffin after fixation and dehydration. The analysis was performed with both $6 \mathrm{w}$ and older animals. For all samples, an HE staining was carried out to assess the general structure and histology of the liver tissue. In addition to this, a Goldner-staining was performed. This staining is specific with regard to connective tissue, and was performed to clarify the assumption that connective tissue was built up in the livers.

The HE staining revealed clear changes in the cellular organisation and structure of the liver tissue of Alb-Cre+ animals in both age groups (Figure 5A, B; Figure 6A, B). In the $6 \mathrm{w}$ old animals, the majority of cells (and nuclei) appeared smaller, especially when compared to the erythrocytes present, while at the same time few noticeably enlarged hepatocytes were observable (Figure 5B). The whole pattern of cells seemed much less 
Alb-Cre-

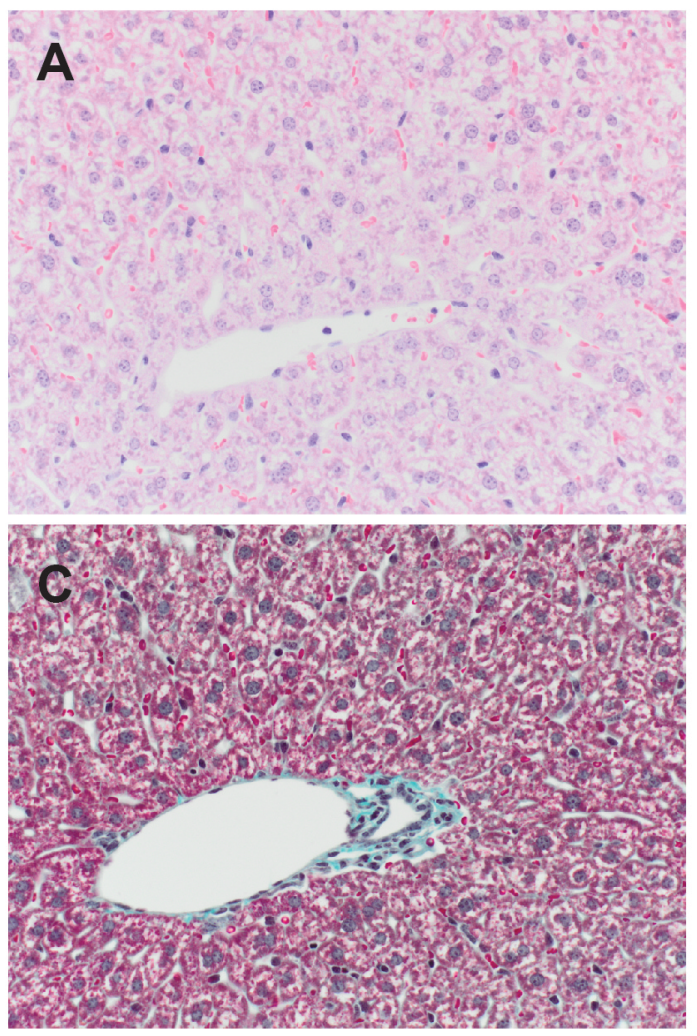

Alb-Cre+
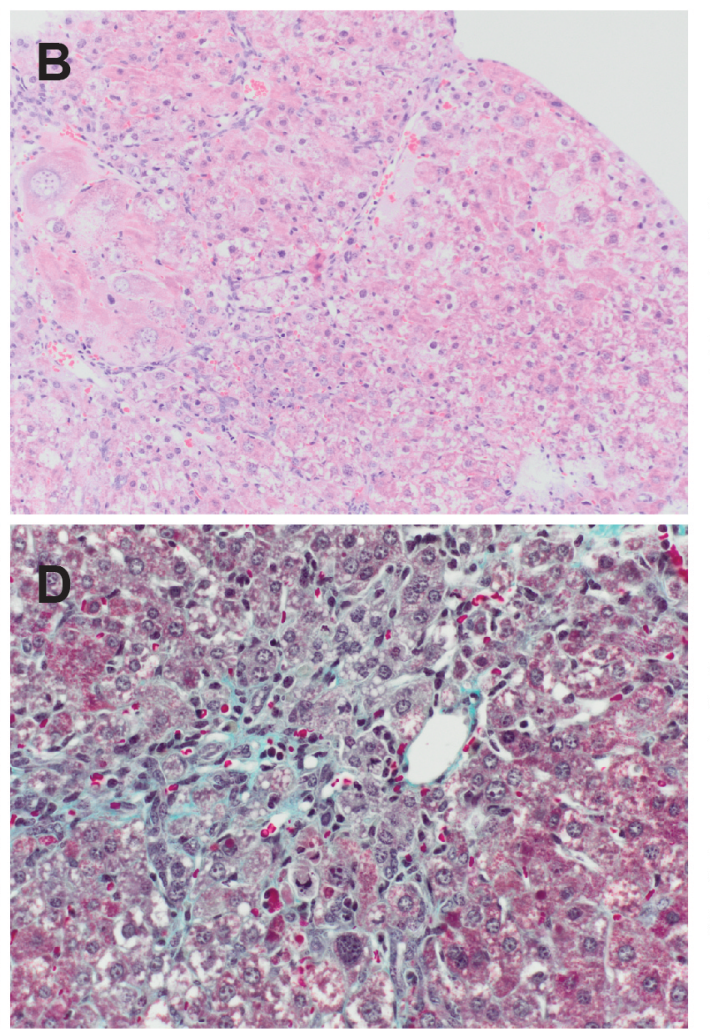

Figure 5: Liver sections of 6 w old Alb-Cre+ animals show drastic changes in the tissue structure and cellular organization.

$3 \mu \mathrm{m}$ sections of livers were stained with either an HE overview staining (A, B) or a Goldner staining (C, D). A and $\mathbf{C}$ show sections of Alb-Cre- animals, whereas $\mathbf{B}$ and $\mathbf{D}$ show sections of Alb-Cre+ animals. The images of HE-stained tissue were taken with a $250 x$ final magnification. The images of Goldner-stained sections are in a $400 x$ final magnification.

regular than in the Alb-Cre- animals. Upon Goldner-staining, the histology revealed a large increase of connective tissue in the liver tissue of Alb-Cre+ animals, visible as blue patches in the tissue parenchyma. Whereas in the Alb-Cre- animals, connective tissue was only found in structures physiologically occurring around blood vessels, in Alb-Cre+ animals the liver tissue was traversed by connective tissue (Figure 5C, D).

Additionally, the Goldner staining showed heterogeneity in the shape of the nuclei and different states of chromatin condensation, which indicates that some cells are undergoing mitosis, while others may be undergoing apoptosis.

In older animals, the tissue of Alb-Cre+ animals showed clear differences compared to that of Alb-Cre- animals, but differed from the histology in the $6 \mathrm{w}$ old animals. In the HE staining, the livers of $\mathrm{Alb}-\mathrm{Cre}+$ animals showed patches of tissue that were structurally comparable to the tissue from Alb-Cre- animals (Figure 6A, B), but enclosed in septa-like 

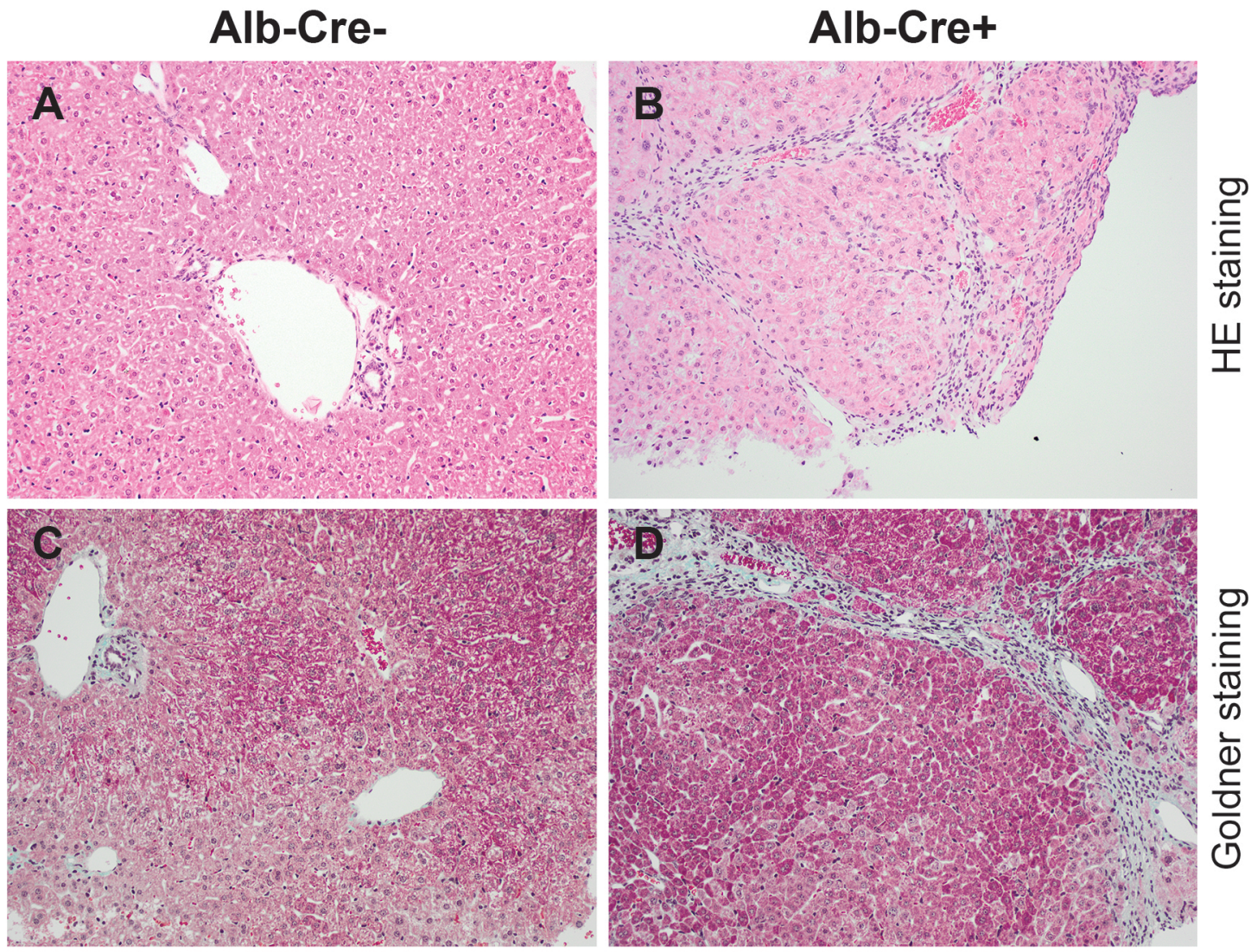

Figure 6: Livers of older Alb-Cre+ animals show a clear histological phenotype.

$3 \mu \mathrm{m}$ sections of livers were stained with either an HE overview staining (A, B) or a Goldner staining (C, D). A and $C$ show sections of Alb-Cre- animals, whereas $B$ and $D$ show sections of Alb-Cre+ animals. All images were taken with a $250 x$ final magnification.

structures. The Goldner staining of sections from the same samples revealed that these septa consisted of connective tissue, marked by the blue structures (Figure 6D). In the Alb-Cre- animals connective tissue in the sections was again only found surrounding the blood vessels (Figure 6C). The nuclei in the two different genotypes in older animals appeared less different than in liver tissue from $6 \mathrm{w}$ old animals, with the nuclei in the AlbCre+ animals showing more consistence in their shape and status compared to $6 \mathrm{w}$ old animals.

Overall, the histological analysis indicated clear liver damage including fibrosis in AlbCre+ animals of both age groups, with the damage being more severe in the $6 \mathrm{w}$ old animals. 


\subsection{Hepatocyte-specific knockout of WRB leads to differential gene expression in Alb-Cre+ animals}

The strong phenotype in the Alb-Cre+ animals implies drastic changes in gene expression to compensate for the observed the damage. To gain further insight into the causes and molecular consequences of this phenotype, a transcriptome analysis was carried out. The analysis was performed with RNA from isolated hepatocytes of $6 \mathrm{w}$ old animals, with four Alb-Cre- and four Alb-Cre+ samples being used for the calculation. The results gave a first indication of differentially expressed genes. For further confirmation a validation on singletarget level needs to be performed.

After normalisation, 3185 genes were found to be differentially expressed with a cut-off of log2 of the fold change $\geq 1$. A gene ontology (GO) term enrichment and functional annotation clustering analysis with this data revealed a strong enrichment in several processes. Overall, 224 functional clusters were annotated with an enrichment score cutoff of 1.5 . Out of 3185 genes, 513 genes were not clustered. Table 3 shows a summary of the 15 most enriched clusters, including the three most enriched GO terms each based on the EASE score (modified Fisher Exact P-Value). Many of the functional annotation clusters are related to cell adhesion, proliferation, cell motility and cell migration/chemoattraction.

Table 3 Functional Annotation Clustering of differentially expressed genes in isolated hepatocytes of 6 w old Alb-Cre+ animals.

2672 out of 3185 genes were subjected to functional annotation clustering with the DAVID software with an enrichment score cut-off of 1.5. Count gives the number of genes per GO term. P-Value = EASE score (modified Fisher Exact P-Value). For each cluster, the three most enriched GO terms are shown.

\begin{tabular}{|c|c|c|}
\hline Term & Count & P-Value \\
\hline \multicolumn{3}{|c|}{ Annotation Cluster 1, Enrichment Score: 18.86} \\
\hline GO:0007155 cell adhesion & 173 & $4.01 \mathrm{E}-26$ \\
\hline GO:0022610 biological adhesion & 173 & $5.02 E-26$ \\
\hline GO:0016337 cell-cell adhesion & 61 & $1.31 \mathrm{E}-06$ \\
\hline \multicolumn{3}{|c|}{ Annotation Cluster 2, Enrichment Score: 14.04} \\
\hline GO:0007049 cell cycle & 164 & $4.36 \mathrm{E}-18$ \\
\hline GO:0022402 cell cycle process & 115 & $1.51 \mathrm{E}-15$ \\
\hline GO:0000278 mitotic cell cycle & 83 & $2.09 E-15$ \\
\hline \multicolumn{3}{|c|}{ Annotation Cluster 3, Enrichment Score: 10.94} \\
\hline GO:0032502 developmental process & 521 & $1.31 \mathrm{E}-17$ \\
\hline GO:0007275 multicellular organismal development & 485 & $2.41 \mathrm{E}-17$ \\
\hline GO:0048856 anatomical structure development & 428 & $1.58 \mathrm{E}-16$ \\
\hline
\end{tabular}




\begin{tabular}{|c|c|c|}
\hline \multicolumn{3}{|l|}{ Annotation Cluster 4, Enrichment Score: 10.38} \\
\hline GO:0009611 response to wounding & 104 & 7.06E-15 \\
\hline GO:0009605 response to external stimulus & 155 & $8.25 \mathrm{E}-13$ \\
\hline GO:0006950 response to stress & 247 & $4.27 \mathrm{E}-12$ \\
\hline \multicolumn{3}{|l|}{ Annotation Cluster 5, Enrichment Score: 8.24} \\
\hline GO:0050793 regulation of developmental process & 148 & $5.45 \mathrm{E}-15$ \\
\hline GO:0051239 regulation of multicellular organismal process & 186 & 1.13E-14 \\
\hline GO:0051094 positive regulation of developmental process & 66 & $2.42 \mathrm{E}-10$ \\
\hline \multicolumn{3}{|l|}{ Annotation Cluster 6, Enrichment Score: 7.84} \\
\hline GO:0007010 cytoskeleton organization & 95 & $7.28 \mathrm{E}-13$ \\
\hline GO:0030036 actin cytoskeleton organization & 52 & $1.07 E-08$ \\
\hline GO:0030029 actin filament-based process & 54 & $1.51 \mathrm{E}-08$ \\
\hline \multicolumn{3}{|l|}{ Annotation Cluster 7, Enrichment Score: 7.34} \\
\hline GO:0032879 regulation of localization & 108 & $9.66 \mathrm{E}-12$ \\
\hline GO:0051050 positive regulation of transport & 41 & 7.15E-07 \\
\hline GO:0051049 regulation of transport & 67 & 1.37E-05 \\
\hline \multicolumn{3}{|l|}{ Annotation Cluster 8, Enrichment Score: 7.24} \\
\hline GO:0006928 cell motion & 97 & 1.79E-10 \\
\hline GO:0040011 locomotion & 94 & 1.30E-09 \\
\hline GO:0016477 cell migration & 65 & $9.12 \mathrm{E}-08$ \\
\hline \multicolumn{3}{|l|}{ Annotation Cluster 9, Enrichment Score: 6.48} \\
\hline GO:0030334 regulation of cell migration & 34 & 8.55E-08 \\
\hline GO:0051270 regulation of cell motion & 37 & 1.46E-07 \\
\hline GO:0040012 regulation of locomotion & 35 & $2.91 \mathrm{E}-06$ \\
\hline \multicolumn{3}{|l|}{ Annotation Cluster 10, Enrichment Score: 6.28} \\
\hline GO:0001817 regulation of cytokine production & 48 & 1.59E-09 \\
\hline GO:0051240 positive regulation of multicellular organismal process & 45 & $6.40 \mathrm{E}-06$ \\
\hline GO:0001819 positive regulation of cytokine production & 23 & $1.45 \mathrm{E}-05$ \\
\hline \multicolumn{3}{|l|}{ Annotation Cluster 11, Enrichment Score: 5.98} \\
\hline GO:0001944 vasculature development & 69 & $1.55 \mathrm{E}-08$ \\
\hline GO:0001568 blood vessel development & 67 & $3.18 \mathrm{E}-08$ \\
\hline GO:0048514 blood vessel morphogenesis & 54 & $1.00 \mathrm{E}-06$ \\
\hline \multicolumn{3}{|l|}{ Annotation Cluster 12, Enrichment Score: 5.58} \\
\hline GO:0040011 locomotion & 94 & 1.30E-09 \\
\hline GO:0042330 taxis & 38 & $7.59 \mathrm{E}-08$ \\
\hline
\end{tabular}




\begin{tabular}{|l|c|c|}
\hline GO:0006935 chemotaxis & 38 & $7.59 \mathrm{E}-08$ \\
\hline \multicolumn{2}{|c|}{ Annotation Cluster 13, Enrichment Score: 4.80 } \\
\hline GO:0030155 regulation of cell adhesion & 36 & $1.15 \mathrm{E}-08$ \\
\hline GO:0045785 positive regulation of cell adhesion & 20 & $1.25 \mathrm{E}-06$ \\
\hline GO:0010810 regulation of cell-substrate adhesion & 14 & 0.002 \\
\hline \multicolumn{2}{|c|}{ Annotation Cluster 14, Enrichment Score: 4.12 } \\
\hline GO:0030154 cell differentiation & 307 & $2.32 \mathrm{E}-11$ \\
\hline GO:0007399 nervous system development & 170 & $4.26 \mathrm{E}-07$ \\
\hline GO:0030030 cell projection organization & 76 & $1.75 \mathrm{E}-06$ \\
\hline \multicolumn{2}{|c|}{ Annotation Cluster 15, Enrichment Score: 3.81} \\
\hline GO:0001775 cell activation & 72 & $4.59 \mathrm{E}-10$ \\
\hline GO:0045321 leukocyte activation & 61 & $8.13 \mathrm{E}-08$ \\
\hline GO:0046649 lymphocyte activation & 48 & $4.35 \mathrm{E}-05$ \\
\hline
\end{tabular}


In addition to the broad GO term analysis, a heatmap was created showing the 50 genes with the highest change in expression when comparing Alb-Cre- with Alb-Cre+ animals (Figure 7). These included genes involved in liver fibrosis and regeneration such as several collagen genes or Tgfbi and Sparc (Nakken et al., 2007). The corresponding list of the genes is listed inTable 7 in the Appendix.

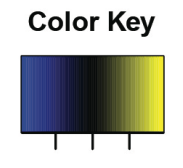

\section{Heatmap for Alb-Cre- vs Alb-Cre+}

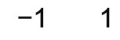

Row Z-Score
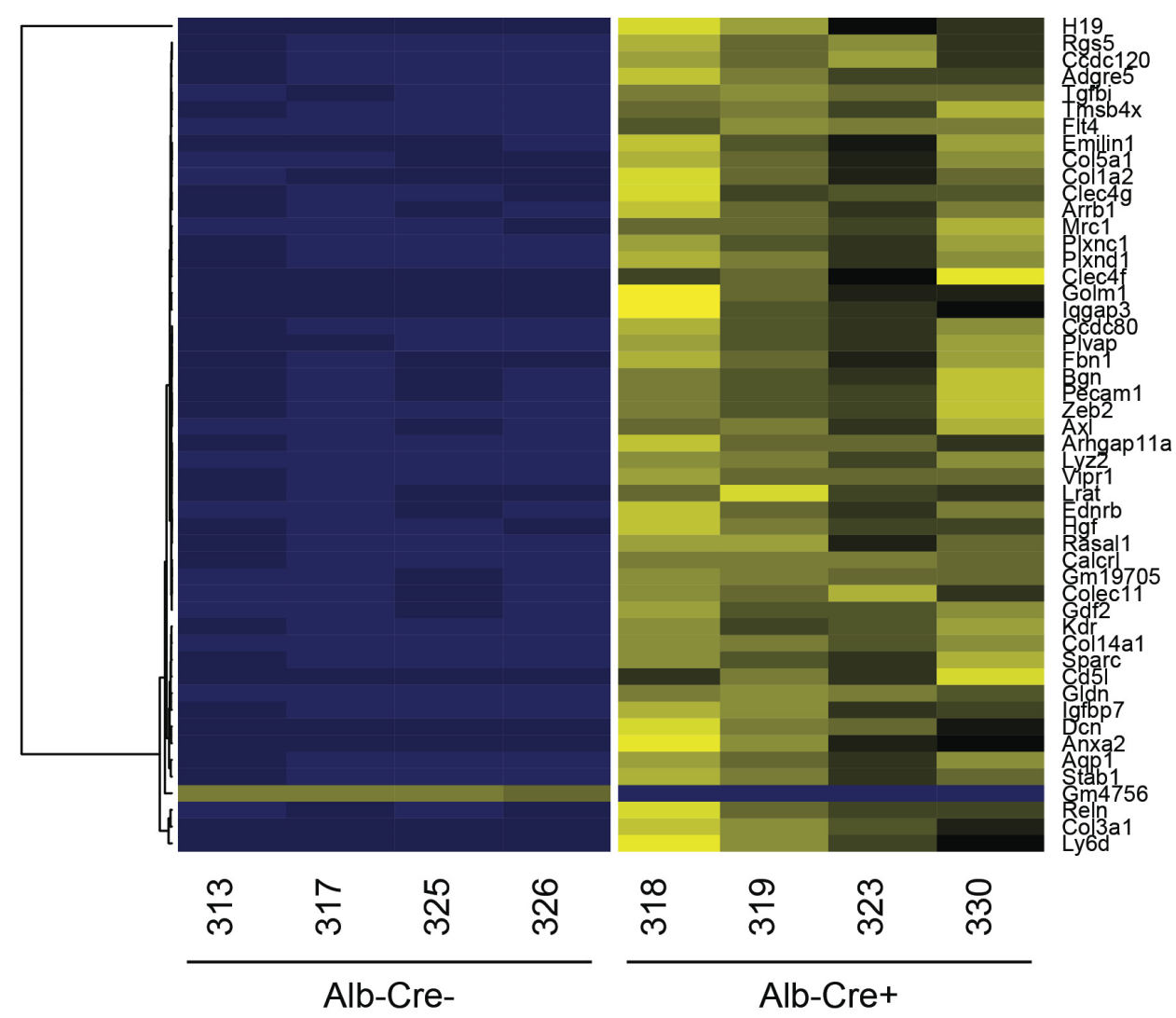

Figure 7: Heatmap of the $\mathbf{5 0}$ genes showing the highest change in differential expression.

The transcriptome of four Alb-Cre- and for Alb-Cre+ animals was analysed for differentially expressed genes. The heatmap shows the genes which displayed the highest change in expression according to FDR-adjusted p-values upon comparing the two genotypes.

Furthermore, TA proteins expressed in hepatocytes were extracted from the transcriptome data. The list can be found in the Appendix (Table 8). Since the transcriptome analysis was carried out only at a late stage of this project, I was not able to follow up on the results regarding the differential expression of some of these TA proteins. The list has to be considered as preliminary data for further analysis. However, in this thesis several 
selected TA proteins were analysed in vivo (cf. section 3.7), and all of these selected TA proteins appeared in the transcriptome.

The selection of TA proteins for following experiments was based on different aspects. Many of selected ones have previously been used in vitro and are part of numerous published studies. Another aspect was whether they were highly conserved between yeast and mouse and were shown to be affected in yeast upon disturbance of the GET pathway. More detailed information regarding the selected TA proteins based on these two aspects can be found in section 3.7. Additionally, the availability of working antibodies for the selected TA proteins was crucial for the analysis. I selected only TA proteins for which reliable antibodies were available. But not only for TA proteins this was a prerequisite. The availability of antibodies for the pathway components was indispensable for investigating the effects of the WRB knockout on the pathway.

In the following sections I will describe the results of further analysis of both pathway components and selected TA proteins.

\subsection{The components of the mammalian GET pathway are influenced by the knockout of WRB in hepatocytes}

Upon expression of the Cre recombinase under the Albumin promoter, the excision of the three middle exons of the floxed WRB allele took place. The consequences of this recombination were detectable at mRNA and steady-state protein level. Real time quantitative PCR (RT-qPCR) and Western Blotting were performed to assess the effects of a WRB knockout in isolated hepatocytes and in total liver homogenate. These experiments were performed in mice of two age groups, as before $6 \mathrm{w}$ old and older animals.

\subsubsection{In 6 week old animals, liver tissue and isolated hepatocytes react differently to the knockout}

Analysis of the livers of $6 \mathrm{w}$ old animals was performed with total liver homogenate as well as with isolated hepatocytes. Since hepatocytes make up about $80 \%$ of the adult liver (Duncan, 2000), and the in situ and histological analyses indicated a strong knockout phenotype, I expected these effects to be reflected at mRNA and steady-state protein level in both total liver homogenate and isolated hepatocytes.

To test whether the excision of the three middle exons (2,3 and 4$)$ of the floxed WRB allele was accomplished, primers were designed to quantify the mRNA levels of WRB via RT-qPCR. The forward primer is positioned at the junction of exon 3 and 4 , while the 
reverse primer anneals in exon 5. Upon recombination of the floxed allele, the forward primer can no longer anneal and no PCR product can be generated.

From both total liver homogenate and isolated hepatocytes of $6 \mathrm{w}$ old animals, RNA was extracted and after reverse transcription to cDNA, RT-qPCR was used to quantify the mRNA levels of the three pathway components: WRB, CAML and TRC40. In RNA samples from isolated hepatocytes, the WRB mRNA level in Alb-Cre+ animals was significantly reduced to about $50 \%$ on average, but the level of reduction varied considerably among individual samples (Figure 8A). This indicates that not all hepatocytes were WRB knockout hepatocytes. However, the mRNA level of WRB in the Alb-Creanimals showed variability as well, indicating that the expression of WRB at mRNA level varied in hepatocytes under physiological conditions.

In total liver homogenate of $6 \mathrm{w}$ old animals, the WRB mRNA level also displayed a significant reduction on average (Figure 9A, D), to less than $50 \%$ compared to Alb-Creanimals. Expression levels in both total liver homogenate and isolated hepatocytes were in a very similar range relative to GAPDH, which was used as reference gene in the analysis. Overall, the results of the RT-qPCR indicated that Cre recombinase mediated excision of exons 2 to 4 of the floxed WRB allele had an effect on the expression level of WRB mRNA.

To evaluate whether downregulation of WRB had an effect on the mRNA levels of the other main components of the pathway, CAML and TRC40, primers were designed to measure the mRNA levels of these two proteins via RT-qPCR. CAML is the direct partner of WRB in the formation of the dimeric GET receptor in the ER membrane, while TRC40 is the cytosolic ATPase that targets TA proteins to the ER membrane. In hepatocytes, the amount of CAML mRNA showed a lot of variation regardless of the genotype of the animals. Overall, CAML mRNA levels of Alb-Cre+ animals did not differ significantly from Alb-Cre- animals, indicating that the downregulation of WRB at mRNA level had no influence on the mRNA level of CAML in hepatocytes (Figure 8B, D). The same trend was observed in the RT-qPCR results with RNA from total liver homogenate of $6 \mathrm{w}$ old mice. The CAML mRNA level did not change as a consequence of the reduction of WRB at mRNA level (Figure 9B, D). The RT-qPCR results for TRC40 displayed a slight increase of TRC40 in isolated hepatocytes of $6 \mathrm{w}$ old Alb-Cre+ animals compared to Alb-Creanimals (Figure $8 C, D$ ). This increase was significant despite the strong variation in the expression of TRC40 in animals of both genotypes $(p=0.04)$. The RT-qPCRs performed with RNA from total liver homogenate from $6 \mathrm{w}$ old Alb-Cre- and Alb-Cre+ animals supported these results. Here, a slight increase of the TRC40 mRNA level was observed in the Alb-Cre+ animals (Figure 9C, D). 
A

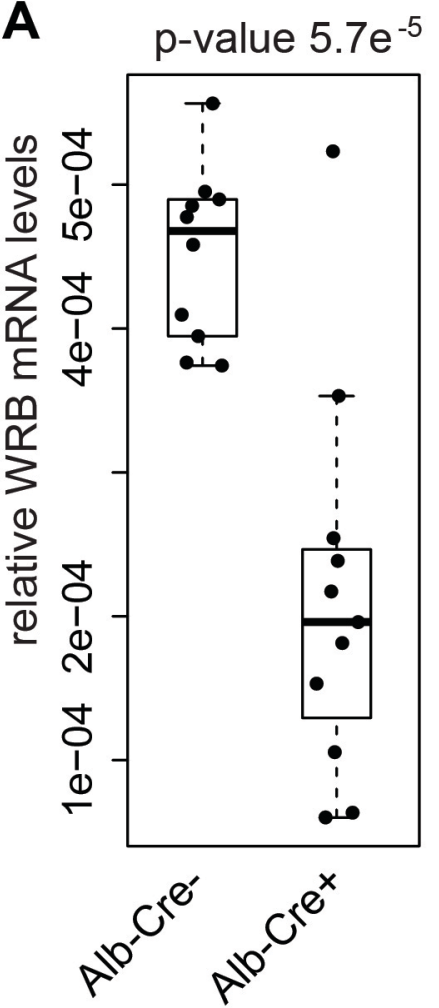

B

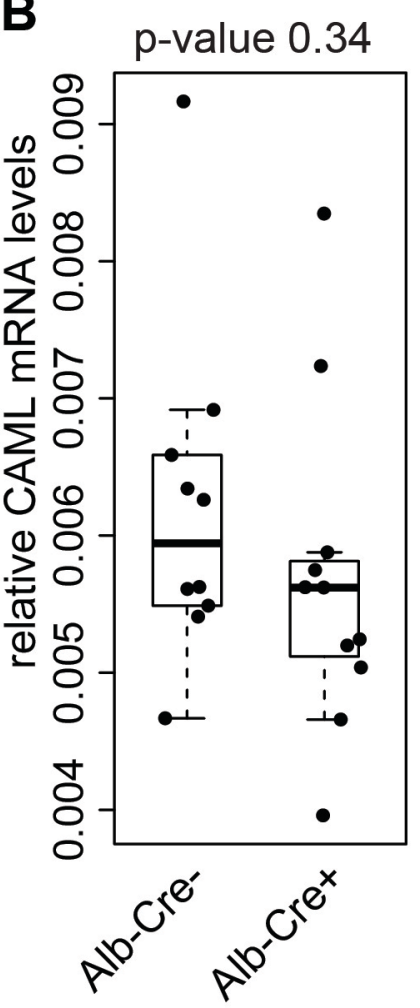

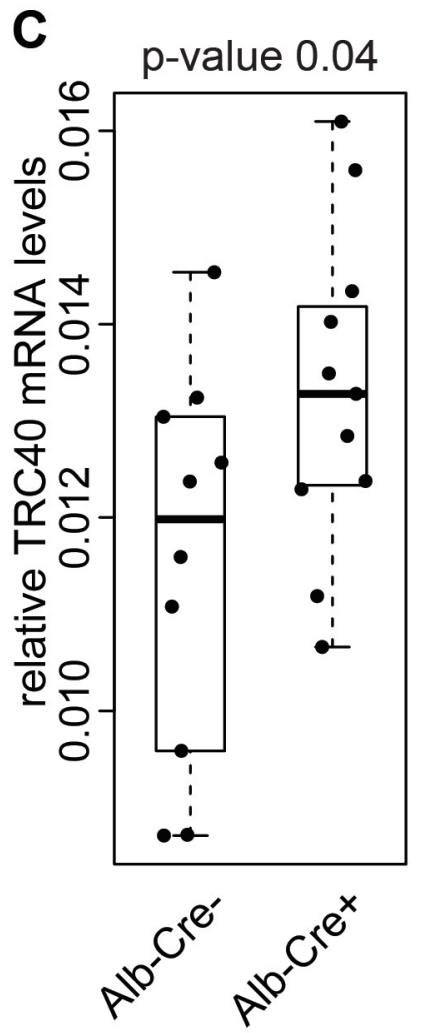

D

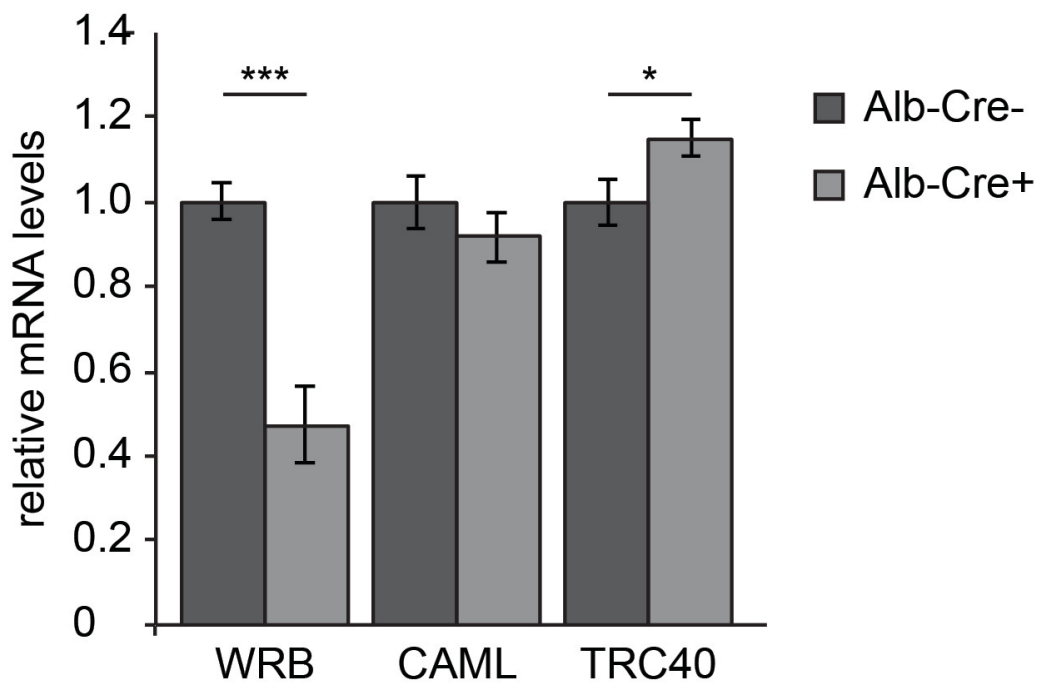

Figure 8: In isolated hepatocytes of $6 \mathrm{w}$ old Alb-Cre+ animals mRNA levels of WRB and TRC40 were significantly changed.

RT-qPCR was performed with mRNA extracted from isolated hepatocytes of $6 \mathrm{w}$ old animals. A, B and C show boxplots of the relative mRNA levels of WRB, CAML and TRC40. The same samples were used, with outliers excluded from calculating the whiskers. Relative levels are given as $2^{\wedge}$-dCP of the target over GAPDH. D shows averages of Alb-Cre- and Alb-Cre+ samples -/+ SEM. Where changes were significant, $p-$ values are indicated over the boxplots and the level of significance is marked in D. For Alb-Cre- animals, $\mathrm{n}=10$, for Alb-Cre+ animals, $\mathrm{n}=11$. 
A

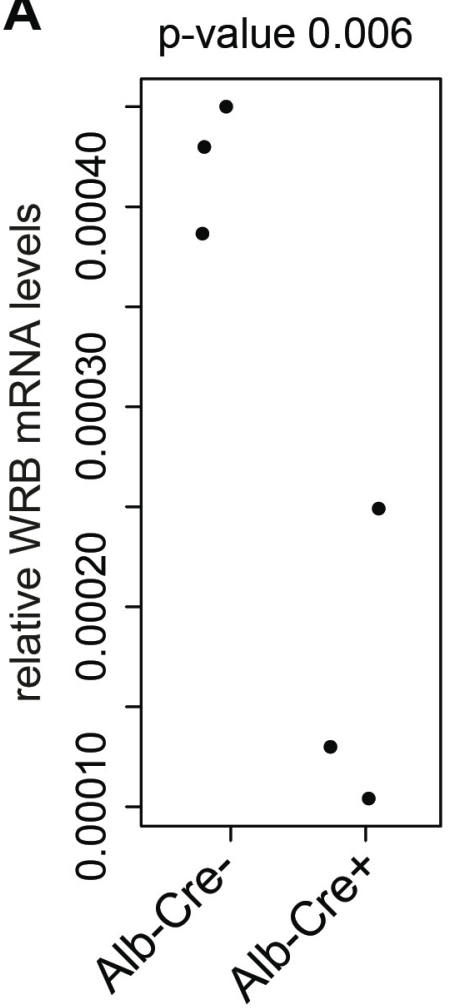

B

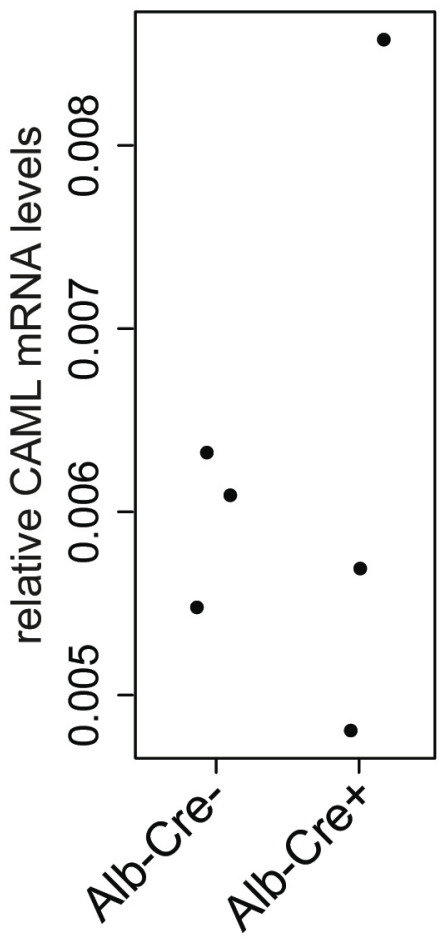

C

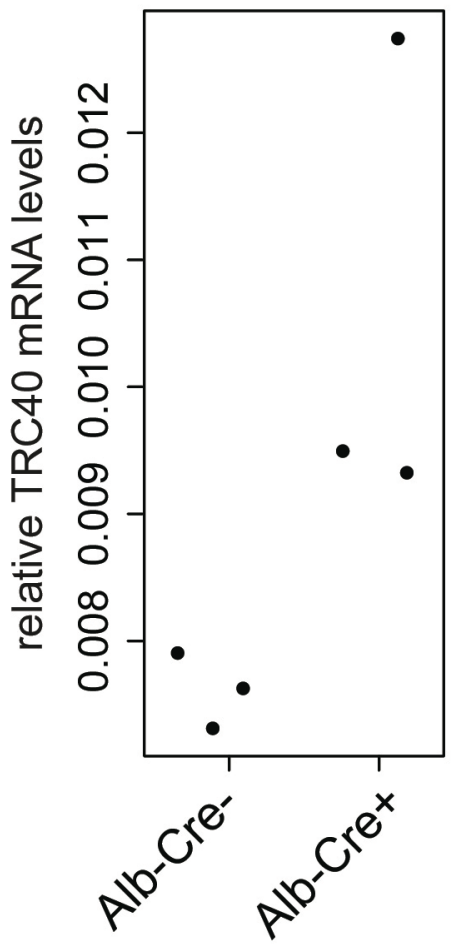

D

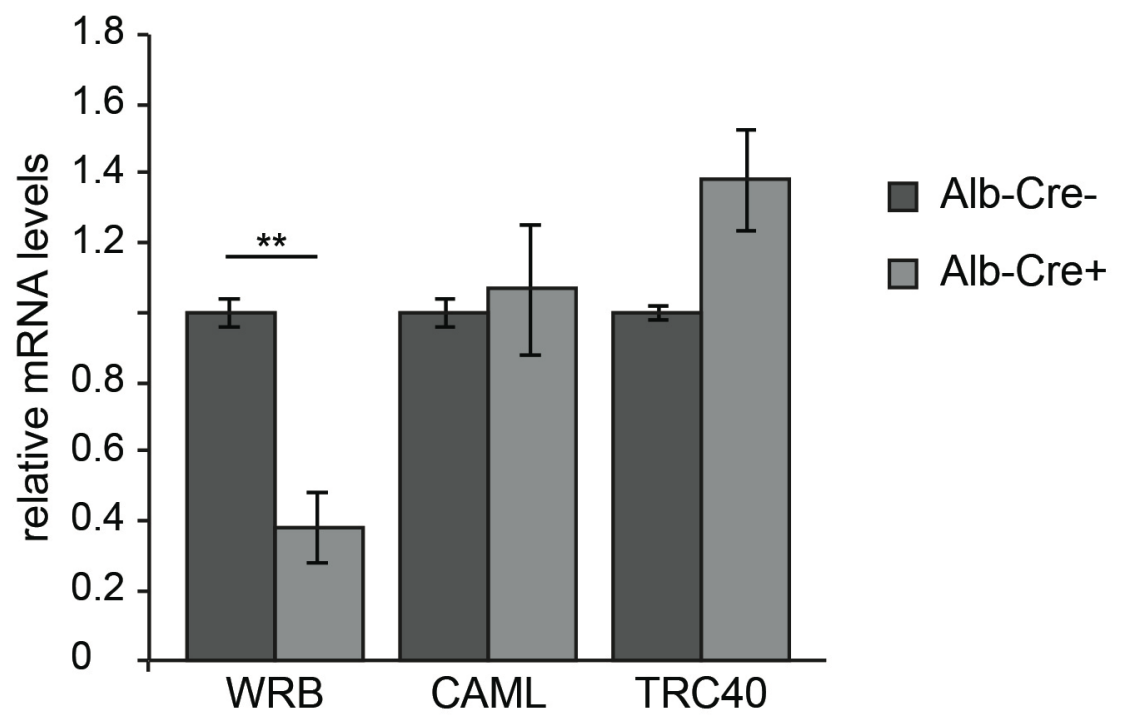

Figure 9: In total liver homogenate of 6 w old Alb-Cre+ animals the mRNA level of WRB was significantly changed.

RT-qPCR was performed with mRNA extracted from total liver homogenate of $6 \mathrm{w}$ old animals. A, B and C show dot plots of the relative mRNA levels of WRB, CAML and TRC40. The same samples were used for al I three plots. Relative levels are given as $2^{\wedge}-\mathrm{dCP}$ of the target over GAPDH. D shows averages of Alb-Cre- and Alb-Cre+ samples -/+ SEM. If changes were significant, $p$-values are indicated over the boxplots and the level of significance is marked in $\mathbf{D}$. For Alb-Cre- animals, $n=3$, for Alb-Cre+ animals, $n=3$. 
Overall, I could observe a significant decrease of WRB at mRNA level in both total liver homogenate and isolated hepatocytes of $6 \mathrm{w}$ old Alb-Cre+ animals. Except for a significant increase of the TRC40 mRNA level in isolated hepatocytes of Alb-Cre+ animals, the other two pathway components remained unchanged.

Since the results of the RT-qPCR indicated a successful recombination of the floxed WRB allele in $6 \mathrm{w}$ old Alb-Cre+ animals, the effect of this recombination on steady-state protein levels was analysed by performing Western Blots for the three pathway components WRB, CAML and TRC40. For this purpose, proteins were extracted from both total liver homogenate and isolated hepatocytes of $6 \mathrm{w}$ old Alb-Cre- and Alb-Cre+ animals.

In the experiments carried out with total liver homogenate, immunoblotting for WRB did not reveal a significant change of the WRB steady-state protein level in the Alb-Cre+ animals (Figure 10A, B), although a tendency towards WRB reduction was observed. The individual samples on the blot however indicated that the steady-state amounts of WRB at protein level varied considerably. Some animals displayed a strong reduction of WRB (cf. animals 208, 209 and 210 in Figure 10A), while the signal on the blot of other animals resembled the situation found in the Alb-Cre- control animals (cf. animals 240 and 241 in Figure 10A). These results again suggested variability in the number of hepatocytes lacking WRB in different Alb-Cre+ livers. Interestingly, the steady-state protein level of the second component of the receptor, CAML, showed a significant decrease in total liver homogenates of Alb-Cre+ animals. CAML protein levels were on average $40 \%$ less in AlbCre+ animals compared to Alb-Cre- control animals (Figure 10A, B). This result suggested that already small changes in the steady-state protein amount of WRB might have a drastic impact on the stability of the dimeric receptor in the ER membrane.

The steady-state protein level of the central targeting component of the pathway, TRC40, was assessed by immunoblot as well. While the level of TRC40 mRNA showed a tendency towards increase in total liver homogenate of Alb-Cre+ animals, this effect was not noticeable at steady-state protein level. No difference at all was observed between the steady-state protein levels of TRC40 in total liver homogenate of Alb-Cre+ animals compared to Alb-Cre- animals (Figure 10A, B).

Although the whole liver of Alb-Cre+ animals displayed a strong phenotype, it might be exactly this liver damage that alters the cell composition (e.g. increased amount of fibroblasts or infiltrating leucocytes compared to the number of hepatocytes) or homogenisation properties of the livers due to occurring fibrosis, and due to this the results might not be representative.

For this reason, all Western Blots were repeated with isolated hepatocytes to evaluate the impact of WRB knockout in only the cells in which the recombination took place. Isolated 
A

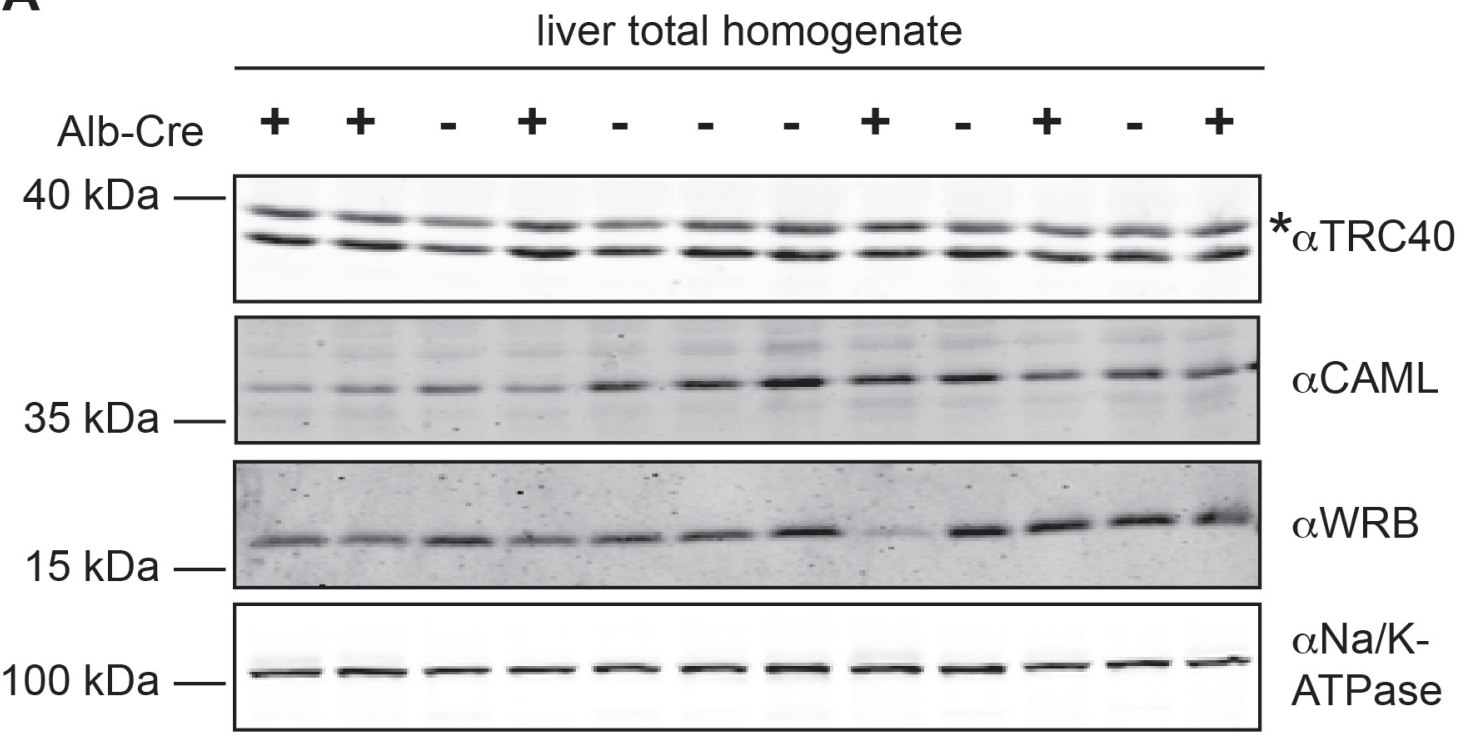

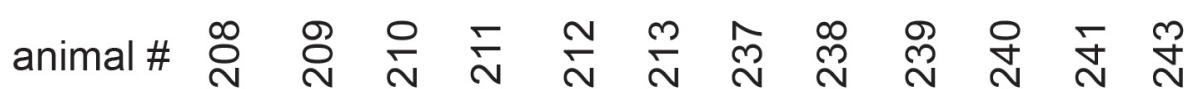

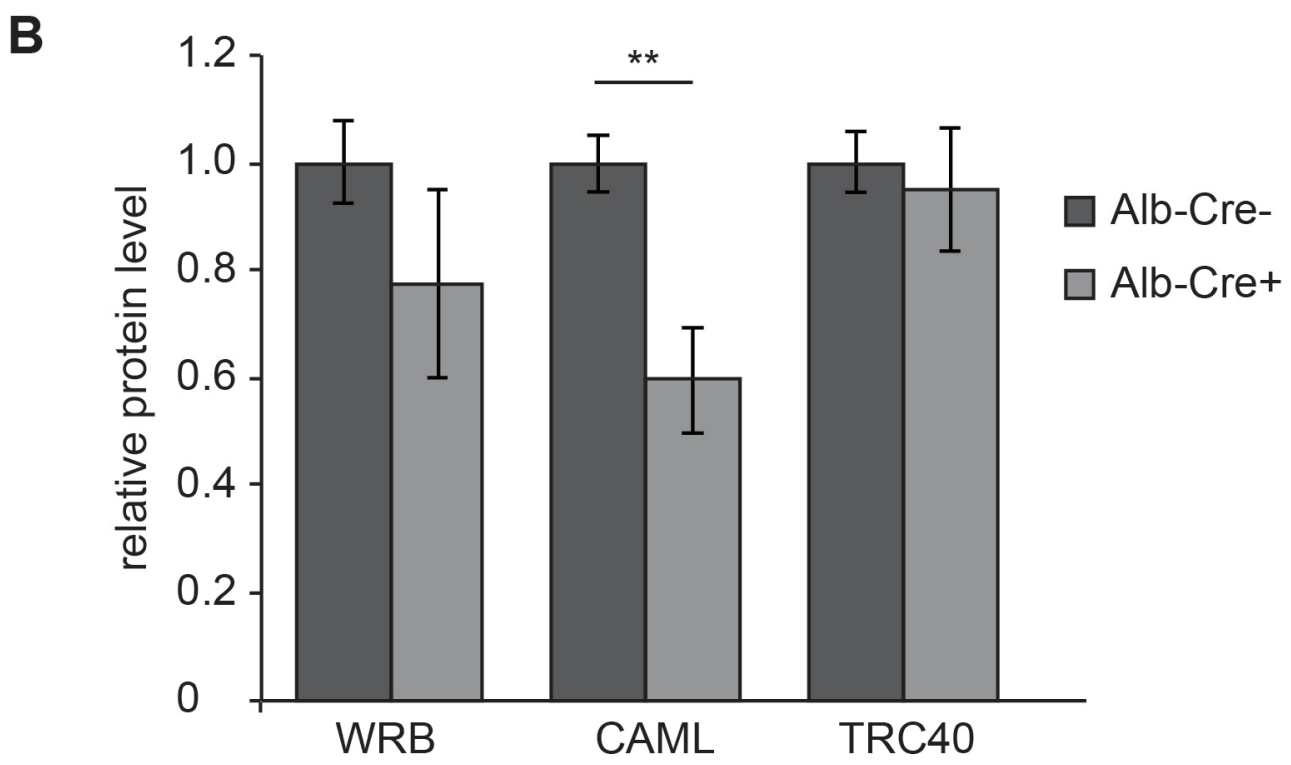

Figure 10: In total liver homogenates of 6 w old Alb-Cre+ animals only CAML was significantly affected at protein level

Protein extracts from total liver homogenates of $6 \mathrm{w}$ old animals were subjected to SDS PAGE and Western Blotting. A shows the immunoblotting with antibodies against the pathway components WRB, CAML and TRC40. The asterisk marks the specific signal obtained with the TRC40 antibody. B shows the quantification of the signals in A. The bars represent averages -/+ SEM. For the changes in CAML $p=0.0052\left({ }^{* *}\right)$. For AlbCre- animals, $n=6$, for Alb-Cre+ animals $n=6$.

hepatocytes from several animals of each genotype were analysed by Western regarding the protein levels of WRB, CAML and TRC40 in these cells. For WRB no significant reduction could be observed in the Alb-Cre+ animals (Figure 11A, B), but isolated hepatocytes showed a tendency towards reduction of WRB. Upon comparing individual animals on the blot, it became evident that the steady-state protein level of WRB varied 
considerably in isolated hepatocytes. While some Alb-Cre+ animals displayed a clearly visible reduction of WRB, other animals of the same genotype resembled the situation of the Alb-Cre- control animals (cf. animals 319 and 330, Figure 11A). The steady-state protein level of CAML in hepatocytes of $6 \mathrm{w}$ old animals decreased in the Alb-Cre+ animals, but unlike the blots of total liver homogenate, the change in the isolated hepatocytes was not significant (Figure 11A, B). However, the individual Alb-Cre+ animals showed strong variation in the amounts of CAML detected, correlating with the WRB steady-state protein level. If WRB was reduced, so was CAML.

For TRC40, the isolated hepatocytes of Alb-Cre+ animals exhibited some increase of TRC40 at protein level, but while this result recapitulates the result of the RT-qPCR for TRC40 in hepatocytes of $6 \mathrm{w}$ old Alb-Cre+ animals, the change at steady-state protein level was not statistically significant (Figure 11A, B).

Since WRB showed that much variation at both mRNA and protein level in the Alb-Cre+ animals, a closer look was taken at the RT-qPCR results of WRB at mRNA level. In total, hepatocytes of 10 Alb-Cre- and 11 Alb-Cre+ animals were subjected to RNA extraction and RT-qPCR (see Figure 8). In both genotypes, the mRNA level varied greatly, suggesting a different amount of knockout hepatocytes in individual Alb-Cre+ animals as well as a physiological variability in WRB expression. Overall, there was a significant reduction of WRB at mRNA level down to $47 \%$ in hepatocytes of Alb-Cre+ animals, but the individual animals displayed a wide range from a very strong reduction to about $15 \%$ up to completely normal WRB mRNA level (the latter animal is depicted as an outlier in Figure 8 ). Since the mRNA level of a protein does not always correlate well with the actual protein level (reviewed in Liu et al., 2016), the question arose whether an average reduction of WRB mRNA down to about $50 \%$ is enough to see an effect at protein level. To address this further, immunoblotting for the pathway components was performed with Alb-Cre+ animals showing different grades of WRB reduction at mRNA level. Two AlbCre+ animals with a very low WRB mRNA level $\left(25^{\text {th }}\right.$ percentile of the boxplot in Figure 8$)$ and two Alb-Cre+ animals with an intermediate WRB mRNA level $\left(50^{\text {th }}\right.$ percentile of the boxplot in Figure 8) were analysed, along with two control Alb-Cre- animals. The results of this experiment displayed a clear correlation between WRB at mRNA level and WRB at steady-state protein level, but not in a linear fashion (Figure 12A). Only if a strong reduction of the WRB mRNA level was seen, was the protein level strongly decreased (animals 292 and 290 in Figure 12A). If the mRNA reduction was moderate, no decrease of WRB at steady-state protein level was observed (animals 337 and 315 in Figure 12A). The same effect was visible for the steady-state protein level of CAML - if a strong reduction of WRB mRNA level, i.e. a high number if knockout hepatocytes, was present, 
A

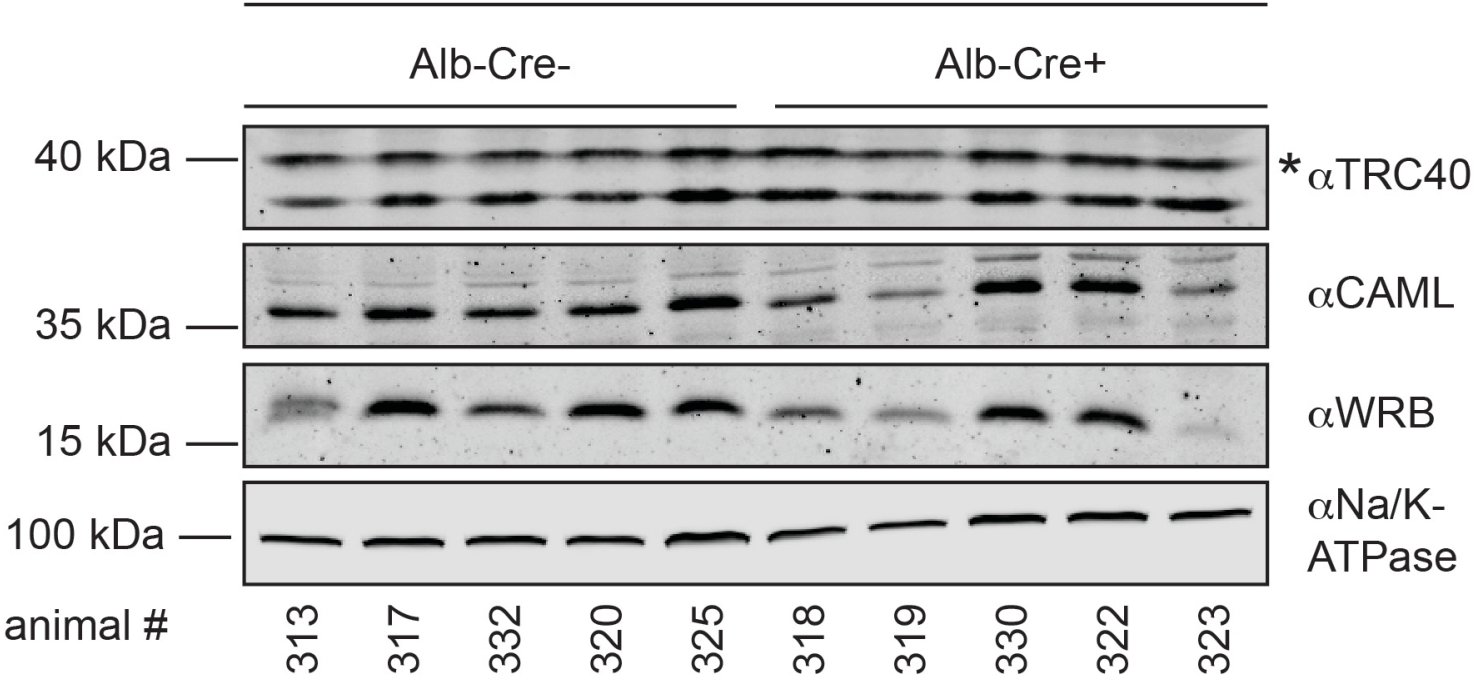

B

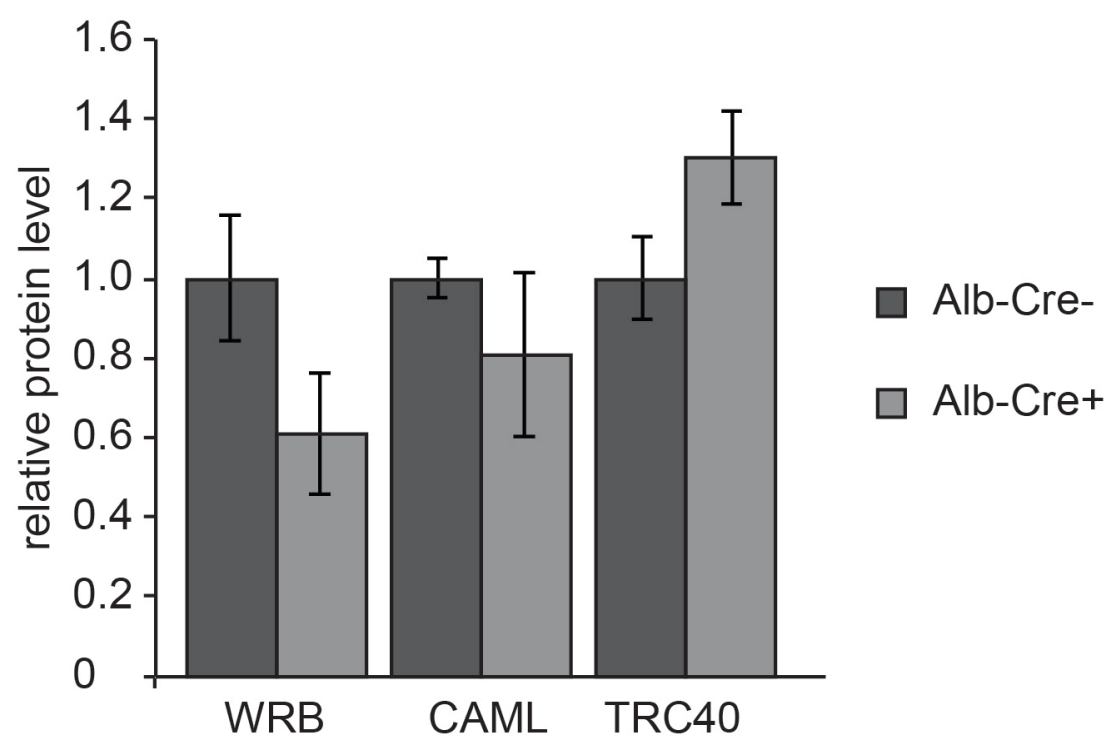

Figure 11: In isolated hepatocytes of $6 \mathrm{w}$ old Alb-Cre+ animals, no significant change of the protein levels of the pathway components was observed.

Protein extracts from isolated hepatocytes of $6 \mathrm{w}$ old animals were subjected to SDS PAGE and Western Blotting. A shows the immunoblotting with antibodies against the pathway components WRB, CAML and TRC40. The asterisk marks the specific signal obtained with the TRC40 antibody. B shows the quantification of the signals in $\mathbf{A}$. The bars represent averages -/+ SEM. $\mathbf{N}=5$ for both Alb-Cre- and Alb-Cre+ animals.

CAML strongly decreased at protein level (Figure 12B, animals 292 and 290). A moderate reduction of WRB at mRNA level led to only a slight or no reduction of CAML at protein level (Figure 12B, animals 337 and 315).

For TRC40 however, yet another effect was observed: In Alb-Cre+ animals that showed a strong reduction of WRB mRNA, the TRC40 steady-state protein level decreased a little (animals 292 and 290 in Figure 12C), while a moderate reduction of WRB at mRNA level 
A

relative WRB protein levels
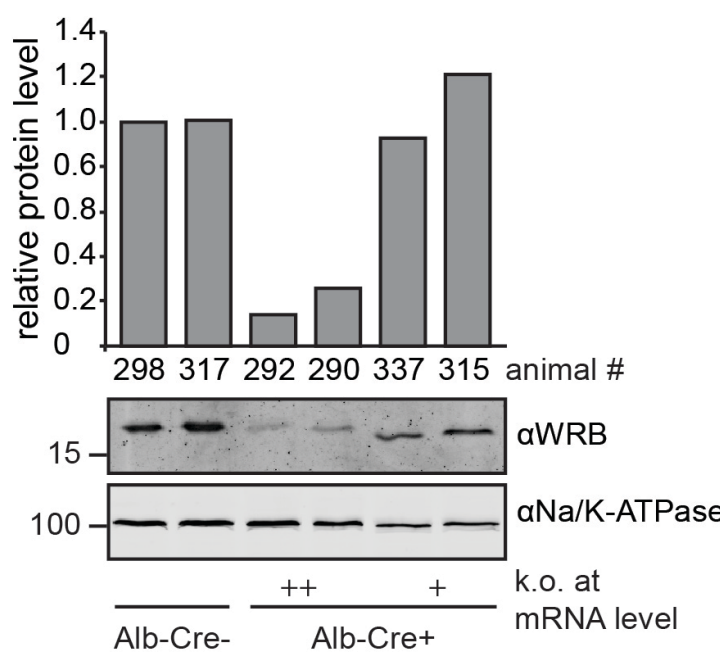

C

relative TRC40 protein levels

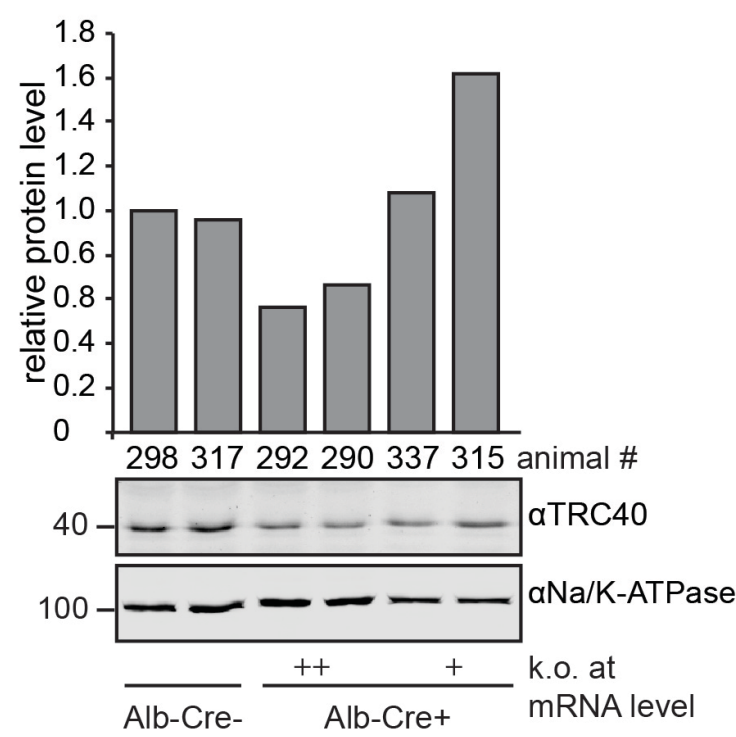

B

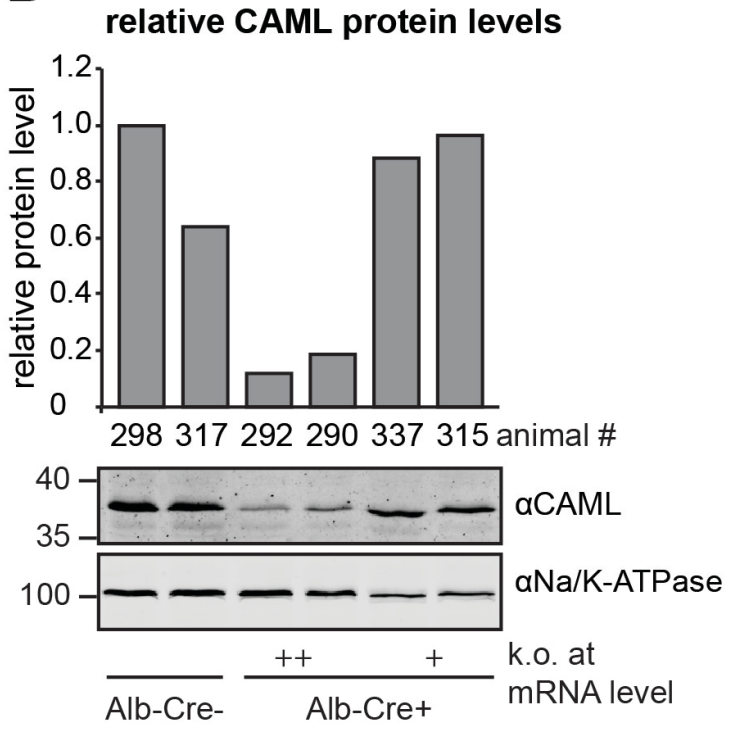

Figure 12: Variability in the knockout strength of WRB at mRNA level correlated with changes at protein level of the pathway components in Alb-Cre+ animals.

Western Blots for the three pathway components were performed with animals showing different knockout grades of WRB at mRNA level (A, WRB; B, CAML; C, TRC40). The strength of the knockout is given under the blots. ++ represents animals from the $25^{\text {th }}$ percentile, + animals from the $50^{\text {th }}$ percentile in Figure 8 . Bars always show the quantification of the protein relative to the Na/K-ATPase.

led to either no change or a slight increase of the TRC40 steady-state protein level (animals 337 and 315 in Figure 12C).

Taken together, these results indicate that the variability of the knockout degree at mRNA level accounts for the non-significant changes in WRB steady-state protein levels in both isolated hepatocytes and total liver homogenate. The results suggest that the livers of all 
animals contained mixtures of knockout hepatocytes and hepatocytes that escaped recombination. In the mosaic tissue or isolated hepatocytes, the reduction of WRB at mRNA level had to be somewhere below a certain threshold (between 20\% and $40 \%$ WRB mRNA left) before a clear effect at the steady-state protein level was visible. Since only about $20 \%$ of the animals analysed did show such a strong reduction of WRB at mRNA level, the average reduction of WRB and CAML steady-state protein levels was not always visible despite the significant average reduction of WRB mRNA level in $6 \mathrm{w}$ old Alb-Cre+ animals.

However, when a substantial reduction of the WRB mRNA level was present, this affected steady-state protein levels of WRB and CAML. For a further characterisation, the analysis of the pathway components was carried out in older animals.

\subsubsection{In older animals, the hepatocyte-specific WRB knockout affects liver tissue and isolated hepatocytes in different ways}

Since the in situ phenotype appeared more severe with increasing age, both total liver homogenate and isolated hepatocytes of older Alb-Cre- and Alb-Cre+ animals were subjected to the same experiments as the samples from $6 \mathrm{w}$ old animals. The expression of the main pathway components WRB, CAML and TRC40 was determined at mRNA and protein level.

In a first screen, I tested whether a successful excision of the middle exons of the floxed WRB allele could be observed in older Alb-Cre+ animals as well and whether this affected the mRNA levels of the other two main components of the pathway, CAML and TRC40. RNA was extracted from both total liver homogenate and isolated hepatocytes, and RTqPCR was performed. In total liver homogenate from older animals, no apparent change of WRB at mRNA level was observed (Figure 13A, D). While the variation in the Alb-Crecontrol animals was comparably small, the Alb-Cre+ animals again displayed a large variability, resulting in no change in the WRB mRNA level on average. Interestingly, the mRNA level of CAML, the partner of WRB in the ER membrane, was significantly increased in Alb-Cre+ animals (Figure 13B, D), which was not the case in the $6 \mathrm{w}$ old animals, independent of the sample type (total liver homogenate or isolated hepatocytes). The mRNA level of the cytosolic component, TRC40, showed a tendency for increase in Alb-Cre+ animals (Figure 13C, D), which had been observed in total liver homogenate and isolated hepatocytes of $6 \mathrm{w}$ old Alb-Cre+ animals as well. In total liver homogenate of older animals, this increase was not significant.

As already mentioned in 3.5.1, it is possible that the loss of WRB leads to massive damage and therefore changes in cellular composition of the liver, resulting in relatively fewer hepatocytes contributing to the total liver mass. 
A

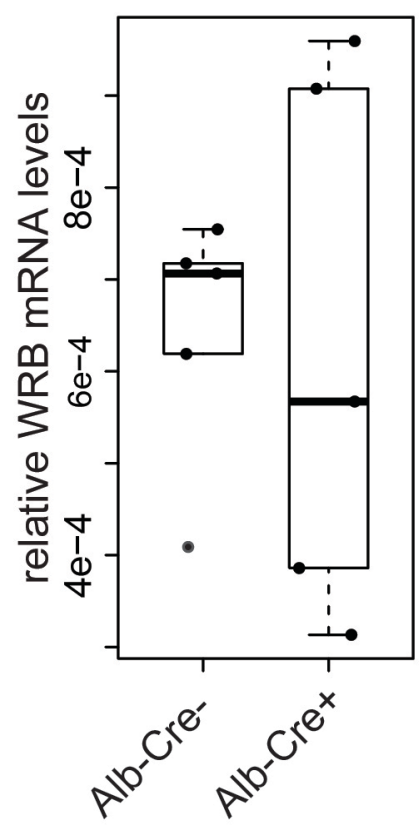

B

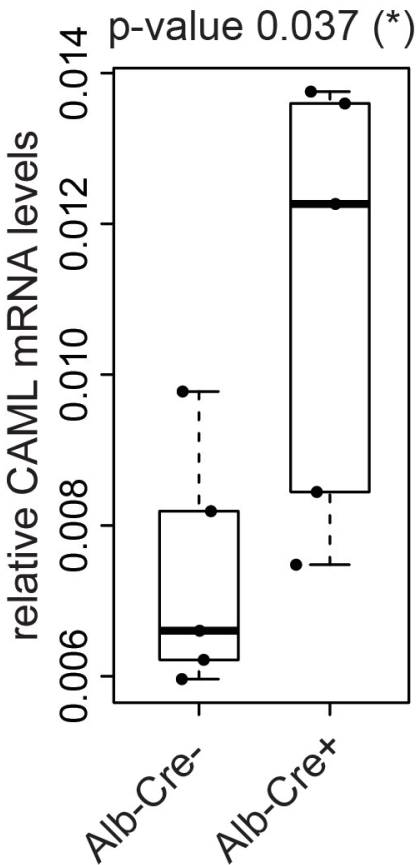

C

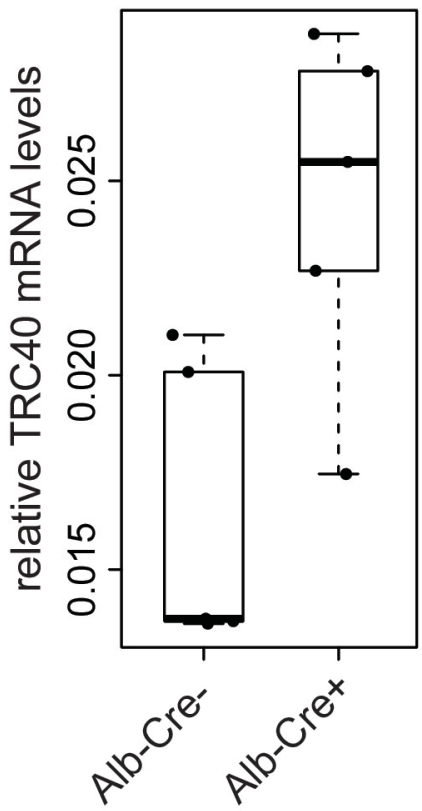

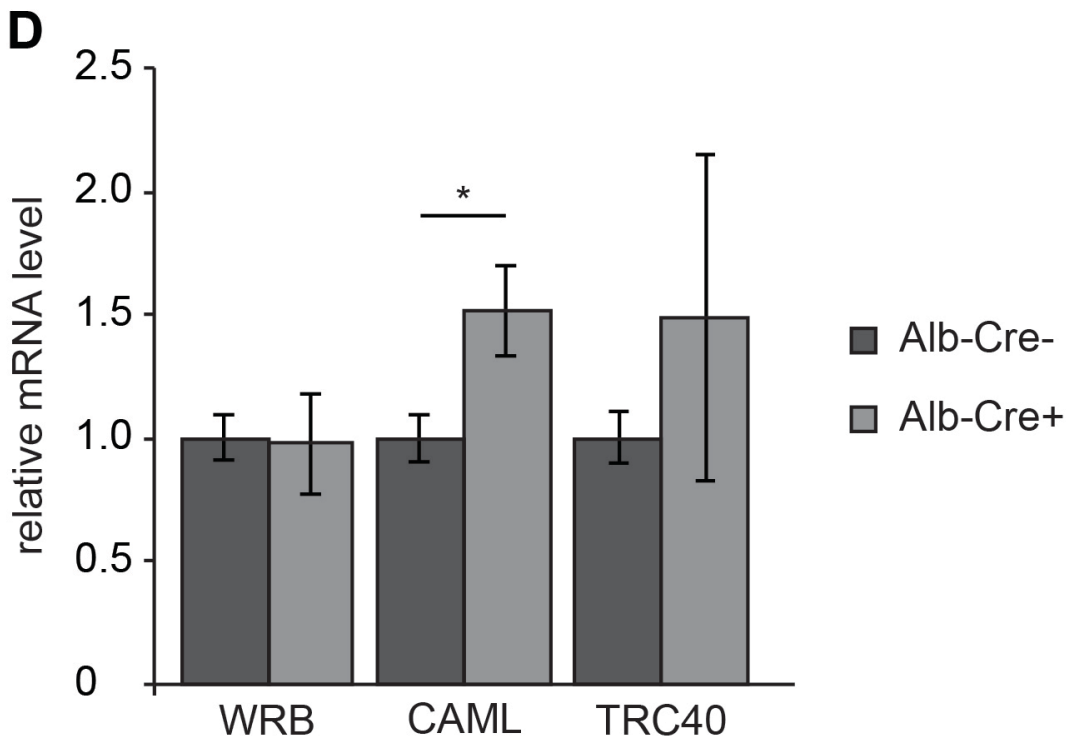

Figure 13: In older Alb-Cre+ animals, WRB and TRC40 remained unchanged at mRNA level, while CAML increased in total liver homogenate.

mRNA isolated from total liver homogenate of older animals was used to analyse mRNA levels of the pathway components by RT-qPCR. A-C show boxplots of the individual samples, with the $2^{\wedge}-\mathrm{dCP}$ values of the target over GAPDH given on the $y$-axis. $\mathbf{D}$ shows the averages -/+ SEM of $\mathbf{A}-\mathbf{C}$. The p-value for the significant change in CAML mRNA levels is given above the boxplot in $\mathbf{B}$ and is also represented in the graph in $\mathbf{D}$. For both Alb-Cre- and Alb-Cre+ animals, $n=5$.

To investigate the effect of WRB knockout exclusively in the cell type in which the recombination occurred, mRNA levels of the pathway components were quantified by RTqPCR with RNA extracted from isolated hepatocytes. 
RT-qPCR with RNA from isolated hepatocytes led to different results than previously observed with RNA from total liver homogenate. When analysing mRNA from isolated hepatocytes, the mRNA level of WRB in Alb-Cre+ animals showed a highly significant decrease compared to Alb-Cre- animals (Figure 14A, D). The level of WRB mRNA was on average decreased to about $50 \%$, which resembled the results observed in isolated hepatocytes from $6 \mathrm{w}$ old animals. Although isolated hepatocytes from only four older animals could be subjected to RT-qPCR, a large variation in the WRB mRNA level can be observed (Figure 14A). Regarding the mRNA level of CAML, no difference was detected when comparing Alb-Cre+ animals to Alb-Cre- control animals (Figure 14B, D). Similar results were seen for TRC40, where the mRNA level in the Alb-Cre+ animals did not differ significantly from the mRNA level in Alb-Cre- animals (Figure 14C, D).

Overall, the results from the RT-qPCR experiments in older animals showed that in total liver homogenate no significant reduction of WRB at mRNA level occurred, but when analysing isolated hepatocytes, a significant decrease of WRB at mRNA level was observed.

Experiments were performed to evaluate how the knockout of WRB translates to WRB steady-state protein amounts in older animals. Proteins were extracted from total liver homogenate and isolated hepatocytes from older animals and immunoblotting for WRB, CAML and TRC40 was carried out. The livers of older animals showed a strong phenotype in situ, so it was assumed that effects of the WRB knockout at protein level should be visible with samples prepared from total liver homogenate.

As for WRB, the immunoblotting with total liver homogenate did not reveal any change in the WRB steady-state protein level when comparing Alb-Cre+ with Alb-Cre- animals (Figure 15). Although individual samples displayed a visible decrease on the blot (animals 175, 176 in Figure 15), the reduction was not significant overall.

CAML did not show a significant change between Alb-Cre+ and Alb-Cre- animals at steady-state protein level in total liver homogenate of older animals (Figure 15), although the mRNA level in total liver homogenate was significantly increased. On the other hand, while showing no significant change at mRNA level, the steady-state protein level of TRC40 was significantly increased in Alb-Cre+ animals compared to the control animals ( $p$-value $=0.04$, Figure 15). These results indicate that changes at mRNA and steadystate protein levels did not necessarily correlate and need further analysis and discussion. To compare the results from total liver homogenate to isolated hepatocytes of older animals, the blots were repeated with isolated hepatocytes. In the blots, one Alb-Cre+ animal was included that did not show any phenotype in situ. It was not included in the quantification, but again supported the finding of the large variability in the WRB knockout in hepatocytes. This sample is marked by an arrowhead in Figure 16. 
A

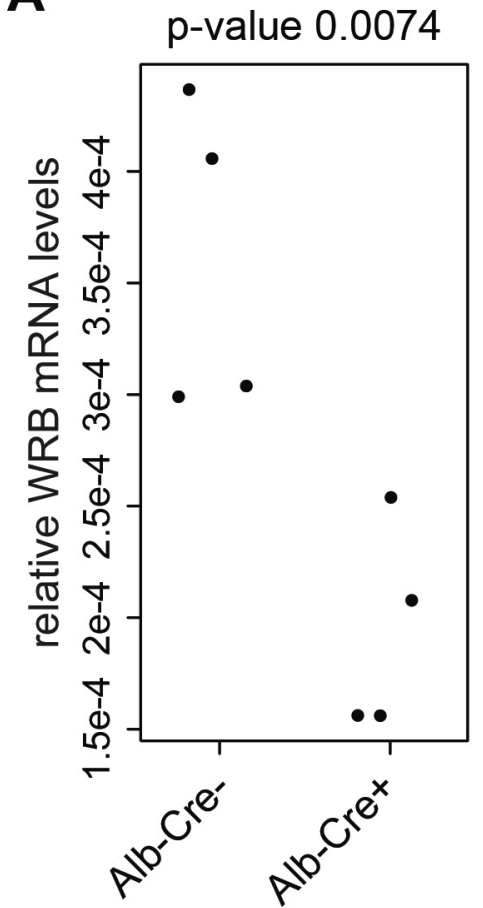

B

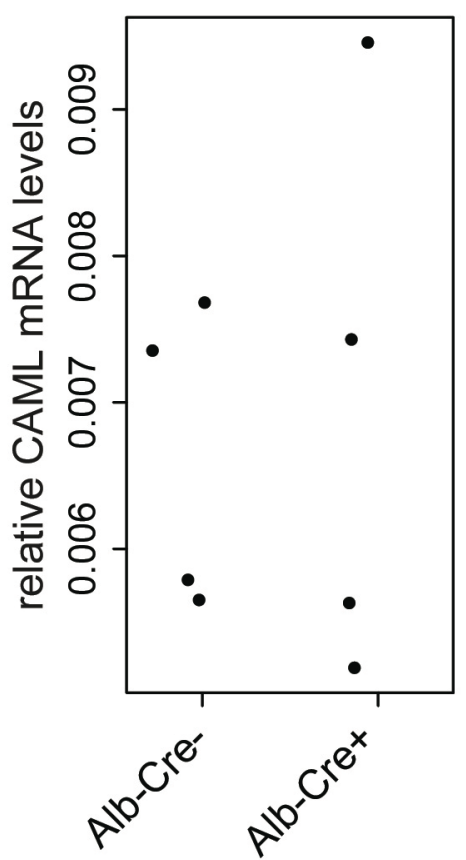

C

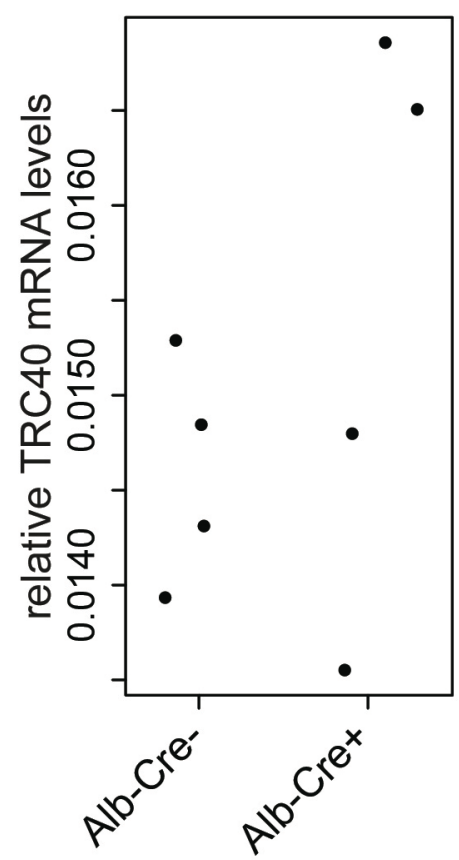

D

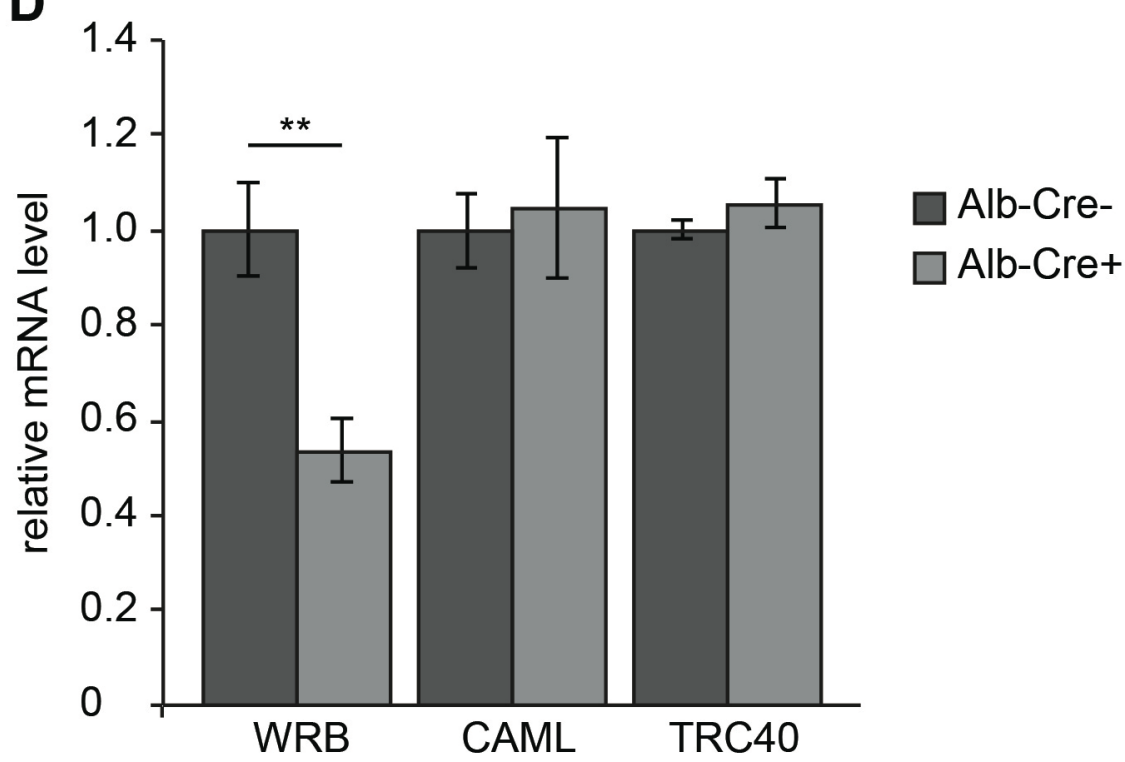

Figure 14: Isolated hepatocytes of older Alb-Cre+ animals showed a significant reduction of WRB at mRNA level.

mRNA of isolated hepatocytes from $\geq 11 \mathrm{w}$ old animals was subjected to RT-qPCR to analyse mRNA levels of the pathway components. $\mathbf{A}$ to $\mathbf{C}$ show dot plots of the individual animals. Relative levels are given as $2^{\wedge}$-dCP of the target over GAPDH. D shows averages -/+ SEM of the plots in $\mathbf{A}$ to $\mathbf{C}$. The significance level of the change in WRB mRNA levels is indicated in A and $\mathbf{D}$. For both Alb-Cre- and Alb-Cre+ animals, $n=4$.

When probing for WRB, isolated hepatocytes from Alb-Cre+ animals showed a significant decrease of WRB at steady-state protein level down to about 60\% (Figure 16). Interestingly, the one animal that was not included in the quantification showed a higher protein level on the Western Blot, indicating a correlation between the absence of phenotype in situ and the amount of WRB protein in hepatocytes. Also for CAML, a 
A

liver total homogenate

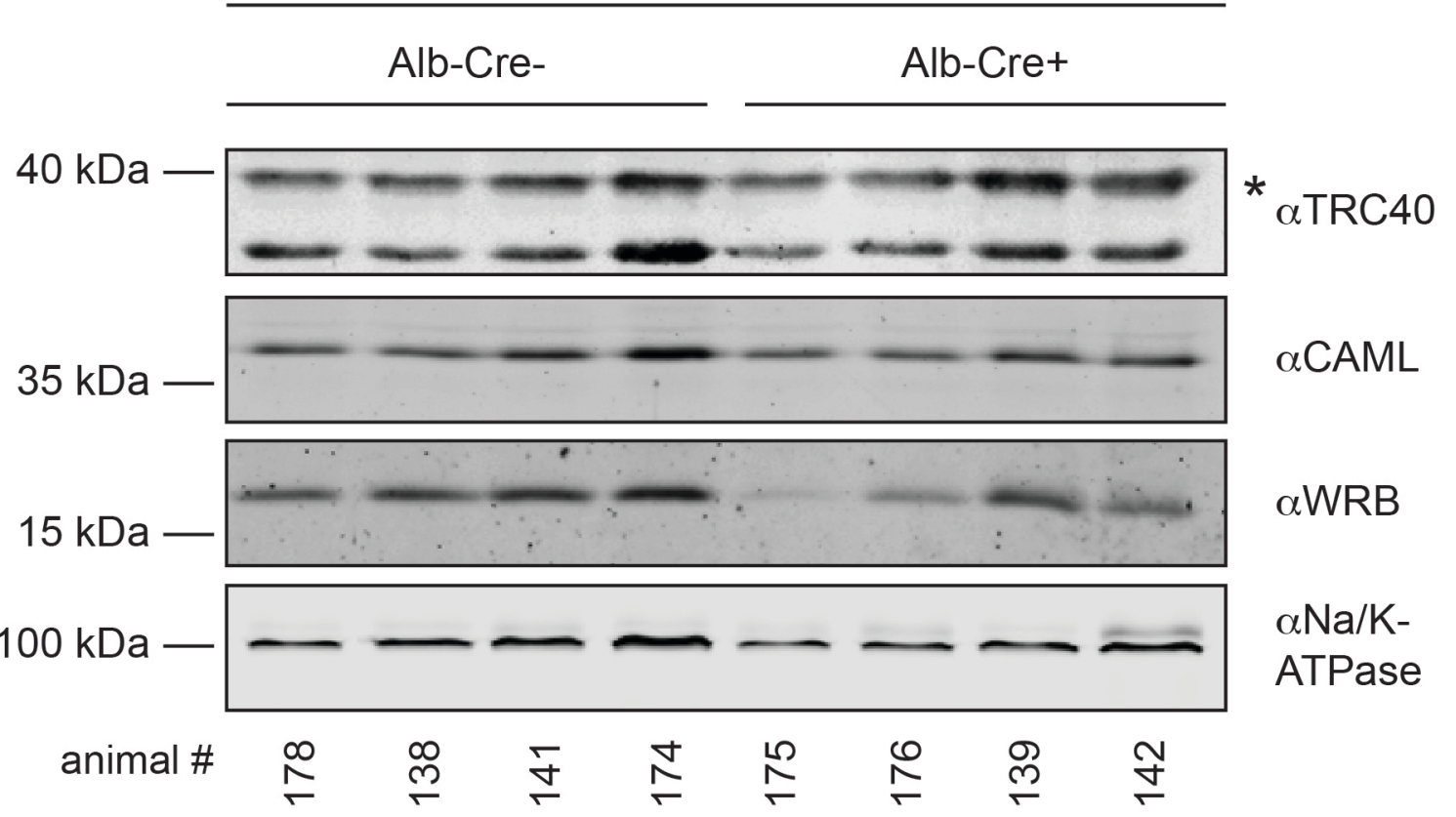

B

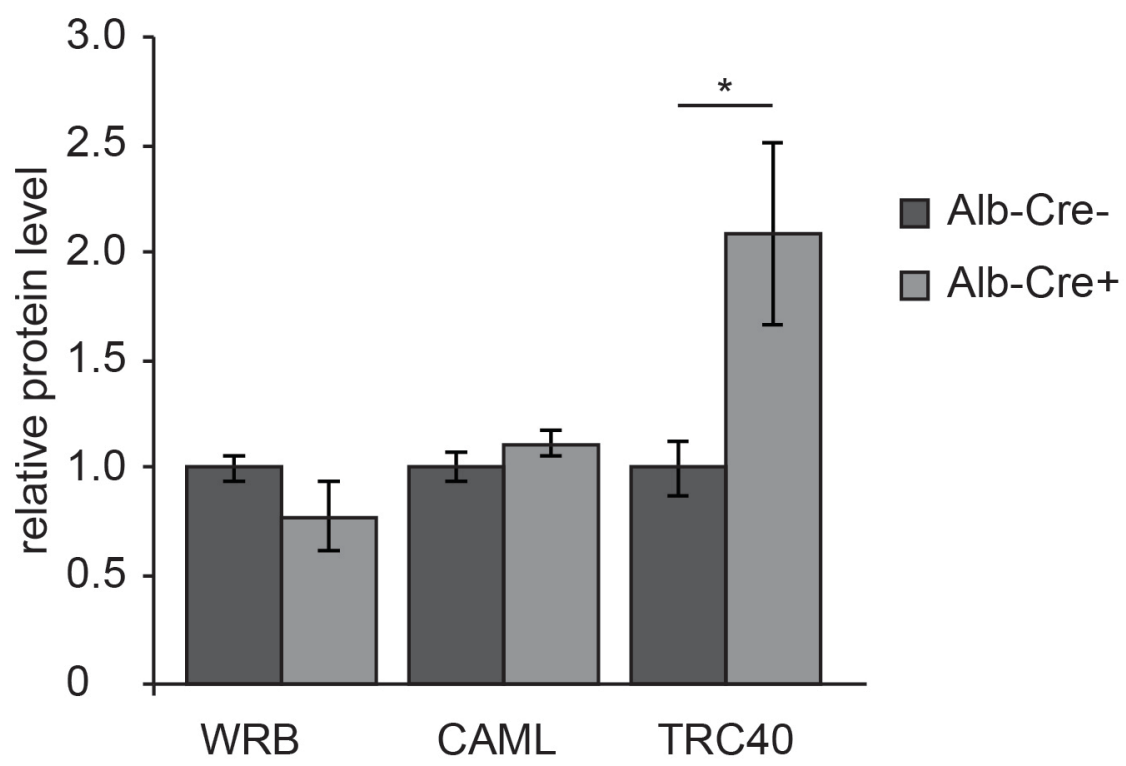

Figure 15: In total liver homogenate from older animals, only TRC40 showed a significant change in Alb-Cre+ animals.

Protein extracts from total liver homogenate of older animals were analysed by Western Blotting. A shows the immunoblotting for WRB, CAML and TRC40. The asterisk marks the specific signal obtained with the TRC40 antibody. $\mathbf{B}$ shows the quantification of $\mathbf{A}$, given as averages -/+ SEM. The significance in the change of TRC40 is indicated in B ( $p$-value $=0.04)$. For Alb-Cre- animals, $n=5$, for Alb-Cre+ animals, $n=5$. The blot always shows only four individuals in each group. Animal numbers are indicated.

significantly decreased steady-state protein level in Alb-Cre+ animals was observed (Figure 16), while again the animal lacking the typical in situ phenotype displayed a much higher signal of CAML on the Western Blot. Additionally, the other Alb-Cre+ animals, which had shown a clear phenotype in situ, varied in the extent of the reduction of WRB 
and CAML, indicating the high variability of the knockout penetrance in hepatocytes. In contrast to WRB and CAML, TRC40 did not show any change at steady-state protein level in the Alb-Cre+ animals compared to Alb-Cre- animals (Figure 16).

A isolated hepatocytes

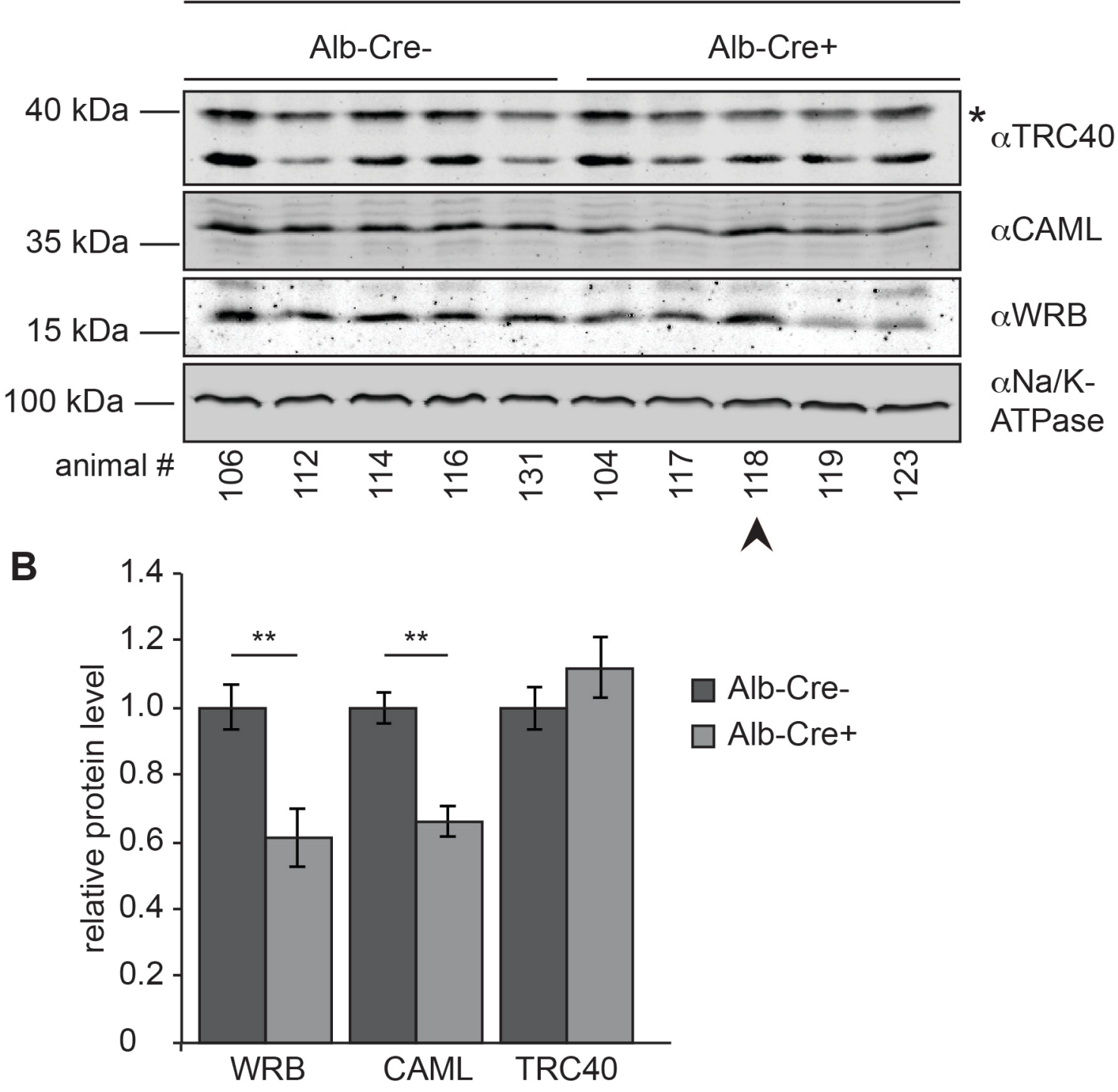

Figure 16: In isolated hepatocytes of older Alb-Cre+ animals, WRB and CAML were significantly reduced at protein level.

Protein extracts from isolated hepatocytes of older animals were analysed by Western Blotting. A shows the immunoblotting for WRB, CAML and TRC40. The asterisk marks the specific signal obtained with the TRC40 antibody. $\mathbf{B}$ shows the quantification of $\mathbf{A}$, given as averages -/+ SEM. The significance in the change of WRB and CAML are indicated in $\mathbf{A}$ and $\mathbf{B}$. For WRB, $p$-value $=0.008$. For CAML, $p$-value $=0.001$. The signal from the Alb-Cre+ animal marked with the arrowhead was not included in the quantification. For Alb-Cre- animals, $n=5$, for Alb-Cre+ animals, $n=4$. 
Taken together, I showed that in older animals the WRB knockout was visible only in isolated hepatocytes, while samples from total liver homogenate did not display a significant reduction of WRB at mRNA or steady-state protein level, despite the strong phenotype of the liver in situ. As previously shown for $6 \mathrm{w}$ old animals, in older animals a large variability in the penetrance of the knockout was observed.

Overall, I could show that the decrease of WRB at mRNA level had to go below a certain threshold to lead to a reduction of WRB at steady-state protein level. Furthermore, a strong decrease of WRB at steady-state protein-level caused a reduction of CAML at steady-state protein level. The following table provides a summary of the results obtained for the pathway components at mRNA and protein level in the different age groups.

Table 4: Summary of the section 3.6.

The levels of mRNA or steady-state protein for the pathway components is shown. $\uparrow$ refers to a significant increase, $\downarrow$ to a significant decrease and - to no significant change. Cells, isolated hepatocytes. Hmg, total liver homogenate.

\begin{tabular}{|c|c|c|c|c|c|c|c|}
\hline & \multicolumn{3}{|c|}{ mRNA } & \multicolumn{3}{|c|}{ protein } \\
\hline & & WRB & CAML & TRC40 & WRB & CAML & TRC40 \\
\hline \multirow{2}{*}{$6 w$} & cells & $\downarrow$ & - & $\uparrow$ & - & - & - \\
\hline & $\mathrm{hmg}$ & $\downarrow$ & - & - & - & $\downarrow$ & - \\
\hline \multirow{2}{*}{$\begin{array}{c}\text { older } \\
\text { animals }\end{array}$} & cells & $\downarrow$ & - & - & $\downarrow$ & $\downarrow$ & - \\
\hline & $\mathrm{hmg}$ & - & $\uparrow$ & - & - & - & $\uparrow$ \\
\hline
\end{tabular}

Since a WRB knockout in hepatocytes led to a decrease in steady-state protein levels of WRB and CAML, the effect of this reduction on selected TA proteins expressed in hepatocytes was analysed. Investigating the consequences of the WRB knockout for substrates of the GET pathway might help to understand the in vivo client spectrum. The effects on selected substrates are described in the next section. 


\subsection{A hepatocyte-specific WRB knockout has varying effects on selected substrates of the mammalian GET pathway}

One of the still largely unknown aspects of the mammalian GET pathway is the in vivo client spectrum, and whether a dependence of some substrates on the pathway is a possible reason for its essential nature in higher eukaryotes. To gain further insight into the behaviour of substrates of the pathway, I analysed total liver homogenate and isolated hepatocytes of $6 \mathrm{w}$ old and older animals regarding selected substrates. The selected TA proteins were the three SNAREs Syntaxin 5 (Stx5), Syntaxin 6 (Stx6) and Syntaxin 8 (Stx8), Emerin (EMD), and the translocon subunit Sec61 $\beta$. These were all expressed in hepatocytes, as was shown in the transcriptome analysis (cf. Table 8). Furthermore, they have been shown in our lab to be substrates of the mammalian GET pathway in vitro or have been published to be substrates of the mammalian GET pathway (Abell et al., 2007; Pfaff et al., 2016; Stefanovic and Hegde, 2007). In the case of Stx5, its yeast homologue Sed5 is affected by deletion of GET pathway components in yeast (Schuldiner et al., 2008).

The following chapters describe the results I obtained when investigating these TA proteins in Alb-Cre+ animals.

\subsubsection{In 6 week old animals, selected substrates behave differently in liver tissue and isolated hepatocytes of Alb-Cre+ animals}

As already described for the pathway components in samples from $6 \mathrm{w}$ old animals, Western Blot analysis was performed for the substrates with both total liver homogenate samples and isolated hepatocytes. The same samples as for analysis of the pathway components were used.

When total liver homogenate was used for Western Blots, two of the four substrates that were analysed showed a significant change at steady-state protein level in Alb-Cre+ animals (Figure 17A, B). Syntaxin 5 (Stx5), a t-SNARE with two different isoforms found in the ER (42 kDa) and the Golgi apparatus (35 kDa) (Hay et al., 1998; Hui et al., 1997), displayed a highly significant decrease down to about $40 \%$ in Alb-Cre+ animals compared to Alb-Cre- animals, while Emerin (EMD), a TA protein of the inner nuclear membrane (Manilal et al., 1998), was significantly increased by about $40 \%$ in Alb-Cre+ animals compared to Alb-Cre- animals (Figure 17). In the case of Stx5, both isoforms were detected with the antibody used, and both isoforms (both appearing in a double band each) showed a similar behaviour upon quantification (Figure 17A, B). The other two substrates tested, Syntaxin 6 (Stx6, located in the membrane of the Golgi apparatus) and 
A

liver total homogenate

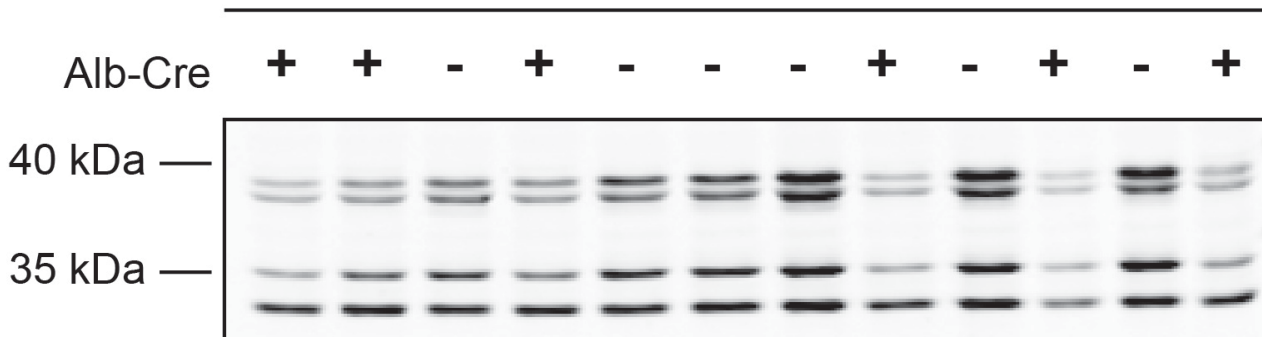

$\alpha$ Stx5

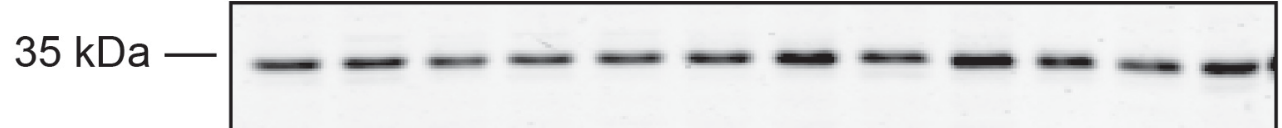

$\alpha \operatorname{Stx} 6$

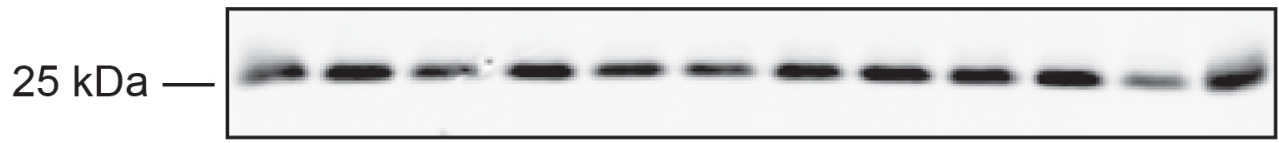

$\alpha \operatorname{Stx} 8$

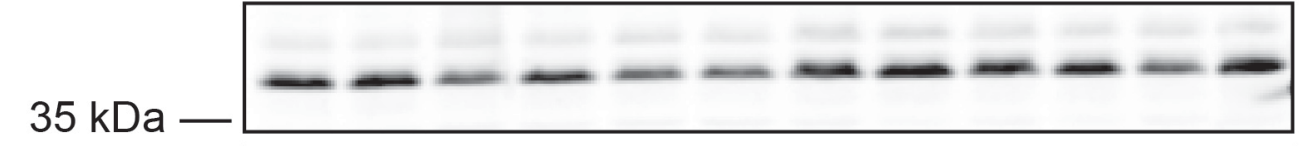

$\alpha E M D$

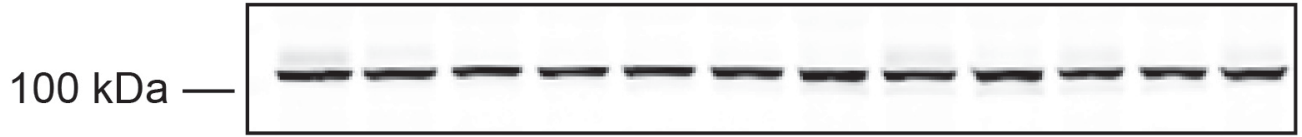

$\alpha \mathrm{Na} / \mathrm{K}-$

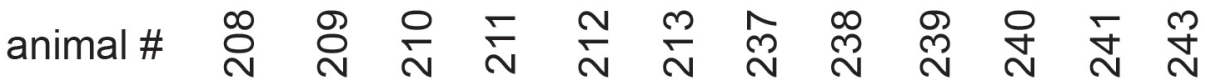

ATPase

B

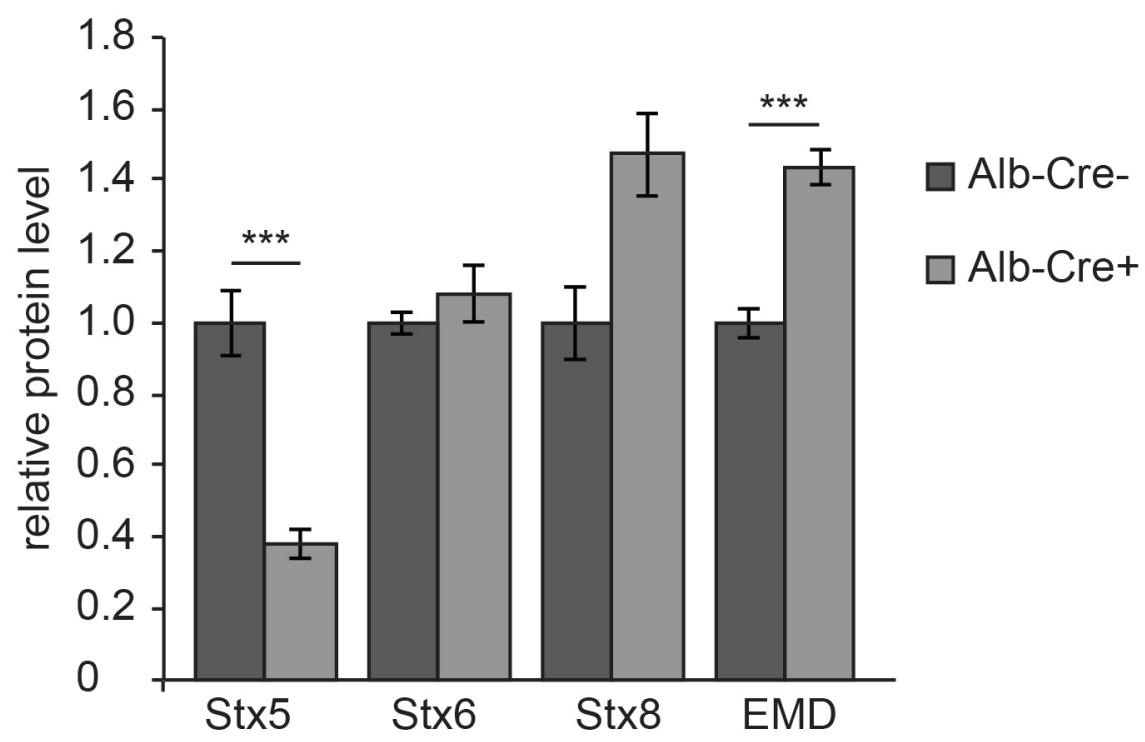

Figure 17: In total liver homogenate of 6 w old Alb-Cre+ animals Stx5 and EMD showed a significant change.

Protein extracts from total liver homogenate of $6 \mathrm{w}$ old animals were subjected to SDS PAGE and Western Blot to analyse the protein level of different substrates of the mammalian GET pathway. Immunoblotting is shown in $\mathbf{A}$. The quantification of the signals in $\mathbf{A}$ is shown in $\mathbf{B}$, bars show averages -/+ SEM. For both AlbCre- and Alb-Cre+ animals, $n=6$. Significance levels of significant changes are indicated in B (for Stx5, $p$ value $=0.0001$, for EMD $p$-value $=0.00006$ ) 
Syntaxin 8 (Stx8), did not show significant differences at steady-state protein level in total liver homogenates of Alb-Cre+ animals compared to Alb-Cre- animals, although Stx8 indicated a tendency to be increased in Alb-Cre+ animals compared to Alb-Cre- animals (Figure 17B).

As described in earlier chapters, the quantification of different substrates in total liver homogenates might be influenced by a putative change of the cellular composition of the liver and different homogenisation properties. For this reason, the Western Blot as well as an RT-qPCR analysis was performed to evaluate the steady-state levels of selected substrates in isolated hepatocytes.

In isolated hepatocytes, all substrates already probed for in total liver homogenate were tested. Additionally, immunoblotting was performed for Sec61 $\beta$, a TA protein that is part of the Sec61 translocon in the ER membrane and has previously been characterised as a substrate of the mammalian GET pathway (Abell et al., 2007; Stefanovic and Hegde, 2007). In contrast to the Western Blots carried out with total liver homogenate, the substrates displayed a different behaviour in isolated hepatocytes. All of the substrates tested (Stx5, Stx6 Stx8, EMD and Sec61ß), were successfully detected (Figure 18A), but only Stx6 changed at steady-state protein level and was significantly reduced to about $56 \%$ in Alb-Cre+ animals (Figure 18B). All other substrates did not show any significant change at steady-state protein level. Sec61 $\beta$ was the only substrate that showed a tendency to be decreased, but not significantly.

To analyse these results further, RT-qPCR was performed for all the substrates that had been previously evaluated by Western Blot. The results of the RT-qPCR revealed that the decrease of Stx6 at protein level correlated with a reduction of Stx6 at mRNA level in hepatocytes of Alb-Cre+ animals compared to Alb-Cre- animals (Figure 19B,F). The reduction of the Stx6 mRNA level down to about $76 \%$ was significant ( $p$-value $=0.014$ ). All the other substrates tested did not show any significant change at mRNA level, but most of them showed quite some variability from sample to sample (Figure 19A-E).

Immunoblotting and RT-qPCR analysis of the $6 \mathrm{w}$ old animals had not shown significantly reduced WRB protein and mRNA steady-state levels (see 3.6.1). Still, some of the substrates reacted to the knockout of WRB despite the mild penetrance. To evaluate how the selected substrates react to a strong reduction of WRB mRNA and protein level, as previously samples with a strong and an intermediate WRB knockout penetrance were used to perform Western Blots and analyse the correlation between WRB reduction and effect on the substrates (cf. Figure 12). Due to very low amounts of material available, only two substrates were investigated - Stx5 and Stx8. Collective and collaborative efforts 
A

isolated hepatocytes

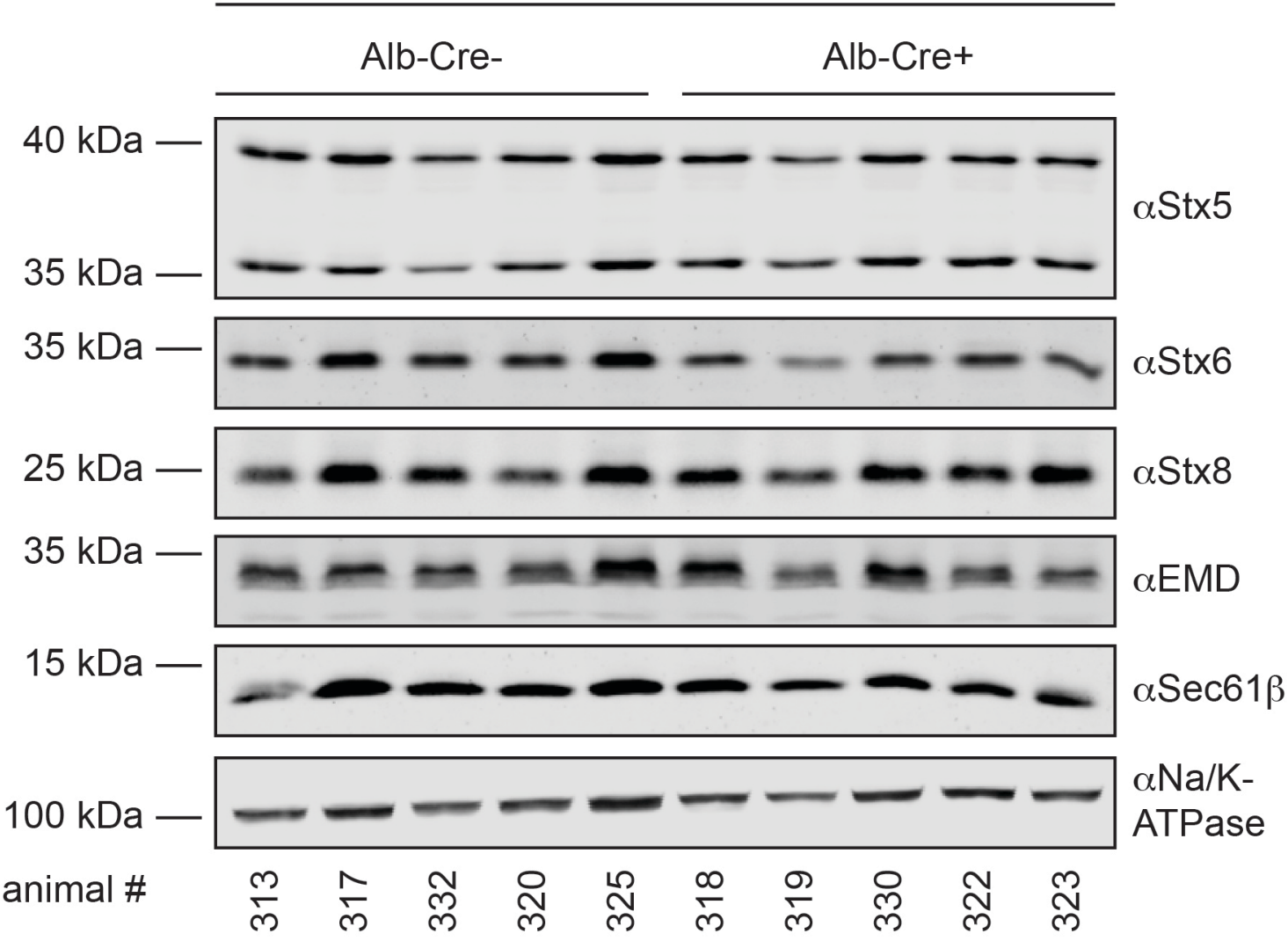

B

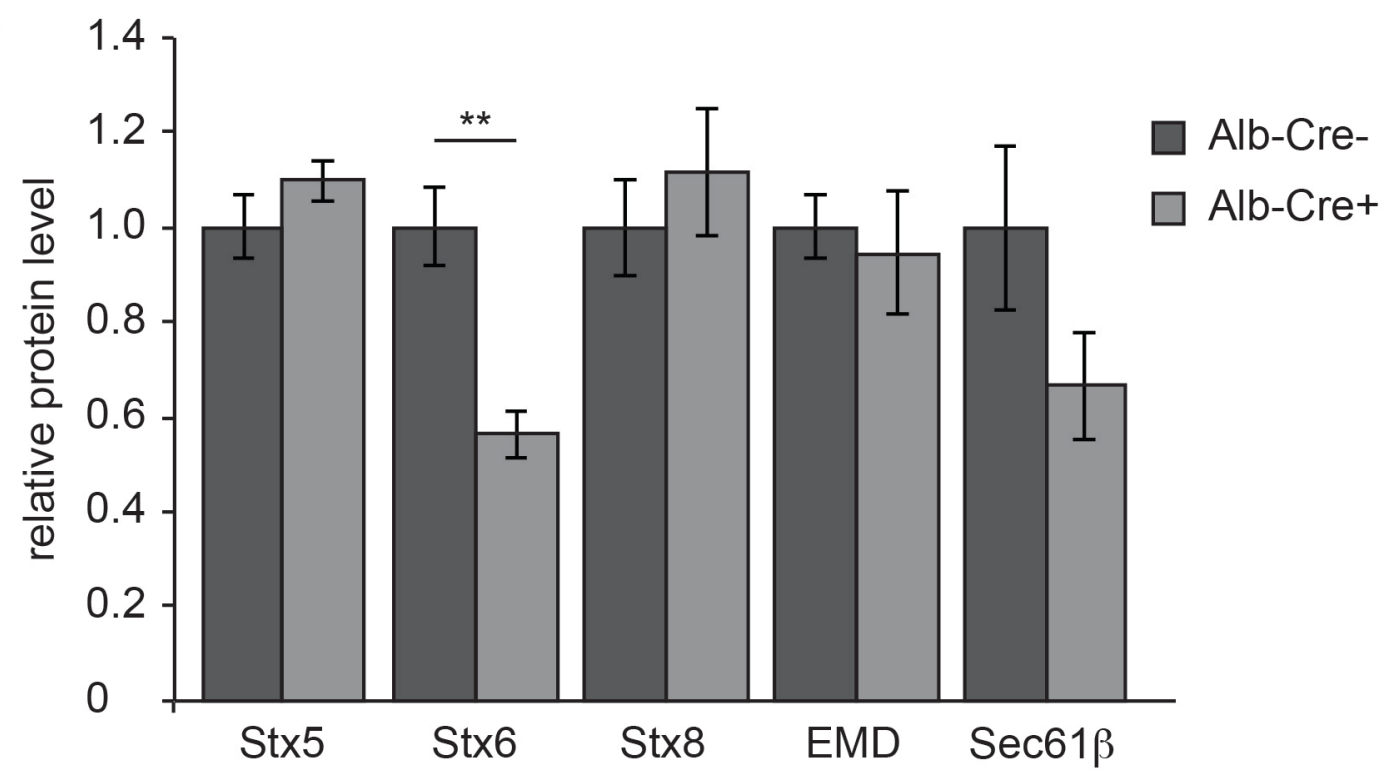

Figure 18: In isolated hepatocytes of $6 \mathrm{w}$ old Alb-Cre+ animals only steady-state protein levels of Stx6 displayed a significant change

Protein extracts from isolated hepatocytes of $6 \mathrm{w}$ old animals were subjected to SDS PAGE and Western Blot to analyse the steady-state protein levels of different substrates of the mammalian GET pathway. Immunoblotting is shown in $\mathbf{A}$. The quantification of the signals in $\mathbf{A}$ is shown in $\mathbf{B}$, bars show averages $-/+$ SEM. For both Alb-Cre- and Alb-Cre+ animals, $n=5$. Significance levels of significant changes are indicated in $\mathbf{B}$ (forStx6, p-value $=0.002$ ). 
A

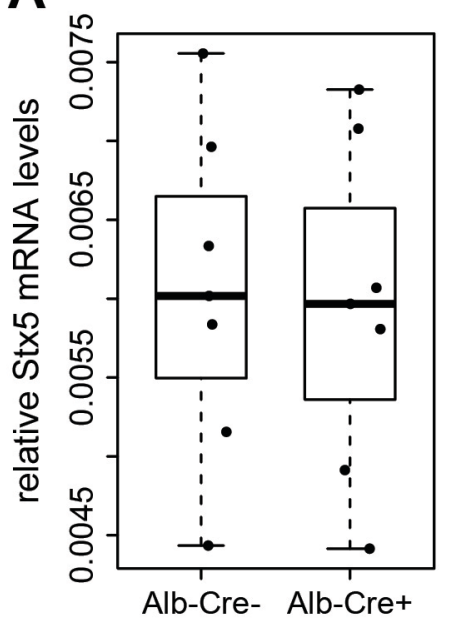

D

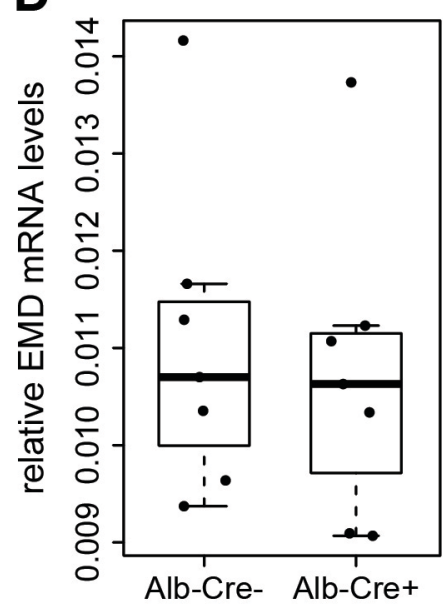

B

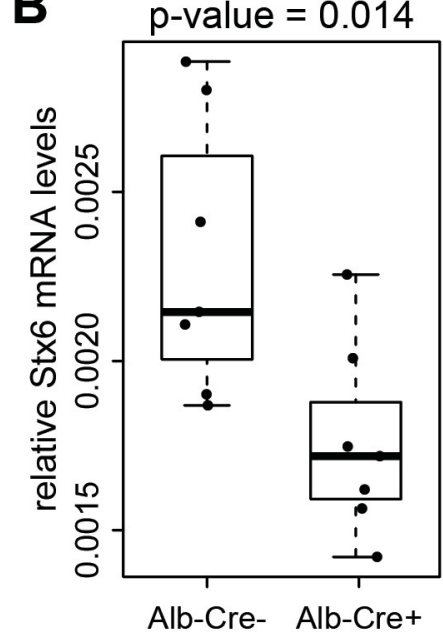

E

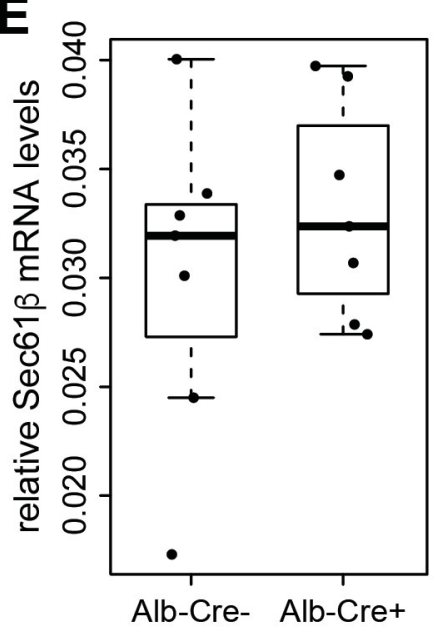

C

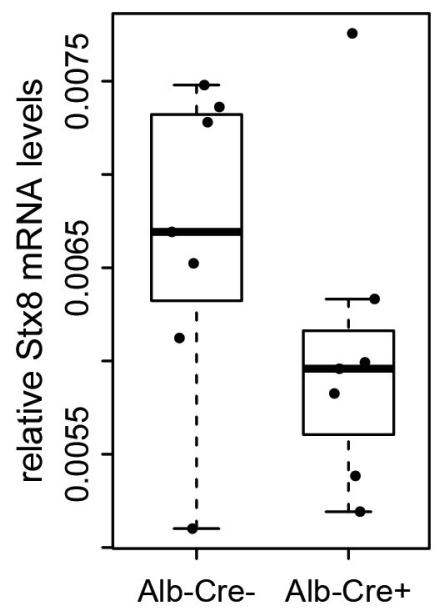

$\mathbf{F}$

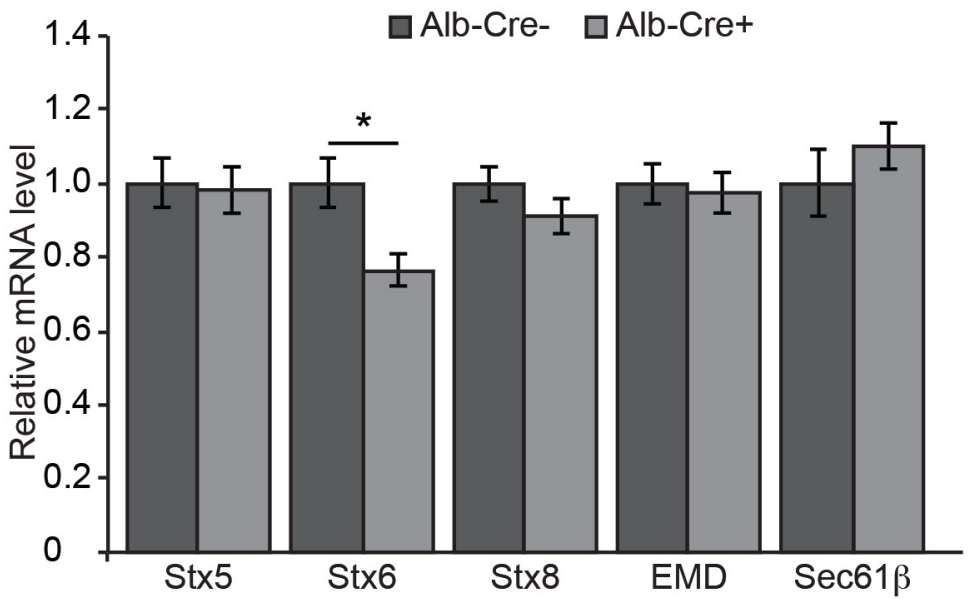

Figure 19: In isolated hepatocytes of 6 w old Alb-Cre+ animals Stx6 was significantly reduced at mRNA level.

mRNA obtained from isolated hepatocytes of $6 \mathrm{w}$ old animals was subjected to RT-qPCR to evaluate the mRNA levels of substrates of the mammalian GET pathway. A to $\mathbf{E}$ show boxplots of the relative mRNA level (plotted as $2^{\wedge}$-dCP values of the targets over GAPDH) of different substrates. Outliers are not included in the whiskers. $\mathbf{F}$ shows the quantification of the boxplots as averages -/+ SEM. The significance level for the change of Stx 6 is indicated in both $\mathbf{B}$ and $\mathbf{F}$. For Alb-Cre-, $n=10$. For Alb-Cre+, $n=11$. 
to analyse the consequences of WRB knockout in different tissues have shown that Stx5 is strongly affected in WRB knockout cardiac myocytes (experiments performed by Jhon Rivera-Monroy and described here for the purpose of discussion). On the other hand Stx8 was not affected in this other mouse model and displayed no significant changes in isolated hepatocytes or total liver homogenate.

The Western Blots revealed that Stx 5 reacted to a WRB knockout and was reduced at steady-state protein level if a strong penetrance of the WRB knockout was present (Figure 20 , animals 292 and 290). A moderate reduction of the WRB mRNA level however did not lead to a large change of Stx 5 at steady-state protein level (Figure 20A, animals 337 and 315). This suggests that due to a lack of a strong WRB reduction, the Stx5 protein level was on average not reduced in the other Western Blots performed (cf. Figure 18). On the other hand, a strong reduction of WRB mRNA level did not decrease the Stx8 steadystate protein level. The changes observed in Figure 20B in animals 292 and 290 are only minor. Interestingly, in the animals with a moderate reduction of WRB at mRNA level (Figure 20B, animals 337 and 315), Stx8 displayed a tendency towards increase, which was also observed in the blots discussed above (cf. Figure 17, Figure 18).

A

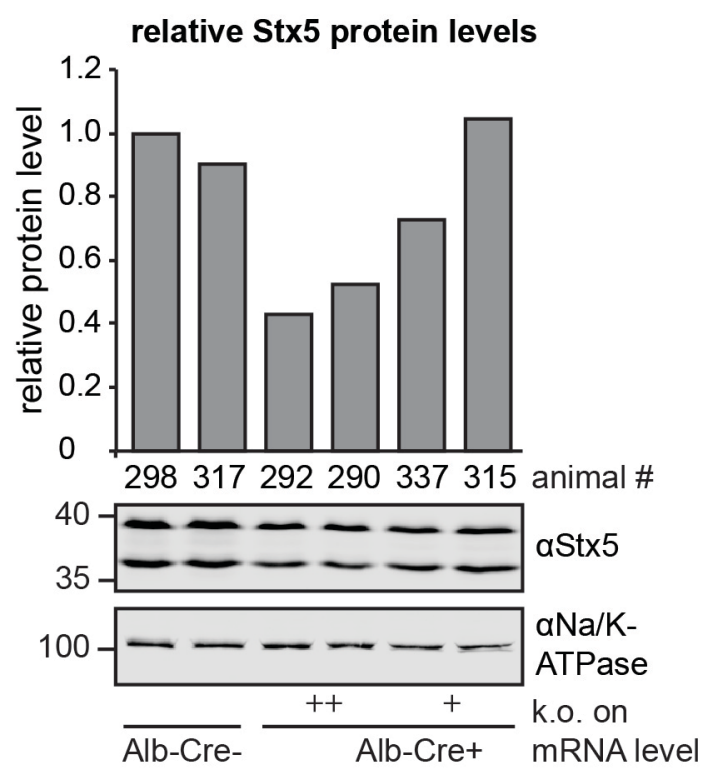

B

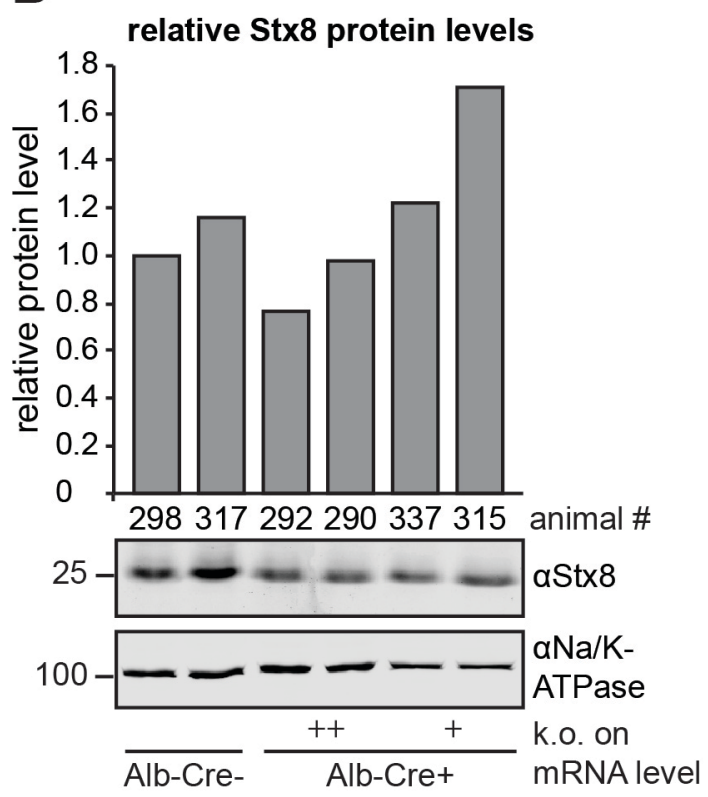

Figure 20: In isolated hepatocytes of $6 \mathrm{w}$ old Alb-Cre+ animals, penetrance of the WRB knockout at mRNA level highly correlated with the change at protein level for Stx5.

Western Blots for Stx5 (A) and Stx8 (B) were performed with animals showing different knockout grades of WRB at mRNA level. The strength of the knockout is given under the blots. ++ represents animals from the $25^{\text {th }}$ percentile, + animals from the $50^{\text {th }}$ percentile in Figure 8 . Bars always show the quantification of the protein relative to the $\mathrm{Na} / \mathrm{K}-\mathrm{ATP}$ ase 
Overall, selected substrates of the pathway behaved differently in $6 \mathrm{w}$ old animals. Only Stx5 and Stx6 displayed a significant decrease at steady-state protein levels, and Stx6 changed at mRNA level as well. However, the presence of this effect varied depending on the sample type, i.e. total liver homogenate or isolated hepatocytes, in both cases. The different extent of the WRB knockout penetrance had an influence on the effect observed in Stx5 and Stx6, with a higher penetrance leading to a stronger effect in the TA proteins. All other analysed TA proteins remained unchanged.

To investigate the development of the WRB knockout, the selected TA proteins were analysed in samples from older animals as well. In the following chapter I will describe the results I obtained from these experiments.

\subsubsection{In older animals, the effect of a WRB knockout on TA proteins depends on the sample type}

For a complete analysis of the WRB knockout, a possible influence of the WRB knockout and the effects involved on substrates of the pathway were analysed in total liver homogenate and isolated hepatocytes of older animals. As opposed to $6 \mathrm{w}$ old animals, the samples from older animals were only analysed by immunoblotting and no RT-qPCR was performed.

The results obtained from Western Blots performed with samples from older animals displayed different results from the experiments with $6 \mathrm{w}$ old animals, but the results as well depended on whether total liver homogenate or isolated hepatocytes of older animals were used. Analysis of total liver homogenate revealed that three out of five substrates showed a significant increase at steady-state protein level in Alb-Cre+ animals compared to Alb-Cre- animals (Figure 21A, B). Stx5, Stx6 and EMD were all increased by at least $50 \%$ (Figure 21B). Stx8 showed a tendency towards increase in Alb-Cre+ animals, but the changes were not significant (Figure 21B). Only Sec61 $\beta$ was within error completely unchanged.

However, when steady-state protein levels of the same substrates were evaluated in isolated hepatocytes of older animals, none of the five substrates showed a significant change when comparing Alb-Cre+ to Alb-Cre- animals (Figure 22A, B). This is all the more surprising considering that WRB and CAML both displayed a significant reduction at steady-state protein level in the same samples (cf. Figure 16). Only Stx5 and Stx8 show a tendency to be increased, but this change was not significant (Figure 22B). All substrates showed variability in the intensity of their signals on the blot, but these variations were not significant. It has to be mentioned that as for the analysis regarding the pathway components, the Alb-Cre+ animal, which did not show any obvious in situ phenotype, was left out of this analysis too (marked with an arrowhead in Figure 22). 
A liver total homogenate
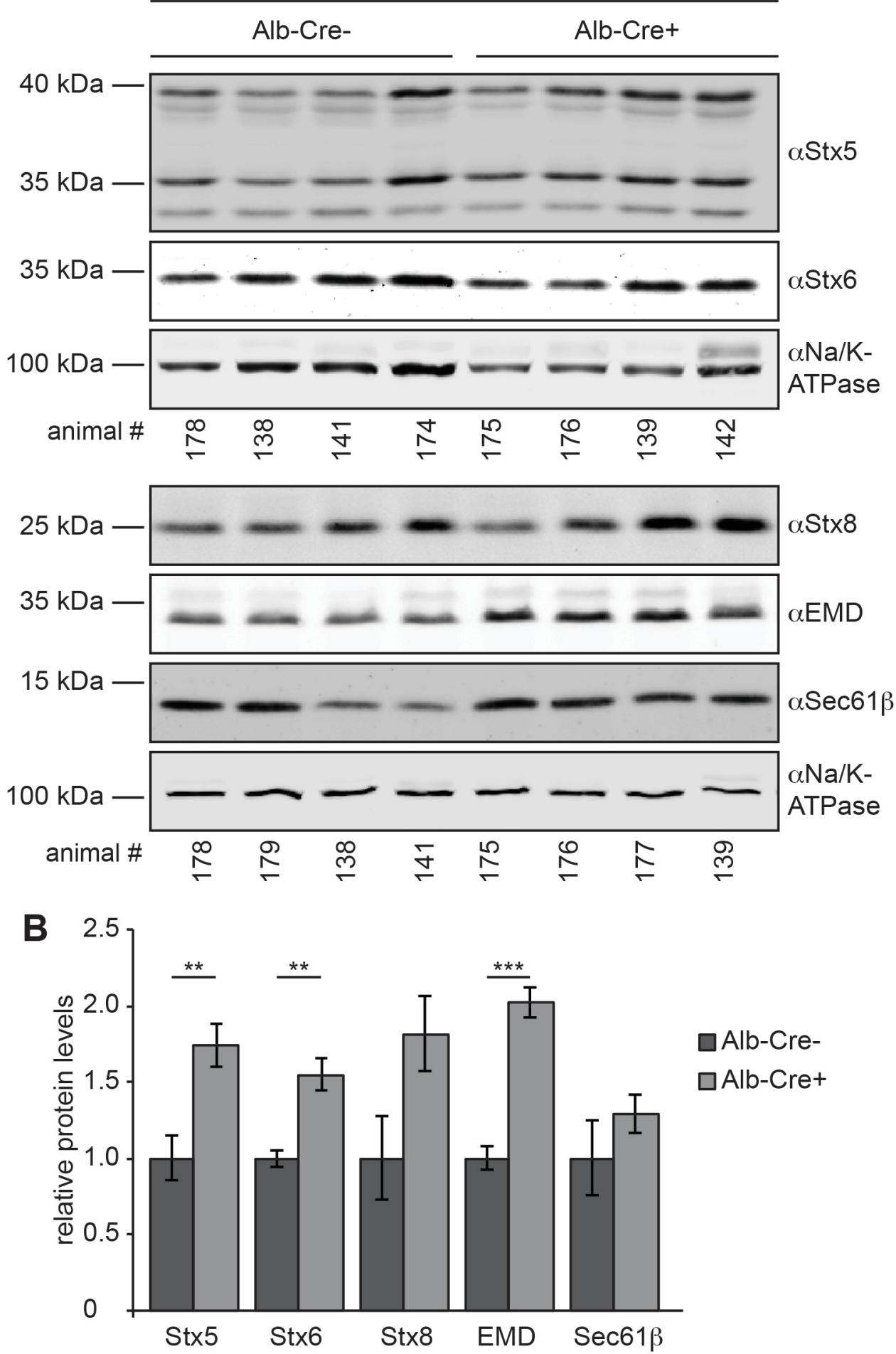

Figure 21: In total liver homogenate of older Alb-Cre+ animals, Stx5, Stx6 and EMD were significantly increased at protein level.

Protein extracts from total liver homogenate of older animals were subjected to SDS PAGE and Western Blot to analyse the protein levels of different substrates of the mammalian GET pathway. Immunoblotting is shown in $\mathbf{A}$. The quantification of the signals in $\mathbf{A}$ is shown in $\mathbf{B}$, bars show averages -/+ SEM. For both Alb-Cre- and Alb-Cre+ animals, $n=5$. Significance levels of significant changes are indicated in B. P-values are as follows: Stx $5=0.007$, Stx $6=0.002$, EMD $=0.0005$. For Alb-Cre- animals, $n=5$, for Alb-Cre+ animals, $n=5$. The blots always show only four individuals in each group. Animal numbers are indicated. 
A
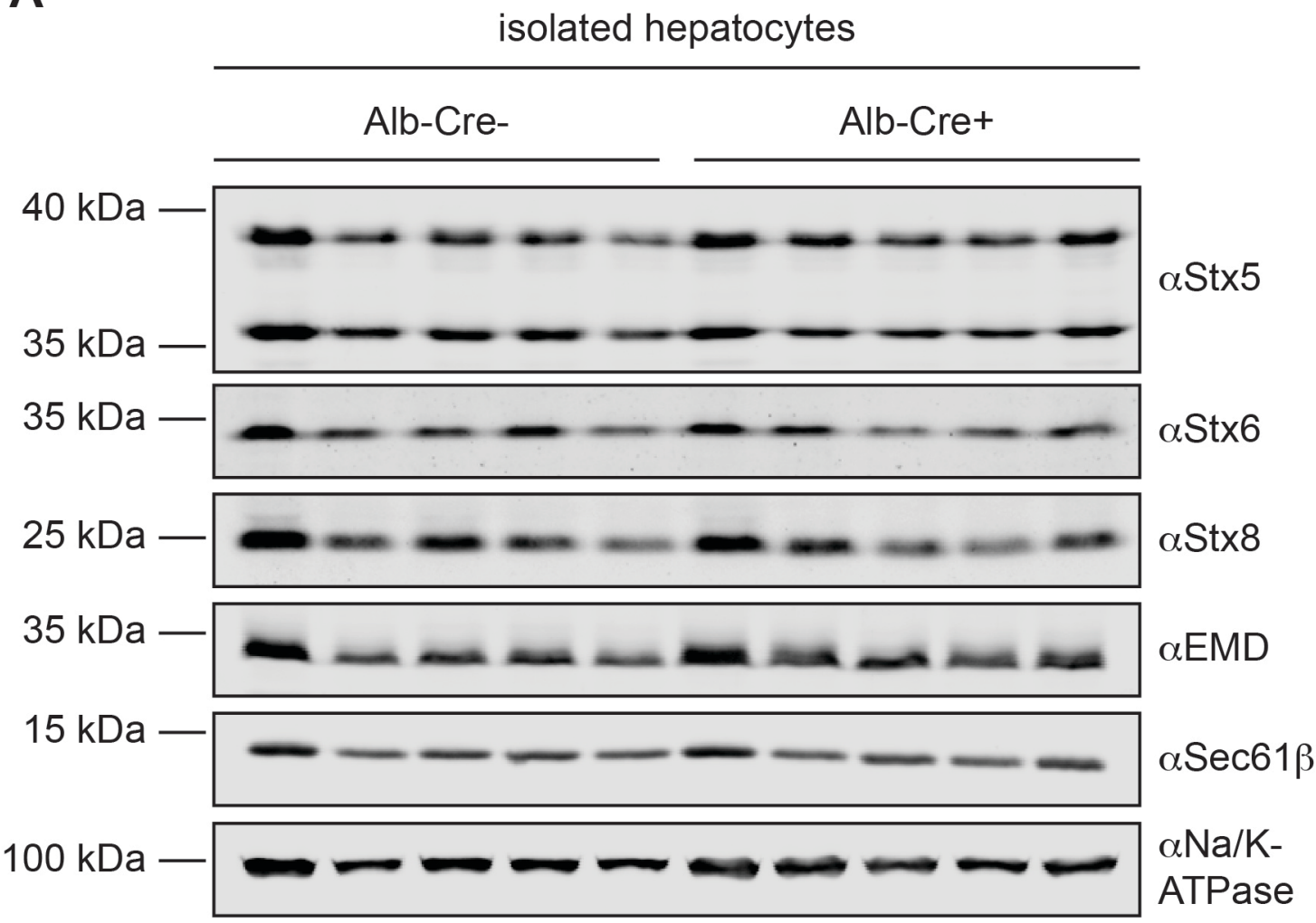

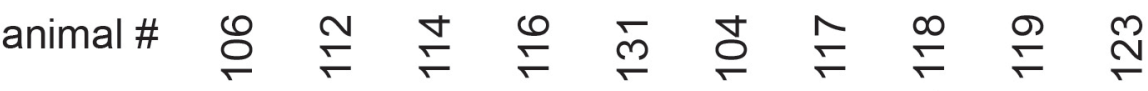

B

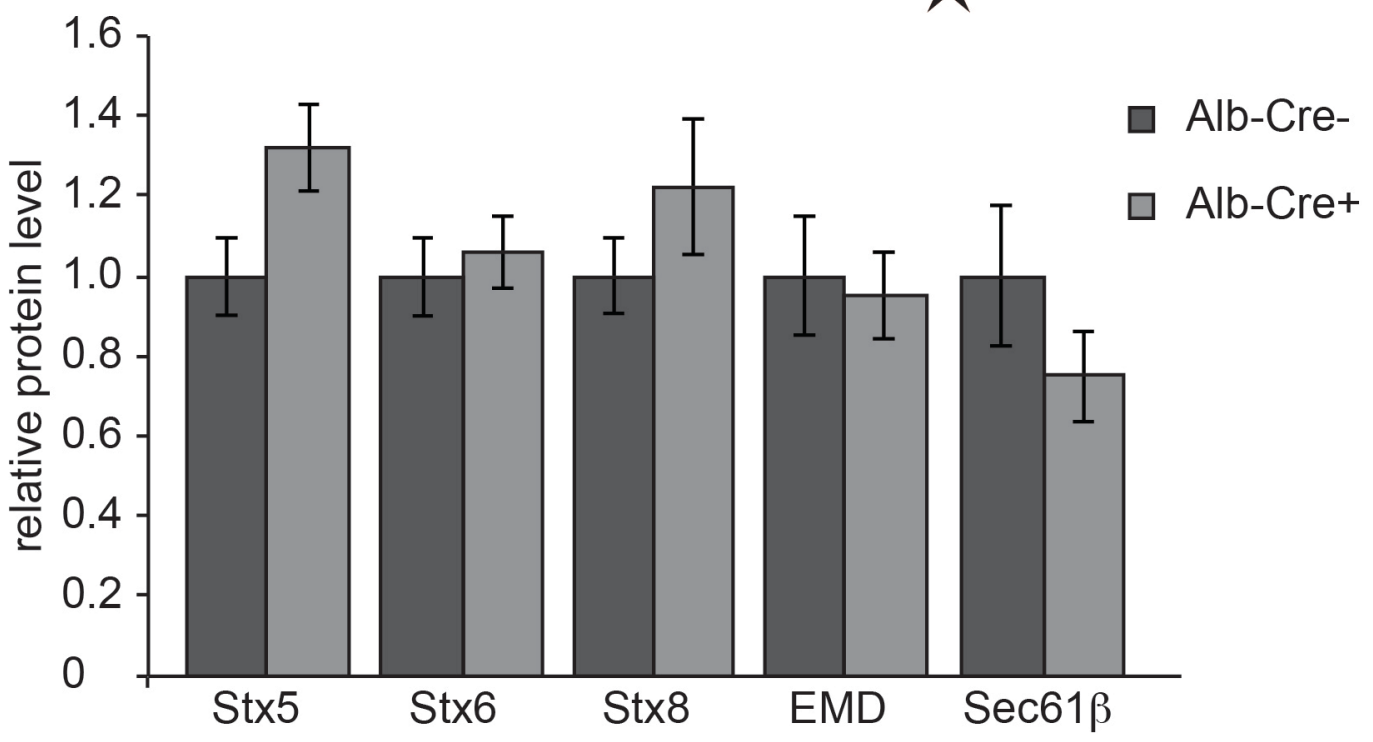

Figure 22: In isolated hepatocytes of older Alb-Cre+ animals, steady-state levels of no TA protein were significantly affected by the WRB knockout.

Protein extracts from isolated hepatocytes of older animals were subjected to SDS PAGE and Western Blot to analyse the protein levels of different substrates of the mammalian GET pathway. Immunoblotting is shown in A. The quantification of the signals in $\mathbf{A}$ is shown in $\mathbf{B}$, bars show averages -/+ SEM. For both Alb-Cre- and Alb-Cre+ animals, $n=5$. 
In conclusion, the selected TA proteins showed a different behaviour in total liver homogenate and isolated hepatocytes. While in total liver homogenate Stx5, Stx6 and EMD significantly increased at steady-state proteins levels, none if the substrates displayed a change in isolated hepatocytes of older animals.

The results obtained from the experiments in the two age groups lead to the conclusion that the observed effect on selected substrates depends on the age as well as the sample type. The penetrance of the WRB in hepatocytes and the mosaic state of the samples might have influenced the findings, as has been described for previous results.

The following table summarises the results concerning the selected substrates for total liver homogenate as well as isolated hepatocytes for the two age groups.

Table 5: Summary of section 3.7.

The of different substrates at mRNA or steady-state protein level are shown. $\uparrow$ refers to a significant increase, $\downarrow$ to a significant decrease and - to no significant change. n/a, not performed. Cells, isolated hepatocytes. Hmg, total homogenate

\begin{tabular}{|c||c|c|c|c|c|c||c|c|c|c|c|}
\hline \multicolumn{2}{|c|}{} & \multicolumn{9}{c||}{ mRNA } & \multicolumn{5}{c|}{ protein } \\
\cline { 2 - 12 } & Stx5 & Stx6 & Stx8 & EMD & Sec61b & Stx5 & Stx6 & Stx8 & EMD & Sec61b \\
\hline \multirow{2}{*}{$6 \mathrm{w}$} & cells & - & $\downarrow$ & - & - & - & - & $\downarrow$ & - & - & - \\
\cline { 2 - 13 } & $\mathrm{hmg}$ & $\mathrm{n} / \mathrm{a}$ & $\mathrm{n} / \mathrm{a}$ & $\mathrm{n} / \mathrm{a}$ & $\mathrm{n} / \mathrm{a}$ & $\mathrm{n} / \mathrm{a}$ & & - & - & & $\mathrm{n} / \mathrm{a}$ \\
\hline \hline \multirow{2}{*}{$\begin{array}{c}\text { older } \\
\text { animals }\end{array}$} & cells & $\mathrm{n} / \mathrm{a}$ & $\mathrm{n} / \mathrm{a}$ & $\mathrm{n} / \mathrm{a}$ & $\mathrm{n} / \mathrm{a}$ & $\mathrm{n} / \mathrm{a}$ & - & - & - & - & - \\
\cline { 2 - 13 } & $\mathrm{hmg}$ & $\mathrm{n} / \mathrm{a}$ & $\mathrm{n} / \mathrm{a}$ & $\mathrm{n} / \mathrm{a}$ & $\mathrm{n} / \mathrm{a}$ & $\mathrm{n} / \mathrm{a}$ & $\uparrow$ & $\uparrow$ & - & $\uparrow$ & - \\
\hline
\end{tabular}

The analysis of steady-state protein levels by Western Blot indicated an influence of the hepatocyte-specific WRB knockout on selected substrates of the GET pathway. To further characterise this effect, I carried out immunofluorescence experiments to gain more insight into this effects in single cell level. The results are summarised in the next chapter. 


\subsection{WRB knockout in hepatocytes influences Stx5 subcellular localisation}

To investigate subcellular localisation of selected substrates, primary hepatocytes were isolated and used for immunofluorescence. Unfortunately, immunofluorescence for the pathway components and some of the substrates could not be performed due to a lack of suitable antibodies. While all antibodies worked very well for Western Blots, only very few could successfully be used for immunofluorescence.

In isolated hepatocytes, the protein level of selected substrates changed upon WRB knockout only in $6 \mathrm{w}$ old animals (cf. Table 5). Immunofluorescence was therefore performed with isolated hepatocytes from $6 \mathrm{w}$ old animals. After plating and fixation, the cells were stained for Stx5 or Stx8, always co-staining with GM130, a marker of the Golgi apparatus (Marra et al., 2001).

Immunofluorescence analysis showed a clear difference in the presence and/or localisation of Stx5 in hepatocytes from Alb-Cre+ animals compared to Alb-Cre- animals (Figure 23). In cells from Alb-Cre- control animals, Stx5 displayed typical Golgi staining, resembling the one of GM130, with a very clear and bright signal (Figure 23A, C). In cells from Alb-Cre+ animals on the other hand, Stx 5 was more or less absent in most of the cells (Figure 23B). In the cells that did show some signal, the pattern did not resemble the typical Golgi staining of GM130 (Figure 23D).

In contrast to Stx5, Stx8 did not show any clear changes in its localisation or staining intensity. The staining in Alb-Cre+ animals resembled the one observed in Alb-Creanimals (Figure 23E, F), which in both cases showed Stx8 to be located around the nucleus. The GM130 Golgi staining looked very similar in the Alb-Cre- and Alb-Cre+ animals (Figure 23G, H).

The results obtained from the immunofluorescence in isolated hepatocytes of $6 \mathrm{w}$ old animals showed that substrates react with different susceptibility to the knockout of WRB. Stx 5 was strongly affected in its cellular distribution and presence, in contrast to Stx8, which was not affected. 
Alb-Cre-
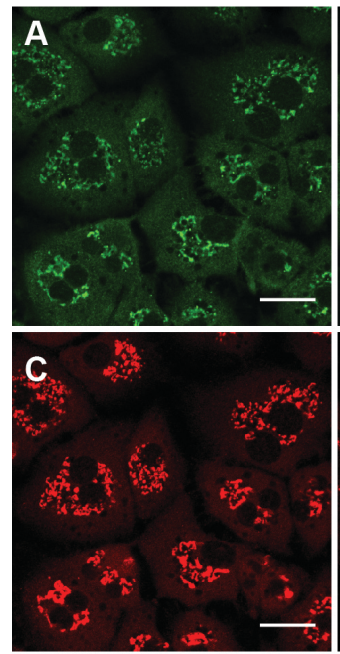

Alb-Cre+

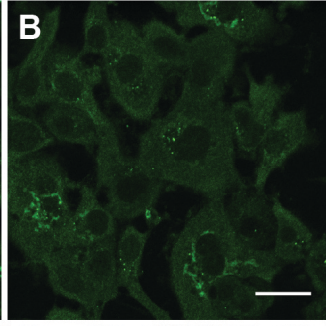

\section{D.}

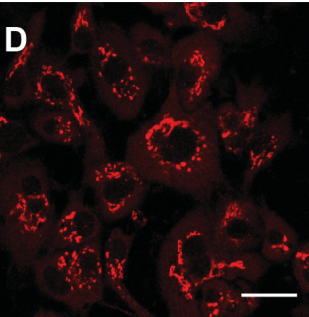

Alb-Cre-
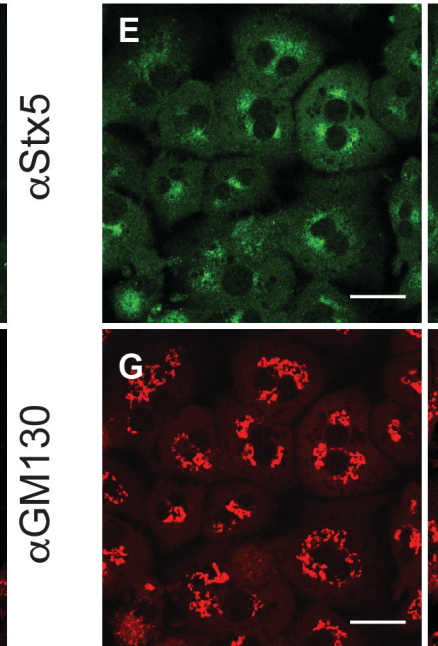

Alb-Cre+

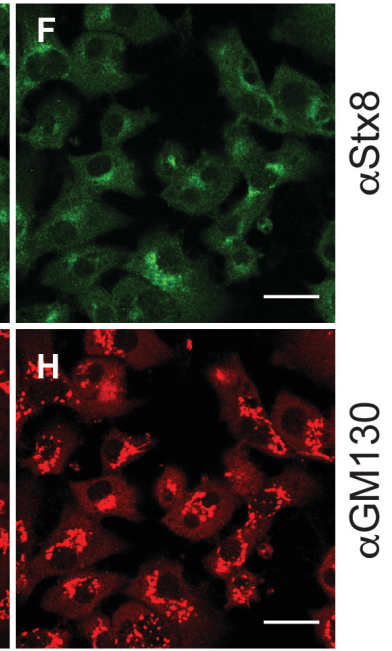

Figure 23: The cellular appearance of Stx 5 was strongly affected in isolated hepatocytes of 6 w old Alb-Cre+ animals.

Isolated hepatocytes of $6 \mathrm{w}$ old animals were subjected to immunofluorescence staining after fixation. Staining was performed for Stx5 (A, B) or Stx8 (E, F). In all cases, a staining for the Golgi protein GM130 was carried out in parallel (C, D, G, H). All images were acquired with a confocal microscope. The scale bar represents $20 \mu \mathrm{m}$. 


\section{Discussion}

The correct insertion of membrane proteins is crucial for the normal function of every cell. For the different types of membrane proteins, different targeting and insertion pathways ensure that the proteins reach their destined membrane. As for the class of TA proteins, one major targeting and insertion route is the mammalian GET pathway. The deletion of individual components of this pathway results in early embryonic lethality in mice, leading to the conclusion that the pathway fulfils essential roles in higher eukaryotes (Mukhopadhyay et al., 2006; Tran et al., 2003). However, the same pathway in yeast is not essential, although it is linked to proteostatic stress (Metz et al., 2006; Schuldiner et al., 2008; Shen et al., 2003). Until now, the reasons behind the indispensability of the pathway in higher eukaryotes are unclear. The in vivo client spectrum of the pathway and its possible connections to the protein quality control machinery of the cell are poorly understood.

To gain more insight into the role of the pathway in vivo and find out about possible substrate dependencies, in this study a mouse model was established in which the pathway was disturbed by deletion of WRB, one part of the heterodimeric receptor of the mammalian GET pathway, in a hepatocyte-specific manner. This knockout results in a substantial liver damage, shown on both macro- and microscopic level. Also on cellular level the knockout influences both, pathway components and TA protein substrates of the pathway. Depending on whether total liver homogenate or isolated hepatocytes were analysed, the results differed. Experiments were performed with mice of two different age groups. I will discuss how the different results obtained may reflect different stages of adaptation to the hepatocyte-specific knockout.

\subsection{Knockout of WRB in hepatocytes leads to substantial liver damage}

So far it was not possible to study the role of the mammalian GET pathway in vivo on a global level. For the pathway components TRC40 and CAML, a global knockout is early embryonic lethal in mice (Mukhopadhyay et al., 2006; Tran et al., 2003). For WRB, this is not yet published but results from our lab suggest that a constitutive knockout of WRB in heart leads to perinatal lethality in mice. The mouse model established for this study displayed a hepatocyte-specific WRB knockout. This was achieved by using the Cre-Lox system, which allows a tissue- or cell-specific deletion of a targeted gene (Orban et al., 1992; Sauer and Henderson, 1990). By expressing the Cre recombinase under the Albumin promoter in a mouse line which carries a WRB allele with the targeting sites for 
the Cre recombinase (LoxP sites) flanking the three middle exons, a hepatocyte-specific knockout of WRB was induced (Postic and Magnuson, 2000; Postic et al., 1999).

Animals with a hepatocyte-specific knockout of WRB were viable, but displayed massive liver damage. In situ, the liver of Alb-Cre+ animals already displayed a strongly damaged phenotype on macroscopic level. The damage was further investigated by histological analysis and blood parameters. Histological analyses were performed to assess any changes on tissue level. Blood parameters were analysed with regard to the levels of the Alanine Transaminase (ALT) and the Aspartate Transaminase (AST). An increase of the serum levels of these enzymes is a typical indicator for liver damage on the cellular level, since they are released from damaged and dying hepatocytes (McClatchey, 2002).

In $6 \mathrm{w}$ old Alb-Cre+ animals, the phenotype on macroscopic level was characterised by a rough surface structure and a change in texture of the liver tissue (Figure 3 ). The further analyses of both blood parameters together with histology suggested a very high level of liver damage at that age. The blood parameters showed a strong increase of both ALT and AST, indicating a high number of damaged hepatocytes (Figure 4). The histology revealed the formation of connective tissue structures, and general change in the cellular organisation of the liver tissue (Figure 5). Connective tissue formation in the liver is a wellknown reaction to liver damage of any kind, leading to liver fibrosis and in the final stages to liver cirrhosis (Friedman, 2000). This process is to current knowledge mainly promoted by stellate cells of the liver. Activation of the stellate cells can happen due to injured hepatocytes and leads to drastic changes in tissue organisation during the response (Friedman, 2000). The high amount of connective tissue present in liver tissue of the $6 \mathrm{w}$ old Alb-Cre+ animals and the changed cellular organisation are therefore concluded to be a pathophysiological response to damaged and dying hepatocytes.

In older animals, the macroscopic change of the liver in Alb-Cre+ animals appeared more drastic than at $6 \mathrm{w}$. The surface of the liver was very rough compared to the appearance in Alb-Cre- animals, and clear nodules were visible. The histological analysis suggested that the nodules were structures containing normal liver tissue encapsulated in connective tissue septa (Figure 6). The levels of ALT and AST in older Alb-Cre+ animals were not as drastically increased as in the $6 \mathrm{w}$ old Alb-Cre+ animals (Figure 4). Taken together, these results suggest that liver damage in the older animals was still present, but not as severe as in the younger animals.

The mouse liver has remarkable regeneration capacities, and a loss of up to $2 / 3$ of the liver mass can be tolerated, and regrowth is possible (Fausto et al., 2006). When comparing the phenotype of the $6 \mathrm{w}$ old animals with the older animals, the decrease in the severity of the liver damage can be explained by constant regeneration of liver tissue. The strong damage in the $6 \mathrm{w}$ old Alb-Cre+ animals is a clear indication that a disturbance 
of the mammalian GET pathway in hepatocytes leads to damage and cell death in these cells. But since a knockout with the Cre recombinase usually never reaches $100 \%$ penetrance, some hepatocytes may evade this fate and can participate in the regeneration process. A closer look at the histology further supports regeneration taking place already in the $6 \mathrm{w}$ old animals. Regeneration in the liver occurs in two distinct steps. First, a cellular hypertrophy takes place, meaning that enlargement of individual cells is promoted to cover for a relatively small loss of liver mass. Upon a high loss of liver mass, additional regeneration by cell division and proliferation takes place, leading to a more or less equal contribution of these two mechanisms to liver regeneration (Miyaoka et al., 2012). The histology in $6 \mathrm{w}$ old Alb-Cre+ animals displayed signs of both mechanisms. Some nuclei appeared to be in the process of mitosis, while at the same time hypertrophic hepatocytes were visible (Figure 5). In older Alb-Cre+ animals, no such markers of liver regeneration were visible in the sections (Figure 6), but elevated levels of ALT and AST in these animals indicate on-going liver damage. Previous studies have shown that fibrosis in the liver can regress to a certain extent (Kisseleva et al., 2012; Taghdouini et al., 2015), which further supports the observation that the amount of connective tissue seemed to decrease with regeneration in the older animals. A positive selection for hepatocytes evading the knockout may contribute to the regeneration. Overall, the different phenotypes observed in $6 \mathrm{w}$ old animals and older animals can be described as acute liver damage in the $6 \mathrm{w}$ old animals and a situation rather resembling chronic liver disease or damage in the older animals.

Furthermore, the transcriptome analysis performed with RNA samples from isolated hepatocytes of $6 \mathrm{w}$ old animals provided additional indications for massive liver damage and fibrosis as well as on-going regeneration at this age. Upon functional annotation clustering of the differentially expressed genes, some of the processes that were highly enriched are involved in the mechanisms of liver fibrosis, while others strongly implemented liver regeneration. Liver fibrosis includes steps like cytokine production and secretion, chemotaxis of stellate cells and leukocyte chemoattraction (Friedman, 2000), and all these processes were represented in the clusters shown in Table 3. On the other hand, the strong enrichment in cell cycle and cell differentiation processes points toward active liver regeneration. Besides this, terms were enriched that are involved in response to wounding and stress, which provides further evidence for the massive liver damage.

Also on single gene level, typical candidate genes involved in fibrosis and regeneration were found. Among the top 50 candidates in Figure 7 are e.g. several collagen genes, and Tgfbi and Sparc. These have been described as typical tissue remodelling and fibrosis genes involved in liver tissue pathology together with other genes not represented in the heatmap, but differentially expressed, such as Loxl2 or Tgfb1 (Nakken et al., 2007). 
Another gene found in the top 50 candidates is the hepatocyte growth factor $(\mathrm{Hgf})$, which is one of the driving forces behind liver regeneration together with other growth factors. One of them, the heparin-binding EGF-like growth factor (HB-EGF) is a key player in liver regeneration (Fausto et al., 2006). HB-EGF is increased in expression as well, though not in the candidates of the top 50 heatmap, similar to other factors involved in liver regeneration. All these factors involved in liver regeneration and fibrosis are shown in Figure 24. The corresponding values can be found in the appendix (Table 9).
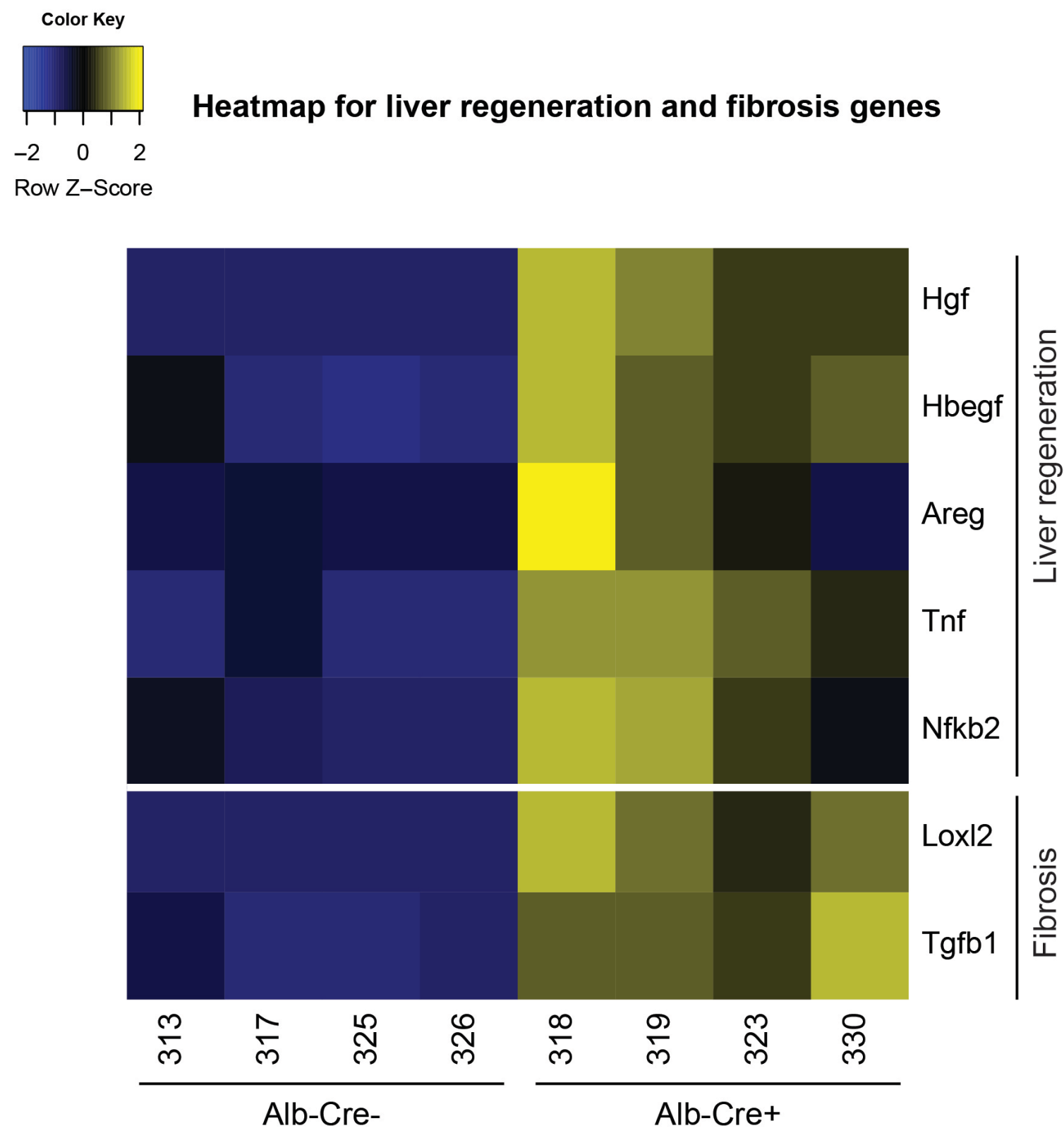

Figure 24: A heatmap for additional genes involved in liver fibrosis and regeneration.

Candidates that showed differential expression in isolated hepatocytes from $6 \mathrm{w}$ old animals and are known to be involved in liver fibrosis and regeneration are summarised in a heatmap. These genes were not among the 50 genes showing the highest differential expression. 
In summary, I was able to show that a hepatocyte-specific knockout of WRB leads to substantial liver damage. This liver damage was observable on macroscopic and microscopic level as well as in specific blood markers. In $6 \mathrm{w}$ old animals, the expression of the Cre recombinase and therefore the deletion of WRB is expected to be at its maximum (Postic and Magnuson, 2000). At this age, this leads to acute liver damage, as shown in the severely increased level of ALT and AST in the blood and in the strong changes observed in the liver tissue. The high regeneration capacities of the murine liver explain the viability of the animals despite the apparent loss of hepatocytes, and why the histological findings and blood parameters in older animals suggest less liver damage with increasing age, resulting in the situation of chronic liver damage. Hepatocytes evading the knockout can either grow in size or eventually proliferate to compensate for the damage.

\subsection{Penetrance of WRB knockout varies strongly in its extent}

The clearly visible liver damage discussed in 4.1 implies that the knockout took place and had a clear effect on the hepatocytes. To prove the knockout, mRNA and steady-state protein levels of WRB were checked in isolated hepatocytes of animals of both age groups. Since other studies have suggested that WRB and CAML can stabilize each other in the membrane (Vilardi et al., 2014), the levels of CAML were assessed as well. In addition, the levels of TRC40 were checked to investigate influences of a WRB knockout on TRC40.

While a decrease of WRB at mRNA level was observed in both age groups, a significant reduction on steady-state protein level was only detected in the isolated hepatocytes of older Alb-Cre+ animals. Interestingly CAML was reduced at steady-state protein level in older Alb-Cre+ animals as well. TRC40 was not affected at protein level in either age group, but was slightly upregulated at mRNA level in the $6 \mathrm{w}$ old animals (cf. Table 4).

The mouse line with the hepatocyte-specific activity of Cre recombinase has been reported to lead to a nearly 100\% effective recombination (according to (Postic et al., 1999) and material available on the jax.org website). The reduction of WRB at mRNA level indicates an active Cre recombinase and successful recombination. Further analysis in $6 \mathrm{w}$ old animals revealed that the level of WRB mRNA reduction differed strongly between individual animals (Figure 8, Figure 9). The results showed that only if a very high reduction of the WRB mRNA level was present, a clear reduction was visible at steady-state protein level (Figure 12). It is a well-described phenomenon that mRNA levels do not necessarily represent protein levels of their expressed protein (Liu et al., 2016). Besides, so far nothing is known about exact expression levels of WRB both at mRNA and steady-state protein level or the stability of either of the molecules. Possible 
explanations for the divergence between mRNA and protein levels of WRB are that WRB protein is very stable, and that WRB mRNA is sufficient in little copy number to lead to a normal expression of WRB. Furthermore, the activation of the Cre recombinase in hepatocytes is not taking place simultaneously in all cells, but rather over time. The liver is the main hematopoietic organ in the mouse foetus and only over time develops to its typical composition with mainly hepatocytes accounting for its mass (Paul et al., 1969; Zaret, 2000). The Albumin promoter driving the Cre recombinase is only active in hepatocytes. Therefore a progressive expression of the Cre recombinase takes place in parallel to differentiation of hepatocytes (Weisend et al., 2009). If WRB expression has already taken place in the precursor cell before the Cre recombinase becomes active and if WRB is a stable protein, the recombination does not necessarily have to influence WRB protein levels immediately. All this can lead to the observed variability in WRB mRNA and protein levels in Alb-Cre+ animals.

In addition to this, the knockout penetrance of a Cre-recombinase never reaches $100 \%$. It is likely that a strong selection for the hepatocytes evading the knockout occurs, eventually leading to a mosaic composition of the liver with knockout and non-knockout hepatocytes in Alb-Cre+ animals. In that case, a constant change in this composition due to loss of hepatocytes followed by proliferation would result in fluctuations of the WRB mRNA and protein levels depending on the ratio of knockout to evaded hepatocytes.

This can explain why the WRB steady-state protein level was significantly reduced in older animals in contrast to $6 \mathrm{w}$ old animals. In older animals the ratio between hepatocytes evading the knockout and WRB knockout hepatocytes still depends on the penetrance of the Cre recombinase and a selection process followed by regeneration and proliferation, which differ from animal to animal.

In addition, the fragility of WRB knockout hepatocytes has to be considered. The isolation process is harsh due to the Collagenase treatment and mechanical shear during the processing steps. The overall impression was that isolated hepatocytes from Alb-Cre+ animals were less viable in culture compared to hepatocytes from Alb-Cre- animals. It is possible that some knockout cells are already lost during the isolation process.

However, if a significant reduction of WRB at steady-state protein level takes place, as observed in some animals at the age of $6 \mathrm{w}$ and in the older animals, the protein level of CAML is decreased as well. This further supports previous findings that the two receptor subunits WRB and CAML stabilize each other in the membrane (Vilardi et al., 2014). For TRC40, the situation is not as clear as for CAML. The TRC40 mRNA level is slightly increased in $6 \mathrm{w}$ old animals, but the mRNA level in older Alb-Cre+ animals and steadystate protein levels in both $6 \mathrm{w}$ old and older Alb-Cre+ animals remained unchanged. Recent findings describe a role for the yeast homologue of TRC40, Get3, as an ATP- 
independent Chaperone under oxidative stress conditions (Voth et al., 2014). A similar role for the mammalian TRC40 has yet to be shown, but since oxidative stress is an important factor in many liver diseases (Cichoż-Lach and Michalak, 2014) and reactive oxygen species (ROS) are involved in fibrosis (Richter and Kietzmann, 2016), it is not unlikely that an increase in ROS could lead to upregulation of TRC40.

Additionally, mRNA and steady-state protein levels of all pathway components were analysed in total liver homogenate to circumvent the hepatocyte isolation process. WRB mRNA was still reduced in $6 \mathrm{w}$ old Alb-Cre+ animals, while CAML mRNA was slightly upregulated in older animals. No further changes at either mRNA or protein level were detected. Although under normal conditions hepatocytes make up $80 \%$ of the liver mass (Paul et al., 1969; Zaret, 2000), the processes involved in liver regeneration after damage can include the attraction of leukocytes via chemoattractants (Friedman, 2000; Lalor et al., 2002). An increase of other cells in the liver could have influenced the analysis performed with total liver homogenate.

\subsection{Substrates show different susceptibility to a disturbed GET pathway}

One of the not fully unravelled aspects of the mammalian GET pathway is its in vivo client spectrum and the question whether certain substrates fully depend on the pathway. The reason why the pathway components are essential in higher eukaryotes is still unknown, but one possible explanation is that a lack of correct targeting for some substrates results in the observed liver damage. In yeast, many of the phenotypes occurring after deleting the GET receptor could be recapitulated by deleting individual TA protein substrates (Schuldiner et al., 2008). The mouse model established in this study provided the opportunity to analyse the effects of a receptor knockout in vivo. For this analysis, I focussed on selected substrates, which included three SNARE proteins (Stx5, Stx6 and Stx8), a protein of the inner nuclear membrane (EMD) and the beta-subunit of the Sec61 translocon. These TA proteins have been previously published as in vitro or in vivo substrates of the mammalian GET pathway (Abell et al., 2007; Pfaff et al., 2016; Stefanovic and Hegde, 2007), or have been shown by experiments in our lab to be clients of the pathway (unpublished). Furthermore, the highly conserved yeast homologue of Stx5, Sed5, is strongly affected in its targeting by deletion of the pathway components in yeast (Schuldiner et al., 2008).

As for the pathway components, effects on the selected substrates were tested in the two age groups previously described. When total liver homogenate was used for the sample preparation, the results differed comparing $6 \mathrm{w}$ old animals to older animals. In $6 \mathrm{w}$ old 
Alb-Cre+ animals, Stx5 showed a significant decrease at steady-state protein level, while it was increased in older Alb-Cre+ animals, as was Stx6. The steady-state protein level of Emerin however was increased in Alb-Cre+ animals of both age groups (Figure 17, Figure 21. As discussed previously, the acute liver damage in $6 \mathrm{w}$ old and the chronic liver damage in older Alb-Cre+ animals along with the regeneration process may have an influence on tissue composition and cellular processes. For Emerin a role has been suggested in regeneration of muscle cells in context with its role as binding partner A-type lamin (Frock et al., 2006; Pekovic and Hutchison, 2008). It is possible that the regeneration and the changed cellular composition lead to the different changes of these proteins.

Upon performing the analysis with isolated hepatocytes, different results were obtained. In older animals displaying chronic liver damage, no significant effect at steady-state protein levels of any substrate were detected in isolated hepatocytes from Alb-Cre+ individuals. On average, effects in isolated hepatocytes of $6 \mathrm{w}$ old animals were only observed in Stx6, which showed a significant decrease at both mRNA and protein level (Figure 18, Figure 19). Interestingly, when analysing individual animals, different results were obtained. In isolated hepatocytes of $6 \mathrm{w}$ old animals that showed a strong reduction of WRB at mRNA and steady-state protein level, Stx5 was affected as well and showed a decreased steady-state protein level (Figure 20). Immunofluorescence performed with isolated hepatocytes from $6 \mathrm{w}$ old animals displayed a clear mistargeting or loss of Stx5 in Alb-Cre+ (Figure 23), whereas Stx5 showed a clear Golgi localisation in Alb-Cre- animals. A third SNARE, Stx8, did not show a significant change in any of the samples. Overall these results suggest that different substrates reacted with a different susceptibility to a disturbed GET pathway.

Both Stx 5 and Stx6 have recently been shown to be affected in their localisation upon TRC40 knockout in $\beta$-cells (Norlin et al., 2016). In the same study, other proteins were not as strongly affected, similar to the results obtained in this study. The reasons for these differences are not yet fully understood. However, results obtained in a collective and collaborative effort to analyse the consequences of WRB knockout in different tissues (performed by Jhon Rivera-Monroy and described here for the purpose of discussion) further support this observation. Using a different mouse model, an inducible cardiomyocyte-specific WRB knockout was realised, and in WRB-deficient cardiomyocytes, Stx5 was the most affected substrate as well. It showed reduced steadystate protein levels and loss of targeting to the Golgi membrane (unpublished data).

One possible model for the different susceptibilities of the TA proteins towards a disturbed GET pathway posits that the TMDs of the substrates have different physico-chemical properties influencing their interaction with different chaperones and defining their target 
mechanism and destination (as reviewed in Borgese and Fasana, 2011). However, as part of the same collaborative project to analyse the client selectivity of the mammalian GET pathway, the differences between Stx5 and Stx8 regarding their TMDs were analysed, and mutagenesis experiments did not deliver any explanation based on the differences in the TMD of the two TA proteins (experiments performed by Dr. Fabio Vilardi and described here for the purpose of discussion). Changing the order of the amino acids in the TMD as well as the hydrophobicity did not alter the observation that Stx5 is more susceptible to a disturbed GET pathway than Stx8 (unpublished data). This supports the idea that some other factors besides the TMD might play a role in the targeting process and explain the differences in how substrates are affected by disturbing the GET pathway. Further experiments performed by Dr. Fabio Vilardi suggest that the observed differences between Stx 5 and Stx 8 are caused by their N-terminal cytosolic domains rather than their TMDs. The cytosolic domain of Stx 5 shows a higher aggregation propensity than the one of Stx8 in vitro, suggesting that not exclusively the properties of the TMD, but also of the $\mathrm{N}$-terminus influence targeting of TA protein substrates.

Interestingly, sequence alignments (Figure 25) show that Stx5 and Stx8 share more sequence identity (appr. 23\%) than Stx5 and Stx6 (appr. 15\%), but still Stx8 was found to be least affected in this study. Just based on the primary sequence of the proteins, there is no explanation for their different behaviour in the Alb-Cre+ animals. This further supports the idea that physico-chemical or structural features may be responsible for the grade of effect on the different substrates. The observed higher aggregation propensity of Stx5 may in vivo present a challenge for the cell, since protein aggregates in the cell can be harmful and need to be resolved or degraded by mechanisms such as autophagy (Glick et al., 2010; Kaur and Debnath, 2015). In yeast it was shown that upon blocking of TA protein targeting to the ER, aggregates of untargeted substrates form in the cytosol (Schuldiner et al., 2008). These observations may provide another explanation for the sensitivity of different substrates towards a disturbed pathway and an influence on the integrity of the cell. If insertion of the TA proteins is hindered, the formation of aggregates can add another stress condition in addition to the lack of correctly inserted TA proteins. How much a cell is affected by a disturbed GET pathway may therefore depend not only on its ability to employ alternative target mechanisms for TA proteins, but also on efficient clearance of aggregated substrates. A so far unravelled connection between the TA protein targeting function and the protein quality control machinery of the cell, mediated by TRC40 may play into this. In yeast, a recent study unveiled a function of Get3, the yeast homologue of TRC40, as an ATP-independent Chaperone under oxidative stress conditions (Voth et al., 2014), and it is possible that in the mammalian system TRC40 can fulfil a similar function. 


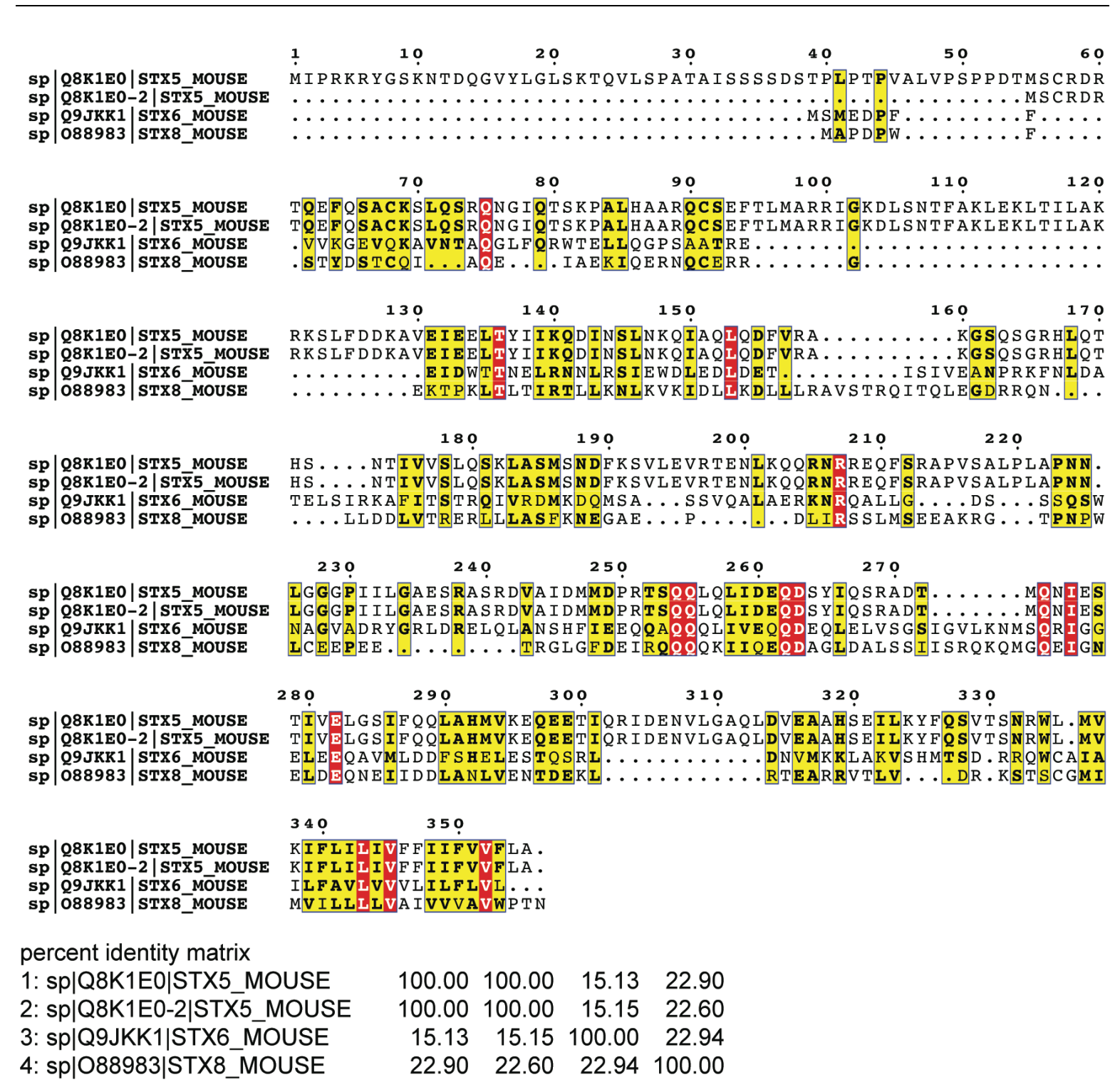

Figure 25: Alignment of Stx5, Stx6 and Stx8.

An alignment of the two Stx5 isoforms, Stx6 and Stx8 was performed with ClustalO (http://www.ebi.ac.uk/Tools/msa/clustalo/). The figure was generated with ESPript.cgi, version ESPript.cgi 4.0.6b. Sequences are given with their UniProt IDs. Percent identity is given in the table in the figure.

However, the reduction of Stx6 on mRNA level can so far not be explained in a satisfactory manner.

Taken together, the results concerning substrate specificity and susceptibility showed that while some substrates were not affected in the Alb-Cre+ animals, others displayed changes at steady-state level of either protein (Stx5) or mRNA and protein (Stx6) in isolated hepatocytes from $6 \mathrm{w}$ old animals. In cells from older animals, these effects were no longer present, presumably due to liver regeneration and stabilisation of the liver. Effects seen in total liver homogenate of animals in both age groups were most likely a result of the underlying regeneration of the liver and a strong mosaic composition of the 
liver regarding knockout cells and cells evading the knockout as well as other infiltrating cell types.

\subsection{Expressed TA proteins in the liver and liver damage}

Functional trafficking and a working ER are crucial for the liver to fulfil its functions in protein synthesis, secretion and metabolic processes. It is not surprising that the disturbance of a pathway that targets proteins to the ER can lead substantial damage even up to cell death. The transcriptome data provides evidence that many TA proteins are expressed in hepatocytes. Table 8 in the appendix contains a subset of TA proteins expressed in hepatocytes of $6 \mathrm{w}$ old animals.

One large group of the expressed TA proteins consists of SNARE proteins such as Stx2, Stx3, Stx5 or Vamp1 and Vamp2 to name a few (see Table 8). Two of them were affected in vivo, namely Stx5 and Stx6. Other TA proteins expressed are e.g. Ube2j1and Ube2j2, which are both Ubiquitin-conjugating enzymes and are involved in ER associated degradation (ERAD) (Araki and Nagata, 2011), or Cytochrome b5, a small hemeprotein acting as an electron carrier, e.g. in Cholesterol synthesis in the ER (Porter, 2015). These versatile functions covered by TA proteins are needed for cell integrity. A decrease in correctly targeted and inserted SNARE proteins may lead to defects in trafficking, and insufficient insertion of TA proteins involved in the ERAD machinery may influence the protein quality control system of the cell. Additionally, defects in lipid metabolism might be a consequence of impaired TA protein targeting. The liver needs all these processes to perform its function, and the strong liver damage might be a pleiotropic effect due to many of these processes being affected. It has been published that ER stress is involved in liver diseases and if the organ cannot cope with the amount of stress, apoptosis is induced (Dara et al., 2011; Malhi and Kaufman, 2011). Besides this, is has been discussed that ER stress might act as a pro-fibrotic stimulus (Tanjore et al., 2013).

Furthermore, inefficient targeting of TA proteins could lead to an accumulation of protein aggregates in the cytosol, which increases the cellular stress. Additionally the results obtained have to be interpreted with regard to the newly identified chaperone function of yeast Get3 (Voth et al., 2014). It is possible that TRC40 plays a similar role in the mammalian system, and can act as a chaperone to either keep uninserted TA proteins in an insertion-competent state, or target them to degradation pathways.

Taken together, the various functions of the TA proteins expressed in the liver and an impairment of the mammalian GET pathway for TA protein targeting can affect the regular liver functions at many different points. This pleiotropic scope of the pathway could explain the observed acute and eventually chronic liver damage in Alb-Cre+ animals. 


\section{Summary and Conclusions}

In this study, a mouse model was established to investigate the role of the mammalian GET pathway in vivo. The Cre-Lox-system was used to realise a hepatocyte-specific knockout of WRB, one subunit of the heterodimeric receptor of the pathway. The consequences of this knockout on the morphological, histological and physiological properties of the liver were characterised. Furthermore, the effect on the expression of the main components of the mammalian GET pathway, WRB, CAML and TRC40, was analysed. In addition, the impact of the hepatocyte-specific knockout on selected TA proteins expressed in hepatocytes was investigated.

I could show that animals with a hepatocyte-specific knockout of WRB were viable and did not exhibit any overall morphological or physiological abnormalities. However, further analysis revealed pronounced signs of liver damage. The morphology and structure of the liver in situ differed severely from control animals and extensive damage was confirmed by histological analysis demonstrating liver fibrosis and elevated plasma levels of the liver damage markers ALT and AST. The phenotype changed from $6 \mathrm{w}$ old animals, where it resembled acute liver damage, to $10 \mathrm{w}$ old animals, where it was consistent with chronic liver damage.

Transcriptome analysis in $6 \mathrm{w}$ old animals revealed both differential expression of genes and an enrichment of functional annotation clusters involved in liver fibrosis and liver regeneration. From this I concluded that the liver was damaged to an extent that led to a loss of hepatocytes and required liver regeneration. Furthermore, a subset of TA proteins expressed in hepatocytes was identified from the transcriptome data.

Analysis of steady-state mRNA and protein levels of the GET pathway components WRB, CAML and TRC40 showed that the penetrance of the WRB knockout in hepatocytes varied. My observations support the notion that the strongly negative or even lethal effects of WRB knockout on hepatocytes eventually caused a selection of cells, which had evaded the knockout. This would result in a mosaic composition of the liver, with a constantly changing ratio of knockout hepatocytes to WRB-expressing cells. However, I observed that even small yet significant reduction in WRB steady-state mRNA and protein levels, lead to a concomitant decrease in the steady-state protein level of CAML, the second receptor subunit of the GET pathway. The protein level of TRC40, the cytosolic targeting component, remained unchanged.

By analysing a selected subset of TA proteins expressed in hepatocytes, I concluded that substrates of the GET pathway vary strongly in their susceptibility towards WRB knockout. The two SNARE proteins Stx5 and Stx6 displayed significant reductions of their steady- 
state protein levels. Additionally, I demonstrated an altered distribution of Stx5 in hepatocytes by immunofluorescence.

In conclusion, this study contributed to gaining deeper insight into the physiological scope and in vivo client selectivity of the mammalian GET pathway. The results indicate that a defect of the mammalian GET pathway in hepatocytes leads to loss of cell integrity and viability. I was able to show that in vivo specific substrates were affected by a WRB knockout while others remained unchanged. The identification of affected and unaffected substrates will enable characterisation of common GET substrate properties and may help in unravelling the client spectrum of the pathway in vivo. Furthermore, the results obtained have to be interpreted in the light of recent findings in yeast, which show a role of the yeast homologue of TRC40, Get3, as an ATP-independent chaperone (Voth et al., 2014). Further research has to be carried out to investigate a role of the mammalian GET pathway in the bigger context of protein quality control additionally to its role in TA protein targeting. 


\section{Bibliography}

Abell, B.M., Pool, M.R., Schlenker, O., Sinning, I., and High, S. (2004). Signal recognition particle mediates post-translational targeting in eukaryotes. Embo J. 23, 2755-2764.

Abell, B.M., Rabu, C., Leznicki, P., Young, J.C., and High, S. (2007). Post-translational integration of tail-anchored proteins is facilitated by defined molecular chaperones. J. Cell. Sci. 120, 1743-1751.

Alberts, B. (2008). Molecular Biology of the Cell (Garland Pub).

Araki, K., and Nagata, K. (2011). Protein folding and quality control in the ER. Cold Spring Harb Perspect Biol 3, a007526.

Baiceanu, A., Mesdom, P., Lagouge, M., and Foufelle, F. (2016). Endoplasmic reticulum proteostasis in hepatic steatosis. Nat Rev Endocrinol.

Barlowe, C.K., and Miller, E.A. (2013). Secretory protein biogenesis and traffic in the early secretory pathway. Genetics 193, 383-410.

Becker, T., Bhushan, S., Jarasch, A., Armache, J.-P., Funes, S., Jossinet, F., Gumbart, J., Mielke, T., Berninghausen, O., Schulten, K., et al. (2009). Structure of monomeric yeast and mammalian Sec61 complexes interacting with the translating ribosome. Science 326, $1369-1373$.

Beckmann, R., Bubeck, D., Grassucci, R., Penczek, P., Verschoor, A., Blobel, G., and Frank, J. (1997). Alignment of conduits for the nascent polypeptide chain in the ribosomeSec61 complex. Science 278, 2123-2126.

Borgese, N., Brambillasca, S., Soffientini, P., Yabal, M., and Makarow, M. (2003). Biogenesis of tail-anchored proteins. Biochem. Soc. Trans. 31, 1238-1242.

Borgese, N., and Fasana, E. (2011). Targeting pathways of C-tail-anchored proteins. Biochim. Biophys. Acta 1808, 937-946.

Bozkurt, G., Stjepanovic, G., Vilardi, F., Amlacher, S., Wild, K., Bange, G., Favaloro, V., Rippe, K., Hurt, E., Dobberstein, B., et al. (2009). Structural insights into tail-anchored protein binding and membrane insertion by Get3. Proc. Natl. Acad. Sci. U.S.a. 106, 21131-21136.

Bram, R.J., and Crabtree, G.R. (1994). Calcium signalling in T cells stimulated by a cyclophilin B-binding protein. Nature 371, 355-358.

Brambillasca, S., Yabal, M., Makarow, M., and Borgese, N. (2006). Unassisted translocation of large polypeptide domains across phospholipid bilayers. J. Cell Biol. 175, 767-777.

Brambillasca, S., Yabal, M., Soffientini, P., Stefanovic, S., Makarow, M., Hegde, R.S., and Borgese, N. (2005). Transmembrane topogenesis of a tail-anchored protein is modulated by membrane lipid composition. Embo J. 24, 2533-2542.

Chang, Y.-W., Chuang, Y.-C., Ho, Y.-C., Cheng, M.-Y., Sun, Y.-J., Hsiao, C.-D., and Wang, C. (2010). Crystal structure of Get4-Get5 complex and its interactions with Sgt2, Get3, and Ydj1. J. Biol. Chem. 285, 9962-9970. 
Chartron, J.W., Gonzalez, G.M., and Clemons, W.M. (2011). A structural model of the Sgt2 protein and its interactions with chaperones and the Get4/Get5 complex. J. Biol. Chem. 286, 34325-34334.

Chartron, J.W., Suloway, C.J.M., Zaslaver, M., and Clemons, W.M. (2010). Structural characterization of the Get4/Get5 complex and its interaction with Get3. Proc. Natl. Acad. Sci. U.S.a. 107, 12127-12132.

Chartron, J.W., VanderVelde, D.G., and Clemons, W.M. (2012a). Structures of the Sgt2/SGTA dimerization domain with the Get5/UBL4A UBL domain reveal an interaction that forms a conserved dynamic interface. Cell Rep 2, 1620-1632.

Chartron, J.W., VanderVelde, D.G., Rao, M., and Clemons, W.M. (2012b). Get5 carboxylterminal domain is a novel dimerization motif that tethers an extended Get4/Get5 complex. J. Biol. Chem. 287, 8310-8317.

Chou, K.-C., and Shen, H.-B. (2007). MemType-2L: a web server for predicting membrane proteins and their types by incorporating evolution information through Pse-PSSM. Biochem. Biophys. Res. Commun. 360, 339-345.

Cichoż-Lach, H., and Michalak, A. (2014). Oxidative stress as a crucial factor in liver diseases. World J. Gastroenterol. 20, 8082-8091.

Colombo, S.F., Longhi, R., and Borgese, N. (2009). The role of cytosolic proteins in the insertion of tail-anchored proteins into phospholipid bilayers. J. Cell. Sci. 122, 2383-2392.

Connolly, T., and Gilmore, R. (1989). The signal recognition particle receptor mediates the GTP-dependent displacement of SRP from the signal sequence of the nascent polypeptide. Cell 57, 599-610.

Copic, A., Dorrington, M., Pagant, S., Barry, J., Lee, M.C.S., Singh, I., Hartman, J.L., and Miller, E.A. (2009). Genomewide analysis reveals novel pathways affecting endoplasmic reticulum homeostasis, protein modification and quality control. Genetics 182, 757-769.

Cross, B.C.S., Sinning, I., Luirink, J., and High, S. (2009). Delivering proteins for export from the cytosol. Nat Rev Mol Cell Biol 10, 255-264.

Dara, L., Ji, C., and Kaplowitz, N. (2011). The contribution of endoplasmic reticulum stress to liver diseases. Hepatology 53, 1752-1763.

Denic, V., Dötsch, V., and Sinning, I. (2013). Endoplasmic reticulum targeting and insertion of tail-anchored membrane proteins by the GET pathway. Cold Spring Harb Perspect Biol 5, a013334.

Duncan, S.A. (2000). Transcriptional regulation of liver development. Dev. Dyn. 219, 131142.

Edgar, C.E., Lindquist, L.D., McKean, D.L., Strasser, A., and Bram, R.J. (2010). CAML regulates Bim-dependent thymocyte death. Cell Death Differ. 17, 1566-1576.

Egeo, A., Mazzocco, M., Sotgia, F., Arrigo, P., Oliva, R., Bergonòn, S., Nizetic, D., Rasore-Quartino, A., and Scartezzini, P. (1998). Identification and characterization of a new human cDNA from chromosome 21q22.3 encoding a basic nuclear protein. Hum. Genet. 102, 289-293. 
Ernst, R., Claessen, J.H.L., Mueller, B., Sanyal, S., Spooner, E., van der Veen, A.G., Kirak, O., Schlieker, C.D., Weihofen, W.A., and Ploegh, H.L. (2011). Enzymatic blockade of the ubiquitin-proteasome pathway. PLoS Biol. 8, e1000605.

Fausto, N., Campbell, J.S., and Riehle, K.J. (2006). Liver regeneration. Hepatology 43, S45-S53.

Friedman, S.L. (2000). Molecular regulation of hepatic fibrosis, an integrated cellular response to tissue injury. J. Biol. Chem. 275, 2247-2250.

Frock, R.L., Kudlow, B.A., Evans, A.M., Jameson, S.A., Hauschka, S.D., and Kennedy, B.K. (2006). Lamin A/C and emerin are critical for skeletal muscle satellite cell differentiation. Genes \& Development 20, 486-500.

Gilmore, R., Blobel, G., and Walter, P. (1982a). Protein translocation across the endoplasmic reticulum. I. Detection in the microsomal membrane of a receptor for the signal recognition particle. J. Cell Biol. 95, 463-469.

Gilmore, R., Walter, P., and Blobel, G. (1982b). Protein translocation across the endoplasmic reticulum. II. Isolation and characterization of the signal recognition particle receptor. J. Cell Biol. 95, 470-477.

Glick, D., Barth, S., and Macleod, K.F. (2010). Autophagy: cellular and molecular mechanisms. J. Pathol. 221, 3-12.

Halic, M., Becker, T., Pool, M.R., Spahn, C.M.T., Grassucci, R.A., Frank, J., and Beckmann, R. (2004). Structure of the signal recognition particle interacting with the elongation-arrested ribosome. Nature 427, 808-814.

Hartmann, E., Rapoport, T.A., and Lodish, H.F. (1989). Predicting the orientation of eukaryotic membrane-spanning proteins. Proc. Natl. Acad. Sci. U.S.a. 86, 5786-5790.

Hay, J.C., Klumperman, J., Oorschot, V., Steegmaier, M., Kuo, C.S., and Scheller, R.H. (1998). Localization, dynamics, and protein interactions reveal distinct roles for ER and Golgi SNAREs. J. Cell Biol. 141, 1489-1502.

Heijne, von, G., and Gavel, Y. (1988). Topogenic signals in integral membrane proteins. Eur. J. Biochem. 174, 671-678.

Hessa, T., Sharma, A., Mariappan, M., Eshleman, H.D., Gutierrez, E., and Hegde, R.S. (2011). Protein targeting and degradation are coupled for elimination of mislocalized proteins. Nature 475, 394-397.

Hu, Z., Potthoff, B., Hollenberg, C.P., and Ramezani-Rad, M. (2006). Mdy2, a ubiquitinlike (UBL)-domain protein, is required for efficient mating in Saccharomyces cerevisiae. J. Cell. Sci. 119, 326-338.

Hui, N., Nakamura, N., Sönnichsen, B., Shima, D.T., Nilsson, T., and Warren, G. (1997). An isoform of the Golgi t-SNARE, syntaxin 5 , with an endoplasmic reticulum retrieval signal. Mol. Biol. Cell 8, 1777-1787.

Jahn, R., and Scheller, R.H. (2006). SNAREs--engines for membrane fusion. Nat Rev Mol Cell Biol 7, 631-643.

Jonikas, M.C., Collins, S.R., Denic, V., Oh, E., Quan, E.M., Schmid, V., Weibezahn, J., 
Schwappach, B., Walter, P., Weissman, J.S., et al. (2009). Comprehensive characterization of genes required for protein folding in the endoplasmic reticulum. Science 323, 1693-1697.

Kalbfleisch, T., Cambon, A., and Wattenberg, B.W. (2007). A bioinformatics approach to identifying tail-anchored proteins in the human genome. Traffic 8, 1687-1694.

Kalies, K.U., Görlich, D., and Rapoport, T.A. (1994). Binding of ribosomes to the rough endoplasmic reticulum mediated by the Sec61p-complex. J. Cell Biol. 126, 925-934.

Kaur, J., and Debnath, J. (2015). Autophagy at the crossroads of catabolism and anabolism. Nat Rev Mol Cell Biol 16, 461-472.

Keenan, R.J., Freymann, D.M., Walter, P., and Stroud, R.M. (1998). Crystal structure of the signal sequence binding subunit of the signal recognition particle. Cell 94, 181-191.

Kisseleva, T., Cong, M., Paik, Y., Scholten, D., Jiang, C., Benner, C., Iwaisako, K., MooreMorris, T., Scott, B., Tsukamoto, H., et al. (2012). Myofibroblasts revert to an inactive phenotype during regression of liver fibrosis. Proc. Natl. Acad. Sci. U.S.a. 109, 94489453.

Kmieć, Z. (2001). Cooperation of liver cells in health and disease. Adv Anat Embryol Cell Biol 161, III-XIII-1-151.

Kutay, U., Ahnert-Hilger, G., Hartmann, E., Wiedenmann, B., and Rapoport, T.A. (1995). Transport route for synaptobrevin via a novel pathway of insertion into the endoplasmic reticulum membrane. Embo J. 14, 217-223.

Kutay, U., Hartmann, E., and Rapoport, T.A. (1993). A class of membrane proteins with a C-terminal anchor. Trends in Cell Biology 3, 72-75.

Lalor, P.F., Shields, P., Grant, A., and Adams, D.H. (2002). Recruitment of lymphocytes to the human liver. Immunol. Cell Biol. 80, 52-64.

Leznicki, P., and High, S. (2012). SGTA antagonizes BAG6-mediated protein triage. Proc. Natl. Acad. Sci. U.S.a. 109, 19214-19219.

Leznicki, P., Clancy, A., Schwappach, B., and High, S. (2010). Bat3 promotes the membrane integration of tail-anchored proteins. J. Cell. Sci. 123, 2170-2178.

Leznicki, P., Roebuck, Q.P., Wunderley, L., Clancy, A., Krysztofinska, E.M., Isaacson, R.L., Warwicker, J., Schwappach, B., and High, S. (2013). The association of BAG6 with SGTA and tail-anchored proteins. PLoS ONE 8, e59590.

Leznicki, P., Warwicker, J., and High, S. (2011). A biochemical analysis of the constraints of tail-anchored protein biogenesis. Biochem. J. 436, 719-727.

Liou, S.-T., and Wang, C. (2005). Small glutamine-rich tetratricopeptide repeat-containing protein is composed of three structural units with distinct functions. Arch. Biochem. Biophys. 435, 253-263.

Liou, S.-T., Cheng, M.-Y., and Wang, C. (2007). SGT2 and MDY2 interact with molecular chaperone YDJ1 in Saccharomyces cerevisiae. Cell Stress Chaperones 12, 59-70.

Liu, Y., Beyer, A., and Aebersold, R. (2016). On the Dependency of Cellular Protein Levels on mRNA Abundance. Cell 165, 535-550. 
Malhi, H., and Kaufman, R.J. (2011). Endoplasmic reticulum stress in liver disease. J. Hepatol. 54, 795-809.

Manilal, S., Nguyen, T.M., and Morris, G.E. (1998). Colocalization of emerin and lamins in interphase nuclei and changes during mitosis. Biochem. Biophys. Res. Commun. 249, 643-647.

Mariappan, M., Li, X., Stefanovic, S., Sharma, A., Mateja, A., Keenan, R.J., and Hegde, R.S. (2010). A ribosome-associating factor chaperones tail-anchored membrane proteins. Nature 466, 1120-1124.

Mariappan, M., Mateja, A., Dobosz, M., Bove, E., Hegde, R.S., and Keenan, R.J. (2011). The mechanism of membrane-associated steps in tail-anchored protein insertion. Nature 477, 61-66.

Marra, P., Maffucci, T., Daniele, T., Tullio, G.D., Ikehara, Y., Chan, E.K., Luini, A., Beznoussenko, G., Mironov, A., and De Matteis, M.A. (2001). The GM130 and GRASP65 Golgi proteins cycle through and define a subdomain of the intermediate compartment. Nat. Cell Biol. 3, 1101-1113.

Mateja, A., Szlachcic, A., Downing, M.E., Dobosz, M., Mariappan, M., Hegde, R.S., and Keenan, R.J. (2009). The structural basis of tail-anchored membrane protein recognition by Get3. Nature 461, 361-366.

McClatchey, K.D. (2002). Clinical Laboratory Medicine (Lippincott Williams \& Wilkins).

Mellman, I., and Warren, G. (2000). The road taken: past and future foundations of membrane traffic. Cell 100, 99-112.

Metz, J., Wächter, A., Schmidt, B., Bujnicki, J.M., and Schwappach, B. (2006). The yeast Arr4p ATPase binds the chloride transporter Gef1p when copper is available in the cytosol. J. Biol. Chem. 281, 410-417.

Mikkola, H.K.A., and Orkin, S.H. (2006). The journey of developing hematopoietic stem cells. Development 133, 3733-3744.

Miller, J.D., Tajima, S., Lauffer, L., and Walter, P. (1995). The beta subunit of the signal recognition particle receptor is a transmembrane GTPase that anchors the alpha subunit, a peripheral membrane GTPase, to the endoplasmic reticulum membrane. J. Cell Biol. 128, 273-282.

Miller, J.D., Wilhelm, H., Gierasch, L., Gilmore, R., and Walter, P. (1993). GTP binding and hydrolysis by the signal recognition particle during initiation of protein translocation. Nature 366, 351-354.

Minami, R., Hayakawa, A., Kagawa, H., Yanagi, Y., Yokosawa, H., and Kawahara, H. (2010). BAG-6 is essential for selective elimination of defective proteasomal substrates. J. Cell Biol. 190, 637-650.

Miyaoka, Y., Ebato, K., Kato, H., Arakawa, S., Shimizu, S., and Miyajima, A. (2012). Hypertrophy and Unconventional Cell Division of Hepatocytes Underlie Liver Regeneration. Curbio 22, 1166-1175.

Montoya, G., Svensson, C., Luirink, J., and Sinning, I. (1997). Crystal structure of the NG domain from the signal-recognition particle receptor FtsY. Nature 385, 365-368. 
Mothes, W., Prehn, S., and Rapoport, T.A. (1994). Systematic probing of the environment of a translocating secretory protein during translocation through the ER membrane. Embo J. 13, 3973-3982.

Mukhopadhyay, R., Ho, Y.-S., Swiatek, P.J., Rosen, B.P., and Bhattacharjee, H. (2006). Targeted disruption of the mouse Asna1 gene results in embryonic lethality. FEBS Lett. 580, 3889-3894.

Murata, K., Degmetich, S., Kinoshita, M., and Shimada, E. (2009). Expression of the congenital heart disease $5 /$ tryptophan rich basic protein homologue gene during heart development in medaka fish, Oryzias latipes. Dev. Growth Differ. 51, 95-107.

Nakken, K.E., Nygård, S., Haaland, T., Berge, K.E., Arnkvaern, K., Ødegaard, A., Labori, K.J., and Raeder, M.G. (2007). Multiple inflammatory-, tissue remodelling- and fibrosis genes are differentially transcribed in the livers of Abcb4 (-/ - ) mice harbouring chronic cholangitis. Scand. J. Gastroenterol. 42, 1245-1255.

Norlin, S., Parekh, V.S., Naredi, P., and Edlund, H. (2016). Asna1/TRC40 Controls $\beta$-Cell Function and Endoplasmic Reticulum Homeostasis by Ensuring Retrograde Transport. Diabetes 65, 110-119.

O'Shea, R.S., Dasarathy, S., and McCullough, A.J. (2010). Alcoholic liver disease. Am. J. Gastroenterol. 105, 14-32-quiz33.

Orban, P.C., Chui, D., and Marth, J.D. (1992). Tissue- and site-specific DNA recombination in transgenic mice. Proc. Natl. Acad. Sci. U.S.a. 89, 6861-6865.

Paul, J., Conkle, D., and Freshney, R.I. (1969). Erythropoietic cell population changes during the hepatic phase of erythropoiesis in the foetal mouse. Cell Proliferation.

Pekovic, V., and Hutchison, C.J. (2008). Adult stem cell maintenance and tissue regeneration in the ageing context: the role for A-type lamins as intrinsic modulators of ageing in adult stem cells and their niches. J. Anat. 213, 5-25.

Pfaff, J., Rivera Monroy, J., Jamieson, C., Rajanala, K., Vilardi, F., Schwappach, B., and Kehlenbach, R.H. (2016). Emery-Dreifuss muscular dystrophy mutations impair TRC40mediated targeting of emerin to the inner nuclear membrane. J. Cell. Sci. 129, 502-516.

Porter, T.D. (2015). Electron Transfer Pathways in Cholesterol Synthesis. Lipids 50, 927936.

Postic, C., and Magnuson, M.A. (2000). DNA excision in liver by an albumin-Cre transgene occurs progressively with age. Genesis 26, 149-150.

Postic, C., Shiota, M., Niswender, K.D., Jetton, T.L., Chen, Y., Moates, J.M., Shelton, K.D., Lindner, J., Cherrington, A.D., and Magnuson, M.A. (1999). Dual roles for glucokinase in glucose homeostasis as determined by liver and pancreatic beta cellspecific gene knock-outs using Cre recombinase. J. Biol. Chem. 274, 305-315.

Powell, L.W., Seckington, R.C., and Deugnier, Y. (2016). Haemochromatosis. Lancet 388, 706-716.

Powis, K., Schrul, B., Tienson, H., Gostimskaya, I., Breker, M., High, S., Schuldiner, M., Jakob, U., and Schwappach, B. (2013). Get3 is a holdase chaperone and moves to deposition sites for aggregated proteins when membrane targeting is blocked. J. Cell. Sci. 
$126,473-483$.

Prinz, A., Behrens, C., Rapoport, T.A., Hartmann, E., and Kalies, K.U. (2000a).

Evolutionarily conserved binding of ribosomes to the translocation channel via the large ribosomal RNA. Embo J. 19, 1900-1906.

Prinz, A., Hartmann, E., and Kalies, K.U. (2000b). Sec61p is the main ribosome receptor in the endoplasmic reticulum of Saccharomyces cerevisiae. Biol. Chem. 381, 1025-1029.

Rabu, C., Wipf, P., Brodsky, J.L., and High, S. (2008). A precursor-specific role for $\mathrm{Hsp} 40 / \mathrm{Hsc70}$ during tail-anchored protein integration at the endoplasmic reticulum. J. Biol. Chem. 283, 27504-27513.

Richter, K., and Kietzmann, T. (2016). Reactive oxygen species and fibrosis: further evidence of a significant liaison. Cell Tissue Res.

Rosendal, K.R., Wild, K., Montoya, G., and Sinning, I. (2003). Crystal structure of the complete core of archaeal signal recognition particle and implications for interdomain communication. Proc. Natl. Acad. Sci. U.S.a. 100, 14701-14706.

Sauer, B., and Henderson, N. (1990). Targeted insertion of exogenous DNA into the eukaryotic genome by the Cre recombinase. New Biol. 2, 441-449.

Schuldiner, M., Collins, S.R., Thompson, N.J., Denic, V., Bhamidipati, A., Punna, T., Ihmels, J., Andrews, B., Boone, C., Greenblatt, J.F., et al. (2005). Exploration of the function and organization of the yeast early secretory pathway through an epistatic miniarray profile. Cell 123, 507-519.

Schuldiner, M., Metz, J., Schmid, V., Denic, V., Rakwalska, M., Schmitt, H.D., Schwappach, B., and Weissman, J.S. (2008). The GET complex mediates insertion of tailanchored proteins into the ER membrane. Cell 134, 634-645.

Shen, J., Hsu, C.-M., Kang, B.-K., Rosen, B.P., and Bhattacharjee, H. (2003). The Saccharomyces cerevisiae Arr $4 p$ is involved in metal and heat tolerance. Biometals 16, 369-378.

Simon, A.C., Simpson, P.J., Goldstone, R.M., Krysztofinska, E.M., Murray, J.W., High, S., and Isaacson, R.L. (2013). Structure of the Sgt2/Get5 complex provides insights into GET-mediated targeting of tail-anchored membrane proteins. Proc. Natl. Acad. Sci. U.S.a. $110,1327-1332$.

Simpson, P.J., Schwappach, B., Dohlman, H.G., and Isaacson, R.L. (2010). Structures of Get3, Get4, and Get5 provide new models for TA membrane protein targeting. Structure 18, 897-902.

Stefanovic, S., and Hegde, R.S. (2007). Identification of a targeting factor for posttranslational membrane protein insertion into the ER. Cell 128, 1147-1159.

Stefer, S., Reitz, S., Wang, F., Wild, K., Pang, Y.-Y., Schwarz, D., Bomke, J., Hein, C., Löhr, F., Bernhard, F., et al. (2011). Structural basis for tail-anchored membrane protein biogenesis by the Get3-receptor complex. Science 333, 758-762.

Suloway, C.J.M., Chartron, J.W., Zaslaver, M., and Clemons, W.M. (2009). Model for eukaryotic tail-anchored protein binding based on the structure of Get3. Proc. Natl. Acad. Sci. U.S.a. 106, 14849-14854. 
Taghdouini, El, A., Najimi, M., Sancho-Bru, P., Sokal, E., and van Grunsven, L.A. (2015). In vitro reversion of activated primary human hepatic stellate cells. Fibrogenesis Tissue Repair 8, 14.

Tajima, S., Lauffer, L., Rath, V.L., and Walter, P. (1986). The signal recognition particle receptor is a complex that contains two distinct polypeptide chains. J. Cell Biol. 103, 1167-1178.

Tanjore, H., Lawson, W.E., and Blackwell, T.S. (2013). Endoplasmic reticulum stress as a pro-fibrotic stimulus. Biochim. Biophys. Acta 1832, 940-947.

Tran, D.D., Russell, H.R., Sutor, S.L., van Deursen, J., and Bram, R.J. (2003). CAML is required for efficient EGF receptor recycling. Dev. Cell 5, 245-256.

van Meer, G., Voelker, D.R., and Feigenson, G.W. (2008). Membrane lipids: where they are and how they behave. Nat Rev Mol Cell Biol 9, 112-124.

Vilardi, F., Lorenz, H., and Dobberstein, B. (2011). WRB is the receptor for TRC40/Asna1mediated insertion of tail-anchored proteins into the ER membrane. J. Cell. Sci. 124, 1301-1307.

Vilardi, F., Stephan, M., Clancy, A., Janshoff, A., and Schwappach, B. (2014). WRB and CAML are necessary and sufficient to mediate tail-anchored protein targeting to the ER membrane. PLoS ONE 9, e85033.

Vogl, C., Panou, I., Yamanbaeva, G., Wichmann, C., Mangosing, S.J., Vilardi, F., Indzhykulian, A.A., Pangršič, T., Santarelli, R., Rodriguez-Ballesteros, M., et al. (2016). Tryptophan-rich basic protein (WRB) mediates insertion of the tail-anchored protein otoferlin and is required for hair cell exocytosis and hearing. Embo J.

Voth, W., Schick, M., Gates, S., Li, S., Vilardi, F., Gostimskaya, I., Southworth, D.R., Schwappach, B., and Jakob, U. (2014). The protein targeting factor Get3 functions as ATP-independent chaperone under oxidative stress conditions. Mol. Cell 56, 116-127.

Wang, F., Brown, E.C., Mak, G., Zhuang, J., and Denic, V. (2010). A chaperone cascade sorts proteins for posttranslational membrane insertion into the endoplasmic reticulum. Mol. Cell 40, 159-171.

Wang, F., Chan, C., Weir, N.R., and Denic, V. (2014). The Get1/2 transmembrane complex is an endoplasmic-reticulum membrane protein insertase. Nature 512, 441-444.

Wang, L.S., D'Souza, L.S., and Jacobson, I.M. (2016). Hepatitis C-A clinical review. J. Med. Virol. 88, 1844-1855.

Wang, Q., Liu, Y., Soetandyo, N., Baek, K., Hegde, R., and Ye, Y. (2011). A ubiquitin ligase-associated chaperone holdase maintains polypeptides in soluble states for proteasome degradation. Mol. Cell 42, 758-770.

Weisend, C.M., Kundert, J.A., Suvorova, E.S., Prigge, J.R., and Schmidt, E.E. (2009). Cre activity in fetal albCre mouse hepatocytes: Utility for developmental studies. Genesis 47, 789-792.

Xu, Y., Cai, M., Yang, Y., Huang, L., and Ye, Y. (2012). SGTA recognizes a noncanonical ubiquitin-like domain in the Bag6-Ubl4A-Trc35 complex to promote endoplasmic reticulum-associated degradation. Cell Rep 2, 1633-1644. 
Yamamoto, Y., and Sakisaka, T. (2012). Molecular machinery for insertion of tailanchored membrane proteins into the endoplasmic reticulum membrane in mammalian cells. Mol. Cell 48, 387-397.

Zaret, K.S. (2000). Liver specification and early morphogenesis. Mech. Dev. 92, 83-88. 


\section{$7 \quad$ Appendix}

Table 6: List of all the animals appearing in this thesis.

All animals used in this thesis are listed with their number, sex and genotype. The age given is the age at the point of sacrifice. For Western Blot and RT-qPCR it is indicated whether isolated hepatocytes (cells) or total liver homogenate (hmg) was used. TA, transcriptome analysis.

\begin{tabular}{|c|c|c|c|c|c|c|c|c|c|}
\hline Mouse \# & Sex & Genotype & Age & $\begin{array}{c}\text { Western } \\
\text { Blot }\end{array}$ & RT-qPCR & TA & IF & Histology & $\begin{array}{l}\text { Blood } \\
\text { analysis }\end{array}$ \\
\hline 92 & $f$ & Alb-Cre- & $15 w$ & & cells & & & & \\
\hline 94 & $\mathrm{~m}$ & Alb-Cre+ & $15 w$ & & cells & & & & \\
\hline 95 & $\mathrm{~m}$ & Alb-Cre- & $15 w$ & & cells & & & & \\
\hline 98 & f & Alb-Cre+ & $14 w$ & & & & & $x$ & $x$ \\
\hline 100 & $f$ & Alb-Cre- & $14 w$ & & & & & $x$ & $x$ \\
\hline 103 & $\mathrm{~m}$ & Alb-Cre- & $30 w$ & & & & & & $x$ \\
\hline 104 & $\mathrm{~m}$ & Alb-Cre+ & $13 w$ & cells & cells & & & & \\
\hline 105 & $\mathrm{~m}$ & Alb-Cre- & $30 w$ & & & & & & $x$ \\
\hline 106 & $m$ & Alb-Cre- & $13 w$ & cells & & & & & \\
\hline 107 & $f$ & Alb-Cre+ & $11 w$ & & & & & $x$ & $x$ \\
\hline 108 & $f$ & Alb-Cre+ & $11 w$ & & & & & $x$ & $x$ \\
\hline 110 & $f$ & Alb-Cre+ & $11 w$ & & cells & & & & \\
\hline 111 & $f$ & Alb-Cre- & $11 w$ & & & & & $x$ & $x$ \\
\hline 112 & $\mathrm{~m}$ & Alb-Cre- & $11 w$ & cells & cells & & & & \\
\hline 113 & $\mathrm{~m}$ & Alb-Cre+ & $11 w$ & & cells & & & & \\
\hline 114 & $\mathrm{~m}$ & Alb-Cre- & $11 w$ & cells & & & & & \\
\hline 115 & $\mathrm{~m}$ & Alb-Cre- & $29 w$ & & & & & & $x$ \\
\hline 116 & $\mathrm{~m}$ & Alb-Cre- & $11 w$ & cells & cells & & & & \\
\hline 117 & $f$ & Alb-Cre+ & $12 w$ & cells & & & & & \\
\hline 118 & $f$ & Alb-Cre+ & $12 w$ & cells & & & & & \\
\hline 119 & $f$ & Alb-Cre+ & $12 w$ & cells & & & & & \\
\hline 123 & $\mathrm{~m}$ & Alb-Cre+ & $12 w$ & cells & & & & & \\
\hline 131 & $\mathrm{~m}$ & Alb-Cre- & $11 w$ & cells & & & & & \\
\hline 132 & $\mathrm{~m}$ & Alb-Cre+ & $14 w$ & & & & & & $x$ \\
\hline 133 & $\mathrm{~m}$ & Alb-Cre+ & $14 w$ & & & & & & $x$ \\
\hline 138 & $f$ & Alb-Cre- & $14 w$ & $\mathrm{hmg}$ & $\mathrm{hmg}$ & & & & $x$ \\
\hline 139 & $f$ & Alb-Cre+ & $14 w$ & $\mathrm{hmg}$ & $\mathrm{hmg}$ & & & & \\
\hline 141 & f & Alb-Cre- & $12 w$ & $\mathrm{hmg}$ & $\mathrm{hmg}$ & & & & $x$ \\
\hline 142 & $f$ & Alb-Cre+ & $12 w$ & $\mathrm{hmg}$ & $\mathrm{hmg}$ & & & & $x$ \\
\hline
\end{tabular}




\begin{tabular}{|c|c|c|c|c|c|c|c|c|c|}
\hline 146 & $\mathrm{~m}$ & Alb-Cre+ & $12 w$ & & & & & & $x$ \\
\hline 174 & $\mathrm{~m}$ & Alb-Cre- & $12 w$ & $\mathrm{hmg}$ & $\mathrm{hmg}$ & & & & \\
\hline 175 & $\mathrm{~m}$ & Alb-Cre+ & $12 w$ & $\mathrm{hmg}$ & $\mathrm{hmg}$ & & & & \\
\hline 176 & $m$ & Alb-Cre+ & $12 w$ & $\mathrm{hmg}$ & $\mathrm{hmg}$ & & & & \\
\hline 177 & $\mathrm{~m}$ & Alb-Cre+ & $12 w$ & $\mathrm{hmg}$ & hmg & & & & \\
\hline 178 & $\mathrm{~m}$ & Alb-Cre- & $12 w$ & $\mathrm{hmg}$ & $\mathrm{hmg}$ & & & & \\
\hline 179 & $\mathrm{~m}$ & Alb-Cre- & $12 w$ & $\mathrm{hmg}$ & $\mathrm{hmg}$ & & & & \\
\hline 208 & $f$ & Alb-Cre+ & $6 w$ & $\mathrm{hmg}$ & $\mathrm{hmg}$ & & & $x$ & \\
\hline 209 & f & Alb-Cre+ & $6 w$ & $\mathrm{hmg}$ & $\mathrm{hmg}$ & & & $x$ & \\
\hline 210 & $f$ & Alb-Cre- & $6 w$ & $\mathrm{hmg}$ & $\mathrm{hmg}$ & & & $x$ & \\
\hline 211 & $\mathrm{~m}$ & Alb-Cre+ & $6 w$ & $\mathrm{hmg}$ & $\mathrm{hmg}$ & & & $x$ & \\
\hline 212 & $\mathrm{~m}$ & Alb-Cre- & $6 w$ & $\mathrm{hmg}$ & $\mathrm{hmg}$ & & & $x$ & \\
\hline 213 & $\mathrm{~m}$ & Alb-Cre- & $6 w$ & $\mathrm{hmg}$ & $\mathrm{hmg}$ & & & $x$ & \\
\hline 229 & $f$ & Alb-Cre- & $6 w$ & & & & & & $x$ \\
\hline 230 & $f$ & Alb-Cre- & $6 w$ & & & & & & $x$ \\
\hline 231 & f & Alb-Cre+ & $6 w$ & & & & & & $x$ \\
\hline 232 & $f$ & Alb-Cre+ & $6 w$ & & & & & & $x$ \\
\hline 233 & $f$ & Alb-Cre+ & $6 w$ & & & & & & $x$ \\
\hline 234 & $\mathrm{~m}$ & Alb-Cre- & $6 w$ & & & & & & $x$ \\
\hline 235 & $\mathrm{~m}$ & Alb-Cre- & $6 w$ & & & & & & $x$ \\
\hline 236 & $\mathrm{~m}$ & Alb-Cre+ & $6 w$ & & & & & & $x$ \\
\hline 237 & $f$ & Alb-Cre- & $6 w$ & $\mathrm{hmg}$ & & & & & $x$ \\
\hline 238 & $f$ & Alb-Cre+ & $6 w$ & $\mathrm{hmg}$ & & & & & $x$ \\
\hline 239 & f & Alb-Cre- & $6 w$ & hmg & & & & & $x$ \\
\hline 240 & $f$ & Alb-Cre+ & $6 w$ & $\mathrm{hmg}$ & & & & & $x$ \\
\hline 241 & $\mathrm{~m}$ & Alb-Cre- & $6 w$ & $\mathrm{hmg}$ & & & & & $x$ \\
\hline 242 & $\mathrm{~m}$ & Alb-Cre- & $6 w$ & & & & & & $x$ \\
\hline 243 & $\mathrm{~m}$ & Alb-Cre+ & $6 w$ & $\mathrm{hmg}$ & $\mathrm{hmg}$ & & & & $x$ \\
\hline 244 & $\mathrm{~m}$ & Alb-Cre- & $6 w$ & & & & & & $x$ \\
\hline 290 & $f$ & Alb-Cre+ & $6 w$ & cells & cells & & $x$ & & \\
\hline 292 & $\mathrm{~m}$ & Alb-Cre+ & $6 w$ & cells & cells & & $x$ & & \\
\hline 298 & $\mathrm{~m}$ & Alb-Cre- & $6 w$ & cells & cells & & $x$ & & \\
\hline 299 & $\mathrm{~m}$ & Alb-Cre- & $6 w$ & cells & cells & & $x$ & & \\
\hline 306 & $f$ & Alb-Cre- & $6 w$ & & cells & & & & \\
\hline 307 & $f$ & Alb-Cre+ & $6 w$ & & cells & & & & \\
\hline 310 & $\mathrm{~m}$ & Alb-Cre+ & $6 w$ & & cells & & & & \\
\hline 313 & $f$ & Alb-Cre- & $6 w$ & cells & cells & $x$ & & & \\
\hline
\end{tabular}




\begin{tabular}{|c|c|c|c|c|c|c|c|c|c|}
\hline $\mathbf{3 1 4}$ & $\mathrm{f}$ & Alb-Cre- & $6 \mathrm{w}$ & & cells & & & & \\
\hline $\mathbf{3 1 5}$ & $\mathrm{f}$ & Alb-Cre+ & $6 \mathrm{w}$ & cells & cells & & & & \\
\hline $\mathbf{3 1 7}$ & $\mathrm{m}$ & Alb-Cre- & $6 \mathrm{w}$ & cells & cells & $\mathrm{x}$ & & & \\
\hline $\mathbf{3 1 8}$ & $\mathrm{m}$ & Alb-Cre+ & $6 \mathrm{w}$ & cells & cells & $\mathrm{x}$ & & & \\
\hline $\mathbf{3 1 9}$ & $\mathrm{m}$ & Alb-Cre+ & $6 \mathrm{w}$ & cells & cells & $\mathrm{x}$ & & & \\
\hline $\mathbf{3 2 2}$ & $\mathrm{f}$ & Alb-Cre+ & $6 \mathrm{w}$ & cells & cells & & & & \\
\hline $\mathbf{3 2 3}$ & $\mathrm{m}$ & Alb-Cre+ & $6 \mathrm{w}$ & cells & cells & $\mathrm{x}$ & & & \\
\hline $\mathbf{3 2 5}$ & $\mathrm{m}$ & Alb-Cre- & $6 \mathrm{w}$ & cells & cells & $\mathrm{x}$ & & & \\
\hline $\mathbf{3 2 6}$ & $\mathrm{m}$ & Alb-Cre- & $6 \mathrm{w}$ & & & $\mathrm{x}$ & & & \\
\hline $\mathbf{3 3 0}$ & $\mathrm{f}$ & Alb-Cre+ & $6 \mathrm{w}$ & cells & cells & $\mathrm{x}$ & & & \\
\hline $\mathbf{3 3 2}$ & $\mathrm{f}$ & Alb-Cre- & $6 \mathrm{w}$ & cells & cells & & & & \\
\hline $\mathbf{3 3 3}$ & $\mathrm{m}$ & Alb-Cre- & $6 \mathrm{w}$ & & cells & & & & \\
\hline $\mathbf{3 3 4}$ & $\mathrm{m}$ & Alb-Cre- & $6 \mathrm{w}$ & & cells & & & & \\
\hline $\mathbf{3 3 7}$ & $\mathrm{m}$ & Alb-Cre+ & $6 \mathrm{w}$ & cells & cells & & & & \\
\hline
\end{tabular}


Table 7: The top 50 of the differentially expressed genes in isolated hepatocytes of $\mathbf{6} \mathbf{w}$ old animals.

The 50 genes showing the highest change in differential expression based on the FDR-adjusted p-values are listed. Description according to Ensembl.org

\begin{tabular}{|c|c|c|c|c|}
\hline Ensembl Gene ID & $\begin{array}{l}\text { Gene } \\
\text { name }\end{array}$ & Description & $\begin{array}{l}\text { log2Fold } \\
\text { Change }\end{array}$ & padj \\
\hline ENSMUSG00000000031 & $\mathrm{H} 19$ & $\begin{array}{l}\text { H19, imprinted maternally expressed } \\
\text { transcript [Source:MGI } \\
\text { Symbol;Acc:MGI:95891] }\end{array}$ & 8.95 & $5.14 \mathrm{E}-120$ \\
\hline ENSMUSG00000026678 & Rgs5 & $\begin{array}{l}\text { regulator of G-protein signaling } 5 \\
\text { [Source:MGI Symbol;Acc:MGI:1098434] }\end{array}$ & 4.86 & $8.40 \mathrm{E}-64$ \\
\hline ENSMUSG00000031150 & Ccdc120 & $\begin{array}{l}\text { coiled-coil domain containing } 120 \\
\text { [Source:MGI Symbol;Acc:MGI:1859619] }\end{array}$ & 4.39 & 1.03E-57 \\
\hline ENSMUSG00000002885 & Adgre5 & $\begin{array}{l}\text { adhesion G protein-coupled receptor E5 } \\
\text { [Source:MGI Symbol;Acc:MGI:1347095] }\end{array}$ & 5.65 & $4.28 \mathrm{E}-86$ \\
\hline ENSMUSG00000035493 & Tgfbi & $\begin{array}{l}\text { transforming growth factor, beta induced } \\
\text { [Source:MGI Symbol;Acc:MGI:99959] }\end{array}$ & 3.66 & 4.15E-62 \\
\hline ENSMUSG00000049775 & Tmsb4x & $\begin{array}{l}\text { thymosin, beta } 4, \mathrm{X} \text { chromosome } \\
\text { [Source:MGI Symbol;Acc:MGI:99510] }\end{array}$ & 4.04 & $1.58 \mathrm{E}-67$ \\
\hline ENSMUSG00000020357 & Flt4 & $\begin{array}{l}\text { FMS-like tyrosine kinase } 4 \text { [Source:MGI } \\
\text { Symbol;Acc:MGI:95561] }\end{array}$ & 3.35 & $5.80 \mathrm{E}-65$ \\
\hline ENSMUSG00000029163 & Emilin1 & $\begin{array}{l}\text { elastin microfibril interfacer } 1 \\
\text { [Source:MGI Symbol;Acc:MGI:1926189] }\end{array}$ & 4.28 & $9.44 \mathrm{E}-49$ \\
\hline ENSMUSG00000026837 & Col5a1 & $\begin{array}{l}\text { collagen, type V, alpha } 1 \text { [Source:MGI } \\
\text { Symbol;Acc:MGI:88457] }\end{array}$ & 5.83 & $2.75 \mathrm{E}-67$ \\
\hline ENSMUSG00000029661 & Col1a2 & $\begin{array}{l}\text { collagen, type I, alpha } 2 \text { [Source:MGI } \\
\text { Symbol;Acc:MGI:88468] }\end{array}$ & 5.83 & $6.88 \mathrm{E}-64$ \\
\hline ENSMUSG00000074491 & Clec4g & $\begin{array}{l}\text { C-type lectin domain family 4, member g } \\
\text { [Source:MGI Symbol;Acc:MGI:1923113] }\end{array}$ & 2.99 & $5.64 \mathrm{E}-43$ \\
\hline ENSMUSG00000018909 & Arrb1 & $\begin{array}{l}\text { arrestin, beta } 1 \text { [Source:MGI } \\
\text { Symbol;Acc:MGI:99473] }\end{array}$ & 3.96 & $1.59 \mathrm{E}-44$ \\
\hline ENSMUSG00000026712 & Mrc1 & $\begin{array}{l}\text { mannose receptor, C type } 1 \text { [Source:MGI } \\
\text { Symbol;Acc:MGI:97142] }\end{array}$ & 2.91 & $1.55 \mathrm{E}-67$ \\
\hline ENSMUSG00000074785 & Plxnc1 & $\begin{array}{l}\text { plexin C1 [Source:MGI } \\
\text { Symbol;Acc:MGI:1890127] }\end{array}$ & 3.24 & $1.31 \mathrm{E}-61$ \\
\hline ENSMUSG00000030123 & Plxnd1 & $\begin{array}{l}\text { plexin D1 [Source:MGI } \\
\text { Symbol;Acc:MGI:2154244] }\end{array}$ & 3.71 & $7.89 E-43$ \\
\hline ENSMUSG00000014542 & Clec4f & $\begin{array}{l}\text { C-type lectin domain family 4, member f } \\
\text { [Source:MGI Symbol;Acc:MGI:1859834] }\end{array}$ & 4.50 & $2.70 \mathrm{E}-44$ \\
\hline ENSMUSG00000021556 & Golm1 & $\begin{array}{l}\text { golgi membrane protein } 1 \text { [Source:MGI } \\
\text { Symbol;Acc:MGI:1917329] }\end{array}$ & 4.39 & $5.64 \mathrm{E}-43$ \\
\hline ENSMUSG00000028068 & Iqgap3 & $\begin{array}{l}\text { IQ motif containing GTPase activating } \\
\text { protein } 3 \text { [Source:MGI } \\
\text { Symbol;Acc:MGI:3028642] }\end{array}$ & 5.85 & $3.55 \mathrm{E}-48$ \\
\hline
\end{tabular}




\begin{tabular}{|c|c|c|c|c|}
\hline ENSMUSG00000022665 & Ccdc80 & $\begin{array}{l}\text { coiled-coil domain containing } 80 \\
\text { [Source:MGI Symbol;Acc:MGI:1915146] }\end{array}$ & 4.61 & $1.19 \mathrm{E}-48$ \\
\hline ENSMUSG00000034845 & Plvap & $\begin{array}{l}\text { plasmalemma vesicle associated protein } \\
\text { [Source:MGI Symbol;Acc:MGI:1890497] }\end{array}$ & 4.28 & $1.98 E-53$ \\
\hline ENSMUSG00000027204 & Fbn1 & $\begin{array}{l}\text { fibrillin } 1 \text { [Source:MGI } \\
\text { Symbol;Acc:MGI:95489] }\end{array}$ & 5.92 & $5.16 \mathrm{E}-54$ \\
\hline ENSMUSG00000031375 & Bgn & $\begin{array}{l}\text { biglycan [Source:MGI } \\
\text { Symbol;Acc:MGI:88158] }\end{array}$ & 4.83 & $3.41 E-59$ \\
\hline ENSMUSG00000020717 & Pecam1 & $\begin{array}{l}\text { platelet/endothelial cell adhesion } \\
\text { molecule } 1 \text { [Source:MGI } \\
\text { Symbol;Acc:MGI:97537] }\end{array}$ & 3.46 & $3.51 \mathrm{E}-44$ \\
\hline ENSMUSG00000026872 & Zeb2 & $\begin{array}{l}\text { zinc finger E-box binding homeobox } 2 \\
\text { [Source:MGI Symbol;Acc:MGI:1344407] }\end{array}$ & 4.24 & $2.43 \mathrm{E}-49$ \\
\hline ENSMUSG00000002602 & Axl & $\begin{array}{l}\text { AXL receptor tyrosine kinase } \\
\text { [Source:MGI Symbol;Acc:MGI:1347244] }\end{array}$ & 5.36 & $2.35 \mathrm{E}-51$ \\
\hline ENSMUSG00000041219 & Arhgap11a & $\begin{array}{l}\text { Rho GTPase activating protein 11A } \\
\text { [Source:MGI Symbol;Acc:MGI:2444300] }\end{array}$ & 4.06 & $5.85 \mathrm{E}-47$ \\
\hline ENSMUSG00000069516 & Lyz2 & $\begin{array}{l}\text { lysozyme } 2 \text { [Source:MGI } \\
\text { Symbol;Acc:MGI:96897] }\end{array}$ & 4.37 & $5.19 E-55$ \\
\hline ENSMUSG00000032528 & Vipr1 & $\begin{array}{l}\text { vasoactive intestinal peptide receptor } 1 \\
\text { [Source:MGI Symbol;Acc:MGI:109272] }\end{array}$ & 3.01 & 3.33E-51 \\
\hline ENSMUSG00000028003 & Lrat & $\begin{array}{l}\text { lecithin-retinol acyltransferase } \\
\text { (phosphatidylcholine-retinol-O- } \\
\text { acyltransferase) [Source:MGI } \\
\text { Symbol;Acc:MGl:1891259] }\end{array}$ & 4.31 & $1.86 E-43$ \\
\hline ENSMUSG00000022122 & Ednrb & $\begin{array}{l}\text { endothelin receptor type B [Source:MGI } \\
\text { Symbol;Acc:MGI:102720] }\end{array}$ & 5.61 & 1.03E-57 \\
\hline ENSMUSG00000028864 & $\mathrm{Hgf}$ & $\begin{array}{l}\text { hepatocyte growth factor [Source:MGI } \\
\text { Symbol;Acc:MGI:96079] }\end{array}$ & 5.06 & $5.19 \mathrm{E}-55$ \\
\hline ENSMUSG00000029602 & Rasal1 & $\begin{array}{l}\text { RAS protein activator like } 1 \text { (GAP1 like) } \\
\text { [Source:MGI Symbol;Acc:MGI:1330842] }\end{array}$ & 6.69 & $8.32 E-46$ \\
\hline ENSMUSG00000059588 & Calcrl & $\begin{array}{l}\text { calcitonin receptor-like [Source:MGI } \\
\text { Symbol;Acc:MGI:1926944] }\end{array}$ & 3.52 & $1.15 E-56$ \\
\hline ENSMUSG00000097113 & Gm19705 & $\begin{array}{l}\text { predicted gene, } 19705 \text { [Source:MGI } \\
\text { Symbol;Acc:MGI:5011890] }\end{array}$ & 3.29 & $2.15 E-45$ \\
\hline ENSMUSG00000036655 & Colec11 & $\begin{array}{l}\text { collectin sub-family member } 11 \\
\text { [Source:MGI Symbol;Acc:MGI:1918943] }\end{array}$ & 4.58 & $2.91 \mathrm{E}-43$ \\
\hline ENSMUSG00000072625 & Gdf2 & $\begin{array}{l}\text { growth differentiation factor } 2 \\
\text { [Source:MGI Symbol;Acc:MGI:1321394] }\end{array}$ & 5.03 & $2.11 \mathrm{E}-43$ \\
\hline ENSMUSG00000062960 & Kdr & $\begin{array}{l}\text { kinase insert domain protein receptor } \\
\text { [Source:MGI Symbol;Acc:MGI:96683] }\end{array}$ & 2.85 & $3.24 \mathrm{E}-45$ \\
\hline ENSMUSG00000022371 & Col14a1 & $\begin{array}{l}\text { collagen, type XIV, alpha } 1 \text { [Source:MGI } \\
\text { Symbol;Acc:MGI:1341272] }\end{array}$ & 5.32 & $5.29 \mathrm{E}-127$ \\
\hline
\end{tabular}


Appendix

\begin{tabular}{|c|c|c|c|c|}
\hline ENSMUSG00000018593 & Sparc & $\begin{array}{l}\text { secreted acidic cysteine rich glycoprotein } \\
\text { [Source:MGI Symbol;Acc:MGI:98373] }\end{array}$ & 4.68 & 3.69E-84 \\
\hline ENSMUSG00000015854 & Cd5I & $\begin{array}{l}\text { CD5 antigen-like [Source:MGI } \\
\text { Symbol;Acc:MGI:1334419] }\end{array}$ & 5.37 & $8.81 E-75$ \\
\hline ENSMUSG00000046167 & Gldn & $\begin{array}{l}\text { gliomedin [Source:MGI } \\
\text { Symbol;Acc:MGI:2388361] }\end{array}$ & 8.41 & 1.45E-95 \\
\hline ENSMUSG00000036256 & Igfbp7 & $\begin{array}{l}\text { insulin-like growth factor binding protein } 7 \\
\text { [Source:MGI Symbol;Acc:MGI:1352480] }\end{array}$ & 3.81 & $3.03 E-58$ \\
\hline ENSMUSG00000019929 & Den & $\begin{array}{l}\text { decorin [Source:MGI } \\
\text { Symbol;Acc:MGI:94872] }\end{array}$ & 5.48 & $1.32 \mathrm{E}-79$ \\
\hline ENSMUSG00000032231 & Anxa2 & $\begin{array}{l}\text { annexin A2 [Source:MGI } \\
\text { Symbol;Acc:MGI:88246] }\end{array}$ & 5.12 & $2.02 \mathrm{E}-45$ \\
\hline ENSMUSG00000004655 & Aqp1 & $\begin{array}{l}\text { aquaporin } 1 \text { [Source:MGI } \\
\text { Symbol;Acc:MGI:103201] }\end{array}$ & 3.29 & $2.25 \mathrm{E}-43$ \\
\hline ENSMUSG00000042286 & Stab1 & $\begin{array}{l}\text { stabilin } 1 \text { [Source:MGI } \\
\text { Symbol;Acc:MGI:2178742] }\end{array}$ & 2.97 & $9.91 \mathrm{E}-46$ \\
\hline ENSMUSG00000109482 & Gm4756 & $\begin{array}{l}\text { predicted gene } 4756 \text { [Source:MGI } \\
\text { Symbol;Acc:MGI:3644906] }\end{array}$ & -4.21 & $1.93 E-82$ \\
\hline ENSMUSG00000042453 & Reln & $\begin{array}{l}\text { reelin [Source:MGI } \\
\text { Symbol;Acc:MGI:103022] }\end{array}$ & 3.89 & $2.55 \mathrm{E}-75$ \\
\hline ENSMUSG00000026043 & Col3a1 & $\begin{array}{l}\text { collagen, type III, alpha } 1 \text { [Source:MGI } \\
\text { Symbol;Acc:MGI:88453] }\end{array}$ & 7.44 & 3.53E-118 \\
\hline ENSMUSG00000034634 & Ly6d & $\begin{array}{l}\text { lymphocyte antigen } 6 \text { complex, locus D } \\
\text { [Source:MGI Symbol;Acc:MGI:96881] }\end{array}$ & 8.40 & 4.43E-109 \\
\hline
\end{tabular}


Table 8: A subset of TA proteins expressed in hepaotcytes from $6 \mathbf{w}$ old animals.

The list was based on the predicted TA proteins from (Kalbfleisch et al., 2007). Entries were verified via Uniprot or via previously quoted publications. Description is according to ensembl.org (BioMart tool). Proteins without a p-value exhibited a strong variance in expression. Data has to be considered preliminary.

\begin{tabular}{|c|c|c|c|c|}
\hline Ensembl Gene ID & $\begin{array}{l}\text { Gene } \\
\text { name }\end{array}$ & Description & $\begin{array}{l}\text { log2Fold } \\
\text { Change }\end{array}$ & padj \\
\hline ENSMUSG00000057789 & Bak1 & $\begin{array}{l}\text { BCL2-antagonist/killer } 1 \text { [Source:MGI } \\
\text { Symbol;Acc:MGI:1097161] }\end{array}$ & 0.60 & 1.87E-02 \\
\hline ENSMUSG00000003873 & Bax & $\begin{array}{l}\text { BCL2-associated X protein [Source:MGI } \\
\text { Symbol;Acc:MGI:99702] }\end{array}$ & 0.62 & 3.43E-03 \\
\hline ENSMUSG00000057329 & $\mathrm{Bc} 12$ & $\begin{array}{l}\text { B cell leukemia/lymphoma } 2 \text { [Source:MGI } \\
\text { Symbol;Acc:MGI:88138] }\end{array}$ & 4.49 & $8.85 \mathrm{E}-16$ \\
\hline ENSMUSG00000032757 & Bet1 & $\begin{array}{l}\text { Bet1 golgi vesicular membrane trafficking } \\
\text { protein [Source:MGI } \\
\text { Symbol;Acc:MGI:1343104] }\end{array}$ & 0.14 & $6.11 \mathrm{E}-01$ \\
\hline ENSMUSG00000024191 & Bnip1 & $\begin{array}{l}\text { BCL2/adenovirus E1B interacting protein } 1 \\
\text { [Source:MGI Symbol;Acc:MGI:109328] }\end{array}$ & 0.06 & 7.71E-01 \\
\hline ENSMUSG00000009075 & Cabp7 & $\begin{array}{l}\text { calcium binding protein } 7 \text { [Source:MGI } \\
\text { Symbol;Acc:MGI:2183437] }\end{array}$ & -1.59 & $1.58 \mathrm{E}-01$ \\
\hline ENSMUSG00000060371 & Caln1 & $\begin{array}{l}\text { calneuron } 1 \text { [Source:MGI } \\
\text { Symbol;Acc:MGI:2155987] }\end{array}$ & -0.86 & $6.73 \mathrm{E}-03$ \\
\hline ENSMUSG00000038292 & Ccdc155 & $\begin{array}{l}\text { coiled-coil domain containing } 155 \\
\text { [Source:MGI Symbol;Acc:MGI:2687329] }\end{array}$ & 1.52 & \\
\hline ENSMUSG00000060240 & Cend1 & $\begin{array}{l}\text { cell cycle exit and neuronal differentiation } 1 \\
\text { [Source:MGI Symbol;Acc:MGI:1929898] }\end{array}$ & 1.57 & $2.28 \mathrm{E}-01$ \\
\hline ENSMUSG00000021097 & Clmn & $\begin{array}{l}\text { calmin [Source:MGI } \\
\text { Symbol;Acc:MGI:2136957] }\end{array}$ & -0.42 & $9.64 \mathrm{E}-02$ \\
\hline ENSMUSG00000024646 & Cyb5a & $\begin{array}{l}\text { cytochrome b5 type A (microsomal) } \\
\text { [Source:MGI Symbol;Acc:MGI:1926952] }\end{array}$ & -0.15 & 4.13E-01 \\
\hline ENSMUSG00000031924 & Cyb5b & $\begin{array}{l}\text { cytochrome b5 type B [Source:MGI } \\
\text { Symbol;Acc:MGl:1913677] }\end{array}$ & -0.46 & 2.64E-05 \\
\hline ENSMUSG00000030409 & Dmpk & $\begin{array}{l}\text { dystrophia myotonica-protein kinase } \\
\text { [Source:MGI Symbol;Acc:MGI:94906] }\end{array}$ & 3.14 & $7.30 \mathrm{E}-18$ \\
\hline ENSMUSG00000001964 & Emd & $\begin{array}{l}\text { emerin [Source:MGI } \\
\text { Symbol;Acc:MGI:108117] }\end{array}$ & -0.07 & 8.05E-01 \\
\hline ENSMUSG00000019054 & Fis1 & $\begin{array}{l}\text { fission, mitochondrial } 1 \text { [Source:MGI } \\
\text { Symbol;Acc:MGI:1913687] }\end{array}$ & 0.03 & $9.06 \mathrm{E}-01$ \\
\hline ENSMUSG00000090019 & Gimap1 & $\begin{array}{l}\text { GTPase, IMAP family member } 1 \\
\text { [Source:MGI Symbol;Acc:MGI:109368] }\end{array}$ & 2.32 & $1.36 \mathrm{E}-04$ \\
\hline ENSMUSG00000043505 & Gimap5 & $\begin{array}{l}\text { GTPase, IMAP family member } 5 \\
\text { [Source:MGI Symbol;Acc:MGI:2442232] }\end{array}$ & 2.72 & $1.01 \mathrm{E}-04$ \\
\hline ENSMUSG00000021192 & Golga5 & $\begin{array}{l}\text { golgi autoantigen, golgin subfamily a, } 5 \\
\text { [Source:MGI Symbol;Acc:MGI:1351475] }\end{array}$ & 0.36 & $9.79 \mathrm{E}-02$ \\
\hline
\end{tabular}




\begin{tabular}{|c|c|c|c|c|}
\hline ENSMUSG00000034243 & Golgb1 & $\begin{array}{l}\text { golgi autoantigen, golgin subfamily b, } \\
\text { macrogolgin } 1 \text { [Source:MGI } \\
\text { Symbol;Acc:MGI:1099447] }\end{array}$ & -0.20 & 2.93E-01 \\
\hline ENSMUSG00000010392 & Gosr1 & $\begin{array}{l}\text { golgi SNAP receptor complex member } 1 \\
\text { [Source:MGI Symbol;Acc:MGI:1858260] }\end{array}$ & -0.22 & $1.06 \mathrm{E}-01$ \\
\hline ENSMUSG00000020946 & Gosr2 & $\begin{array}{l}\text { golgi SNAP receptor complex member } 2 \\
\text { [Source:MGI Symbol;Acc:MGI:1927204] }\end{array}$ & 0.33 & 2.83E-02 \\
\hline ENSMUSG00000046607 & Hrk & $\begin{array}{l}\text { harakiri, BCL2 interacting protein (contains } \\
\text { only BH3 domain) [Source:MGI } \\
\text { Symbol;Acc:MGI:1201608] }\end{array}$ & 0.01 & $9.94 \mathrm{E}-01$ \\
\hline ENSMUSG00000042686 & Jph1 & $\begin{array}{l}\text { junctophilin } 1 \text { [Source:MGI } \\
\text { Symbol;Acc:MGI:1891495] }\end{array}$ & -2.17 & $3.09 \mathrm{E}-03$ \\
\hline ENSMUSG00000017817 & Jph2 & $\begin{array}{l}\text { junctophilin } 2 \text { [Source:MGI } \\
\text { Symbol;Acc:MGI:1891496] }\end{array}$ & -1.21 & \\
\hline ENSMUSG00000025318 & Jph3 & $\begin{array}{l}\text { junctophilin } 3 \text { [Source:MGI } \\
\text { Symbol;Acc:MGI:1891497] }\end{array}$ & 0.33 & 7.60E-01 \\
\hline ENSMUSG00000022208 & Jph4 & $\begin{array}{l}\text { junctophilin } 4 \text { [Source:MGI } \\
\text { Symbol;Acc:MGI:2443113] }\end{array}$ & -1.09 & \\
\hline ENSMUSG00000025037 & Maoa & $\begin{array}{l}\text { monoamine oxidase A [Source:MGI } \\
\text { Symbol;Acc:MGI:96915] }\end{array}$ & 0.43 & 3.99E-01 \\
\hline ENSMUSG00000040147 & Maob & $\begin{array}{l}\text { monoamine oxidase B [Source:MGI } \\
\text { Symbol;Acc:MGI:96916] }\end{array}$ & -0.43 & $1.96 \mathrm{E}-01$ \\
\hline ENSMUSG00000038612 & Mcl1 & $\begin{array}{l}\text { myeloid cell leukemia sequence } 1 \\
\text { [Source:MGI Symbol;Acc:MGI:101769] }\end{array}$ & 0.50 & $1.66 \mathrm{E}-02$ \\
\hline ENSMUSG00000026150 & Mff & $\begin{array}{l}\text { mitochondrial fission factor [Source:MG| } \\
\text { Symbol;Acc:MGI:1922984] }\end{array}$ & 0.04 & $8.58 \mathrm{E}-01$ \\
\hline ENSMUSG00000032392 & Parp16 & $\begin{array}{l}\text { poly (ADP-ribose) polymerase family, } \\
\text { member } 16 \text { [Source:MGI } \\
\text { Symbol;Acc:MGI:2446133] }\end{array}$ & 0.49 & $3.20 \mathrm{E}-02$ \\
\hline ENSMUSG00000056043 & Rgs9bp & $\begin{array}{l}\text { regulator of G-protein signalling } 9 \text { binding } \\
\text { protein [Source:MGI } \\
\text { Symbol;Acc:MGI:2384418] }\end{array}$ & 2.07 & $7.32 \mathrm{E}-02$ \\
\hline ENSMUSG00000017686 & Rhot1 & $\begin{array}{l}\text { ras homolog family member T1 } \\
\text { [Source:MGI Symbol;Acc:MGI:1926078] }\end{array}$ & -0.04 & 8.23E-01 \\
\hline ENSMUSG00000025733 & Rhot2 & $\begin{array}{l}\text { ras homolog family member T2 } \\
\text { [Source:MGI Symbol;Acc:MGI:2384892] }\end{array}$ & -0.10 & $6.56 \mathrm{E}-01$ \\
\hline ENSMUSG00000027879 & Sec22b & $\begin{array}{l}\text { SEC22 homolog B, vesicle trafficking } \\
\text { protein [Source:MGI } \\
\text { Symbol;Acc:MGI:1338759] }\end{array}$ & 0.34 & $1.84 \mathrm{E}-01$ \\
\hline ENSMUSG00000053317 & Sec61b & $\begin{array}{l}\text { Sec61 beta subunit [Source:MGI } \\
\text { Symbol;Acc:MGI:1913462] }\end{array}$ & 0.12 & 7.83E-01 \\
\hline ENSMUSG00000027808 & Serp1 & $\begin{array}{l}\text { stress-associated endoplasmic reticulum } \\
\text { protein } 1 \text { [Source:MGI } \\
\text { Symbol;Acc:MGI:92638] }\end{array}$ & 0.22 & 4.01E-01 \\
\hline
\end{tabular}




\begin{tabular}{|c|c|c|c|c|}
\hline ENSMUSG00000052584 & Serp2 & $\begin{array}{l}\text { stress-associated endoplasmic reticulum } \\
\text { protein family member } 2 \text { [Source:MGI } \\
\text { Symbol;Acc:MGI:1919911] }\end{array}$ & 0.13 & $9.40 \mathrm{E}-01$ \\
\hline ENSMUSG00000021870 & SImap & $\begin{array}{l}\text { sarcolemma associated protein } \\
\text { [Source:MGI Symbol;Acc:MGI:1933549] }\end{array}$ & 0.06 & 6.99E-01 \\
\hline ENSMUSG00000028879 & Stx12 & $\begin{array}{l}\text { syntaxin } 12 \text { [Source:MGI } \\
\text { Symbol;Acc:MGI:1931027] }\end{array}$ & 0.28 & $6.01 \mathrm{E}-02$ \\
\hline ENSMUSG00000027522 & Stx16 & $\begin{array}{l}\text { syntaxin } 16 \text { [Source:MGI } \\
\text { Symbol;Acc:MGI:1923396] }\end{array}$ & -0.13 & 5.66E-01 \\
\hline ENSMUSG00000029125 & Stx18 & $\begin{array}{l}\text { syntaxin } 18 \text { [Source:MGI } \\
\text { Symbol;Acc:MGI:1918366] }\end{array}$ & 0.09 & 7.77E-01 \\
\hline ENSMUSG00000007207 & Stx1a & $\begin{array}{l}\text { syntaxin 1A (brain) [Source:MGI } \\
\text { Symbol;Acc:MGI:109355] }\end{array}$ & 2.10 & $6.48 \mathrm{E}-03$ \\
\hline ENSMUSG00000030806 & Stx1b & $\begin{array}{l}\text { syntaxin 1B [Source:MGI } \\
\text { Symbol;Acc:MGI:1930705] }\end{array}$ & -1.25 & $1.59 \mathrm{E}-03$ \\
\hline ENSMUSG00000029428 & Stx2 & $\begin{array}{l}\text { syntaxin } 2 \text { [Source:MGI } \\
\text { Symbol;Acc:MGI:108059] }\end{array}$ & 1.02 & 1.11E-08 \\
\hline ENSMUSG00000041488 & Stx3 & $\begin{array}{l}\text { syntaxin } 3 \text { [Source:MGI } \\
\text { Symbol;Acc:MGI:103077] }\end{array}$ & 0.62 & $5.83 E-03$ \\
\hline ENSMUSG00000030805 & Stx4a & $\begin{array}{l}\text { syntaxin 4A (placental) [Source:MGI } \\
\text { Symbol;Acc:MGI:893577] }\end{array}$ & -0.38 & 2.53E-01 \\
\hline ENSMUSG00000010110 & Stx5a & $\begin{array}{l}\text { syntaxin 5A [Source:MGI } \\
\text { Symbol;Acc:MGI:1928483] }\end{array}$ & -0.06 & 7.78E-01 \\
\hline ENSMUSG00000026470 & Stx6 & $\begin{array}{l}\text { syntaxin } 6 \text { [Source:MGI } \\
\text { Symbol;Acc:MGI:1926235] }\end{array}$ & -0.52 & 3.56E-03 \\
\hline ENSMUSG00000019998 & Stx7 & $\begin{array}{l}\text { syntaxin } 7 \text { [Source:MGI } \\
\text { Symbol;Acc:MGI:1858210] }\end{array}$ & 0.45 & 3.19E-02 \\
\hline ENSMUSG00000020903 & Stx8 & $\begin{array}{l}\text { syntaxin } 8 \text { [Source:MGI } \\
\text { Symbol;Acc:MGI:1890156] }\end{array}$ & 0.12 & $6.08 \mathrm{E}-01$ \\
\hline ENSMUSG00000037318 & Traf3ip3 & $\begin{array}{l}\text { TRAF3 interacting protein } 3 \text { [Source:MG| } \\
\text { Symbol;Acc:MGI:2441706] }\end{array}$ & 0.35 & 7.66E-01 \\
\hline ENSMUSG00000028277 & Ube2j1 & $\begin{array}{l}\text { ubiquitin-conjugating enzyme E2J } 1 \\
\text { [Source:MGI Symbol;Acc:MGI:1926245] }\end{array}$ & 0.19 & 3.59E-01 \\
\hline ENSMUSG00000023286 & Ube2j2 & $\begin{array}{l}\text { ubiquitin-conjugating enzyme E2J } 2 \\
\text { [Source:MGI Symbol;Acc:MGI:2153608] }\end{array}$ & 0.02 & 9.57E-01 \\
\hline ENSMUSG00000002395 & Use1 & $\begin{array}{l}\text { unconventional SNARE in the ER } 1 \\
\text { homolog (S. cerevisiae) [Source:MGI } \\
\text { Symbol;Acc:MGI:1914273] }\end{array}$ & -0.38 & $5.13 E-03$ \\
\hline ENSMUSG00000030337 & Vamp1 & $\begin{array}{l}\text { vesicle-associated membrane protein } 1 \\
\text { [Source:MGI Symbol;Acc:MGI:1313276] }\end{array}$ & -0.07 & 8.57E-01 \\
\hline ENSMUSG00000020894 & Vamp2 & $\begin{array}{l}\text { vesicle-associated membrane protein } 2 \\
\text { [Source:MGI Symbol;Acc:MGI:1313277] }\end{array}$ & -0.88 & $1.52 \mathrm{E}-02$ \\
\hline ENSMUSG00000028955 & Vamp3 & $\begin{array}{l}\text { vesicle-associated membrane protein } 3 \\
\text { [Source:MGI Symbol;Acc:MGI:1321389] }\end{array}$ & 0.27 & 2.29E-01 \\
\hline
\end{tabular}


Appendix

\begin{tabular}{|l|c|l|c|c|}
\hline ENSMUSG00000026696 & Vamp4 & $\begin{array}{l}\text { vesicle-associated membrane protein 4 } \\
\text { [Source:MGI Symbol;Acc:MGI:1858730] }\end{array}$ & 0.07 & $8.53 \mathrm{E}-01$ \\
\hline ENSMUSG00000073002 & Vamp5 & $\begin{array}{l}\text { vesicle-associated membrane protein 5 } \\
\text { [Source:MGI Symbol;Acc:MGI:1858622] }\end{array}$ & 0.17 & $8.25 \mathrm{E}-01$ \\
\hline ENSMUSG00000051412 & Vamp7 & $\begin{array}{l}\text { vesicle-associated membrane protein 7 } \\
\text { [Source:MGI Symbol;Acc:MGI:1096399] }\end{array}$ & 0.03 & $9.34 \mathrm{E}-01$ \\
\hline ENSMUSG00000050732 & Vamp8 & $\begin{array}{l}\text { vesicle-associated membrane protein 8 } \\
\text { [Source:MGI Symbol;Acc:MGl:1336882] }\end{array}$ & 0.15 & $5.96 \mathrm{E}-01$ \\
\hline ENSMUSG00000024091 & Vapa & $\begin{array}{l}\text { vesicle-associated membrane protein, } \\
\text { associated protein A [Source:MGI } \\
\text { Symbol;Acc:MGl:1353561] }\end{array}$ & 0.22 & $2.34 \mathrm{E}-01$ \\
\hline ENSMUSG00000054455 & Vapb & $\begin{array}{l}\text { vesicle-associated membrane protein, } \\
\text { associated protein B and C [Source:MGl } \\
\text { Symbol;Acc:MGI:1928744] }\end{array}$ & 0.03 & $9.16 \mathrm{E}-01$ \\
\hline
\end{tabular}


Table 9: Differentially expressed genes in hepatocytes from $6 \mathrm{w}$ old animals involved in liver regeneration or liver fibrosis.

The transcriptome data was analyses regarding typical genes involved in liver regeneration or liver fibrosis that are not represented in the Top50 changed genes. The $\log 2$ of the fold change is given along with the pvalue. Description is according to ensembl.org (BioMart tool).

\begin{tabular}{|c|c|c|c|c|}
\hline Ensembl Gene ID & $\begin{array}{l}\text { Gene } \\
\text { name }\end{array}$ & Description & log2FoldChange & padj \\
\hline \multicolumn{5}{|c|}{ Genes involved in liver regeneration } \\
\hline ENSMUSG00000028864 & $\mathrm{Hgf}$ & $\begin{array}{l}\text { hepatocyte growth factor } \\
\text { [Source:MGI } \\
\text { Symbol;Acc:MGI:96079] }\end{array}$ & 5.06 & $5.19 \mathrm{E}-55$ \\
\hline ENSMUSG00000024486 & Hbegf & $\begin{array}{l}\text { heparin-binding EGF-like } \\
\text { growth factor [Source:MGI } \\
\text { Symbol;Acc:MGI:96070] }\end{array}$ & 1.91 & 8.84E-07 \\
\hline ENSMUSG00000029378 & Areg & $\begin{array}{l}\text { amphiregulin [Source:MGI } \\
\text { Symbol;Acc:MGI:88068] }\end{array}$ & 3.32 & $3.41 \mathrm{E}-05$ \\
\hline ENSMUSG00000024401 & $\operatorname{Tnf}$ & $\begin{array}{l}\text { tumor necrosis factor } \\
\text { [Source:MGI } \\
\text { Symbol;Acc:MGI:104798] }\end{array}$ & 3.10 & 4.19E-04 \\
\hline ENSMUSG00000025225 & Nfkb2 & $\begin{array}{l}\text { nuclear factor of kappa light } \\
\text { polypeptide gene enhancer in } \\
\text { B cells 2, p49/p100 } \\
\text { [Source:MGI } \\
\text { Symbol;Acc:MGI:1099800] }\end{array}$ & 1.11 & 3.94E-05 \\
\hline \multicolumn{5}{|c|}{ Genes involved in liver fibrosis } \\
\hline ENSMUSG00000034205 & Loxl2 & $\begin{array}{l}\text { lysyl oxidase-like } 2 \\
\text { [Source:MGI } \\
\text { Symbol;Acc:MGI:2137913] }\end{array}$ & 4.94 & 2.75E-24 \\
\hline ENSMUSG00000002603 & Tgfb1 & $\begin{array}{l}\text { transforming growth factor, } \\
\text { beta } 1 \text { [Source:MGI } \\
\text { Symbol;Acc:MGI:98725] }\end{array}$ & 3.16 & 3.46E-11 \\
\hline
\end{tabular}




\section{Curriculum vitae Lena Musiol}

\section{Personal Information}

Date of birth

Place of birth

Education

10/2012 -

14.05.2013

23.08.2012

$10 / 2011$ -

$04 / 2009-09 / 2011$

$03 / 2008$

10/2006-03/2009

10/2003-09/2006

28.06.2003
27/11/1984

Nümbrecht, Germany
PhD student Department of Molecular Biology, Göttingen University Medical School and International Max Planck Research School for Molecular Biology, Georg August University, Göttingen, Germany MSc degree, grade of thesis 1.3, overall grade 1.26 (A, excellent) Master's examination, overall grade 1.23 (A, excellent) $\mathrm{MSc} / \mathrm{PhD}$ program "Molecular Biology", International Max Planck Research School, Georg August University, Göttingen, Germany Leibniz University Hannover, BSc Biology, grade 1.5 (very good) Preliminary vet-medical examinations in physiology (grade 2.0) and biochemistry (grade 2.0)

University of Veterinary Medicine Hannover (Foundation), Veterinary Medicine

Albert-Ludwigs-University Freiburg, Biology, intermediate exam (Vordiplom), overall grade 2.5 (good)

University entrance diploma, overall grade 1.3

\section{Extracurricular activities (selection)}

$09 / 2013$

$04 / 2010-03 / 2011$

$06 / 2009-08 / 2011$
Organizer of the $10^{\text {th }} \mathrm{PhD}$ Symposium "Horizons in Molecular Biology", Göttingen

Elected member of the student's council, Leibniz University Hannover

Elected member of the student representatives of the Faculty of Life Science, Leibniz University Hannover

Member of the student representatives for Biology, Leibniz University Hannover

\section{Scholarships and Awards}

$10 / 2014$

Travel grant award: Göttingen Graduate School for Neurosciences, Bio- physics, and Molecular Biosciences (GGNB) for the EMBO conference "ER as a Hub for Organelle Communication" in Girona, Spain

10/2011 - 09/2012 International Max Planck Research School support 